\title{
Sistematización de la alfarería del área de San Pedro de Atacama
}

\author{
Carlos Thomas, Claudio Massone \\ y $M$. Antonia Benavente
}

\section{Formulación del. problema y objetivos del estudio}

1.1. La necesidad de sistematización del material cerámico, como requisito previo para un análisis cronológico del complejo del "rapé"

El estado actual de la arqueología chilena presenta un cuadro poco uniforme en lo que respecta a la posición cronológica del complejo del "rapé". En el área de Arica, el complejo alucinógeno ha sido detectado en correspondencia a fechas tempranas: 500 a.C. (cf. Fociacci, 1982). Para el área de San Pedro, en cambio, las fechas correspondientes a dicho complejo son relativamente más tardías ya que varían entre el 250 y el 1050 d.C. (cf. NúÑEz, 1976). Finalmente para el área de Caspana, Calama y alrededores no se dispone de fechados en relación con el complejo.

Por otra parte, las fechas tempranas consignadas para Arica estan asociadas a formas de tabletas cuya presencia, por el momento, debe considerarse exclusiva de dicha localidad. Lo mismo sucede con los fechados de San Pedro. Desafortunadamente, las únicas dos formas de tabletas presentes tanto en Arica, como en San Pedro y como en el área de Caspana-Calama, no pueden, a la fecha, ser asimiladas a una determinada posición cronológica.

A la luz de esta somera revisión, resulta evidente la imposibilidad de llegar a determinar (al menos momentáneamente), por asociación entre sitios y morfología, la posición temporal de las formas de tabletas - y consiguientemente del complejo en su totalidad-de las tres áreas mencionadas.

En consecuencia, se estima oportuno intentar definir la dimensión cronológica del complejo de rapé a partir del tratamiento sistemático de otro elemento que, tradicionalmente, ha sido básico para la resolución de este tipo de problemas: la cerámica. 


\subsection{Circunscripción del análisis al área de San Pedro de Alacama}

El haber seleccionado la alfarería como probable indicador cronológico, relativo al complejo de rapé, se traduce en una reducción del ámbito geográfico de análisis.

En efecto, en el área de Arica, si bien ésta presenta una secuencia cronológica de elementos cerámicos bastante precisa, no ha sido posible registrar acabadamente los elementos del complejo que, hipotéticamente, pudieron estar relacionados con dicha secuencia cronológica. Por otra parte, en relación a las localidades de Caspana, Chiu-Chiu y Calama, los elementos pertenecientes al complejo alucinógeno, de las cuales se tiene conocimiento, no son sino un agregado de ítems fuera de contexto (algunos de ellos constituyen colecciones de privados). Para tales elementos no hay referencias que permitan formular, en propiedad, alguna hipótesis de asociación con las evidencias cerámicas de dichas localidades, las cuales sí presentan cierto tipo de ordenamiento cronológico en lo que a alfarería se refiere.

Por estas razones, el análisis, que se presenta en este artículo, se circunscribirá geográficamente al área de San Pedro, la cual presenta un completo registro de restos cerámicos relacionados con elementos propios del complejo del rapé.

\subsection{Antecedentes generales del contexto cerámico de San Pedro de Atacama}

Para quien está interesado en la Arqueología del área circumpuneña, se presenta como uno de los problemas más relevantes y aún sin una respuesta satisfactoria aquel de la cronología cerámica de San Pedro de Atacama.

Trabajos de Latcham (cf. 1928), Montané (cf. 1963), Munizaga (cf. 1963), tienen como finalidad precisar tipos y variedades cerámicas para el área en cuestión (Rojo Pulido, Negro Pulido, Negro Grabado y Rojo Violáceo).

En 1963, año del Congreso Internacional de San Pedro de Atacama, se intentó establecer una secuencia cronológica apoyándose en las precisiones tipológicas arriba mencionadas. Este intento se tradujo en un conjunto de observaciones generales que solamente tienen un valor referencial.

Orellana (cf. 1963) propone a San Pedro de Atacama como cultura a través del manejo del concepto de sitio tipo, formulando, además, una secuencia cronológica para la zona que abarca un lapso que va desde pasado el $311 \mathrm{~d}$.C. hasta, aproximadamente, el 1500 d.C. Esta secuencia está configurada por tres períodos denominados San Pedro I, II y III.

Por su parte Le Paige (cf. 1963) supone intuitivamente que las fases que configuran la secuencia cultural planteada por Orellana son susceptibles de ser subdivididas más finamente en términos temporales, ciñéndose a la realidad contextual observada.

Posteriormente, M. Tarragó (cf. 1968, 2976), basándose en técnicas tanto de seriación arqueológica como de asociación estadística, trató de precisar ese conjunto de observaciones iniciales incluyendo una secuencia cronológica más 
detallada. Esta reconoce ocho momentos que abarcan temporalmente desde 1760 a.C. hasta el 1500 d.C. '. Los tipos alfareros contemplados por la secuencia de Orellana (cf. 1963) quedarían ahora comprendidos de acuerdo con la autora en seis períodos que abarcan un lapso entre el 300 d.C. y el 1500 d.C.

La fase I de la secuencia de Tarragó está configurada por cerámica ordinaria y urnas de base cónica de Solor 6 cuya datación de RC 14 indicara Orellana para el 311 d.C.

Por otra parte, Tarragó postula la necesidad de particularizar las tipologías manejadas siguiendo un criterio morfológico e intenta una correlación con los diversos tipos del área de San Pedro con materiales alfareros trasandinos.

Paralelamente, nuevos trabajos y consideraciones de Le Paige (cf. 1971) han dado a luz nuevas variedades cerámicas que él denominó de transición:

a) Una temprana, representada por algunas formas cerámicas negras cuya superficie está coloreada con ocre, asociadas algunas veces con urnas, algunas de estas últimas con aplicaciones antropomórficas.

b) Otra denominada "negra casi pulida" a la que este autor atribuye una datación más tardía.

Núñez, Bittmann y Le Paige (cf. 1978) apoyándose en fechados radiométricos constituyen una periodificación genérica. Enmarcan cronológicamente "la cultura de San Pedro de Atacama" desde el 500 a.C. hasta el 1536 d.C., dividiendo este lapso de tiempo en "los inicios" (500 a.C. - 300 d.C.), "el florecimiento cultural" (300 d.C. - 900 d.C.) y "hacia la formación de la etnía atacameña" (900 d.C. - 1536 d.C.).

Resumiendo, puede decirse que, a la fecha, para la región de San Pedro se cuenta con una serie de información, la cual está enmarcada cronológicamente de modo tentativo y apoyada en construcciones tipológicas y comparaciones con materiales de zonas vecinas. Tales observaciones adolecen de una base estratigráfica propia de la región.

Las fechas radiométricas obtenidas a partir de 1963, que deberían suplir este vacío, son escasas, poco claras (por ejemplo se han utilizado los tacos señalizadores de entierros, siendo algunos de estos últimos colectivos, lo que impide individualizar a qué inhumación corresponde el fechado del taco) y por último la asignación de correspondencia temporal al componente cerámicoen cuestión ha suscitado polémicas entre los especialistas.

Ultimamente, y como un esfuerzo claro de resolver este problema, se han procesado a través del método de termoluminiscencia una serie de muestras recolectadas por Berenguer en 1984, procedentes de excavaciones realizadas por Gustavo Le Paige y Antonieta Costa. Si bien estas muestras son limitadas y

\footnotetext{
${ }^{1}$ Estas fechas han sido incluidas al margen por la autora en el artículo enviado a uno de los autores.
} 
seleccionadas arbitrariamente, ya que sólo se trata de 14 elementos correspondientes a tres yacimientos (Quitor 5, Quitor 6 y Toconao Oriente), la lista de fechas del manuscrito (cf. Roman et al., 1984) puede servir para una eventual nueva lectura más ajustada de las secuencias cerámicas ya comentadas.

\subsection{Objetivos del Análisis}

De acuerdo con lo expuesto en los puntos anteriores, dos son los objetivos generales que rigen la investigación presentada en este artículo:

a) Lograr un ordenamiento en términos cronológicos relativos de la variada información sobre la problemática de la Alfarería de San Pedro de Atacama, el cual deberá traducirse en una secuencia temporal de los diferentes grupos que conforman los conjuntos cerámicos conocidos para el área.

b) Precisar la ubicación cronológica de las diferentes formas de tabletas de rapé presentes en el área por contrastación con los grupos cerámicos a los cuales se encuentren asociadas.

Cumplidos estos objetivos generales se estará en condiciones de responder a los siguientes problemas específicos, cuales son:

a) Determinar cuáles son los grupos cerámicos que, en propiedad, configuran la denominada cultura San Pedro, como asimismo precisar su dimensión temporal.

b) Determinar si las tabletas de rapé, y por extensión el resto del complejo, constituyen otros elementos de la cultura San Pedro.

\section{Material, métodos y Técnicias}

Para alcanzar los objetivos propuestos se recurrió a tres fuentes de información tradicionales (cf. Dury, 1965: 276 apud HAGGETT, 1976: 242), a saber:

a) Documental: Aportada por una revisión de las publicaciones sobre el particular, seleccionando aquella que permita un mejor manejo analítico.

b) De Gabinete: correspondiente a los resultados de una previa revisión exhaustiva de colecciones cerámicas del Museo de San Pedro que se realizó desde 1981 hasta 1984 .

c) Teórica: derivada de la aplicación de métodos y técnicas cuantitativas a la totalidad, o a parte, de la información de gabinete antes mencionada.

El manejo de estos tres tipos de información tiene acento en el tratamiento analítico y sistemático (cf. Cl.ARKe, 1978: passim; cf. DunNel.I., 1971: passim) de los datos. Metodológicamente ése puede resumirse en la siguiente secuencia de pasos:

a) Homologación de la información: Se hace referencia aquí a la agregación de los datos analíticamente manejables presentes en la literatura arqueológica, de 
los resultados de la revisión de las colecciones cerámicas del Museo de San Pedro de Atacama (las cuales no son otra cosa que el resultado empírico de los estudios realizados por Gustavo Le Paige) y de los resultados teoréticos relativos a dichas colecciones.

b) Formulación de Supuestos: Los que apuntan a la fijación de hitos temporales para agregados de grupos cerámicos. Estos supuestos tienen su origen en los fechados radiocarbónicos existentes más confiables y sirven de parámetro cronológico para el desarrollo de los pasos siguientes.

c) Asociación entre grupos cerámicos: Recurriendo a técnicas cuantitativas que se detallan en los acápites pertinentes, se procede a determinar asociaciones relevantes entre los grupos cerámicos definidos a través del paso a) considerando, asimismo, los supuestos formulados en el paso b).

d) Construcción de secuencia cerámica: La que se resuelve mediante el tratamiento sistemático de los resultados obtenidos en el paso anterior.

e) Confrontación de la secuencia construida con fechados cronológicos actualizados.

f) Análisis de asociación de grupos de tabletas de rapé con los grupos cerámicos secuencialmente ordenados. A partir de los antecedentes de agrupación de tipos de tabletas publicados por los autores (cf. Thomas y Benavente, 1984), el grado de asociación de tales grupos con la secuencia cerámica definida en el paso d), se pretende, en función de las asociaciones observadas, determinar la posición cronológica de los distintos grupos de tabletas de rapé.

g) Discusión de resultados, conclusiones y formulación de hipótesis.

El desarrollo del análisis enunciado presupone la aplicación de técnicas diversas. Se trata, en algunos casos, de técnicas tradicionales en el quehacer arqueológico como aquellas que deben aplicarse en los pasos a), b) y g). El paso e) implica tanto la utilización de técnicas tradicionales, como una posible aplicación de técnicas cuantitativas. Los pasos c), d) y f) presuponen sea la aplicación de instrumentos de análisis propios de técnicas cuantitativas, sea la evaluación sistemática de los resultados obtenidos.

En el caso de la asociación entre grupos cerámicos, se estima oportuna la aplicación del test no paramétrico de "correlación de perfil" (cf. HofsTATTER, 1960). Mientras que, para la asociación de grupos de tabletas a secuencia cerámica se aplicará el test de "chi-cuadrado de contingencia" (cf. MaxwELL, 1966), que también se considera como un test no paramétrico (cf. Dixon y MASSEY, 1973: 276). Se aplica este tipo de instrumento cuantitativo de análisis, ya que tanto las tabletas como la cerámica constituyen un tipo de muestra accidental.

Dichos instrumentos se tratarán en detalle en los acápites de presentación de resultados.

\section{INFORMACIÓN DOCUMENTAL}

De toda la bibliografía revisada -que de alguna forma se trató al plantear el problema que genera esta investigación- sólo los trabajos de Miriam Noemí 
Tarragó (cf. 1968, 1976) son los que presentan una base de datos adecuada para un manejo analítico.

El primero de ellos, titulado "Secuencias culturales de la etapa Agroalfarera de San Pedro de Atacama", está destinado a afinar la secuencia elaborada en el Congreso de Arqueología de 1963. Trata por ello in extenso de los aspectos espaciales y temporales que dicha secuencia presupone.

El segundo trabajo "Alfarería típica de San Pedro" encara el estudio con un objetivo fundamentalmente morfoclasificatorio. La metodología seguida por la investigadora en estos dos trabajos puede resumirse en los siguientes pasos:

a) Un análisis y descripción de la alfarería local de acuerdo a "las normas de descripción de tipos cerámicos" adoptados por la Convención Nacional de Antropología, reunida en Córdoba, Argentina, complementada en su definición de formas con los criterios propuestos por Anna Shepard (1963).

b) El empleo del método de seriación de los ajuares asociados. La explicitación del método más la cantidad de vasijas enteras analizadas (2414) hacen que este trabajo pueda ser, y es, útil especialmente para un tratamiento analítico cuantitativo.

Algunos aspectos, sin embargo, debilitan este trabajo, y ellos son:

a) En el tipo negro pulido (1929 ejemplares) se analizan formas completas. En cambio, en el rojo pulido sólo bases y asas. Formas y bases en el negro grabado. El casi pulido y el violáceo son sólo mencionados.

b) Se carece de información detallada de los tests estadísticos a los que se sometió la muestra.

Para efectos del análisis, cuyos resultados se presentan en este artículo, se consideró, en particular, la información contenida en los siguientes cuadros de la publicación de dicha autora: 1 - (cf. Tarragó, 1976: 48), 11 - (cf. op. cit. 52), $1 \mathrm{II}$ - (cf. of. cit. 56), IV - (cf. op. cit. 59). En general se consideraron los contenidos de sus dos artículos citados más el apéndice de Cortelezzi (1976).

\section{INFORMACIÓN DE GABINETE}

A partir de 1981 hasta 1984 , los autores del presente artículo han procedido a una extensa y completa revisión del material contextual correspondiente al complejo de rapé existente en el Museo Arqueológico de San Pedro de Atacama, material que fuera consignado por el Reverendo Padre Gustavo Le Paige.

Después de haber revisado, en 1981 , la colección de tabletas de rapé y los contextos asociados a éstas, se procedió en 1982 a agrupar los diversos elementos contextuales y a registrar, dibujar y fotografiar la cerámica asociada a tabletas.

En 1983 se revisan contextos que no manifiestan la presencia de tabletas de rapé. El registro, dibujos y fotografías de la cerámica en ellos presente se realizó en 1984 .

Los resultados obtenidos de este proceso de revisión sirven, al menos en lo 
que a cerámica se refiere, para actualizar y completar la muestra cerámica manejada por Tarragó en 1968, que ya se mencionó en el acápite anterior.

El resultado de esta actualización y homologación, que constituye parte fundamental de la base de datos a la cual se hace referencia a lo largo de este artículo, se consigna en anexo $\mathrm{N}^{\circ} \mathrm{l}$ (q. v.).

\section{INFORMACIÓN TEÓRICA}

\subsection{Sistematización de la cerámica asociada a tabletas, según data de gabinete.}

Como antecedente, debe señalarse, en relación al material cerámico asociado a tabletas de rapé analizado en 1982, el proceso de sistematización del que fue objeto y sus resultados. Tal sistematización se tradujo en una definición de grupos cerámicos.

Se recurrió, para tal efecto, a un método cuantitativo no clasificatorio, basado en técnicas estadísticas de análisis de correlación multivariada similares a las que emplearan los autores en referencia a las tabletas de rapé (cf. Тномаs y Benavente, 1984). Dado el volumen de información, que redunda en una complejización en el análisis, este proceso de definición de grupos cerámicos (de acuerdo a los métodos señalados) se realizó a través del empleo de procesamiento computacional de datos y arrojó los resultados que se presentan, en forma gráfica, en las figuras $1,2,3$ y 4 (q.v.).

La interpretación de lo graficado en dichas figuras no es sino la definición de los siguientes grupos obtenidos:

Grupo A: Definido por vasijas no restringidas, alisadas de color gris - negro.

Al : Vasijas de contorno simple y lados invertidos. Labio convexo y base cóncava.

A2 : Vasija de contorno inflexionado y lados cóncavos. Labio evertido y base recta.

A3 : Vasija de contorno restringido inflexionado y lado cóncavo. Labio evertido y base recta.

Han sido también agrupados bajo la denominación de "escudillas" e identificadas por Le Paige como "cuasi o casi pulidas" (cf. 1964).

Grupo B: Se trata de ceramios conocidos bajo la denominación de vasijas restringidas independientes, de contornos inflexionados, son de color negro y su tratamiento de superficie es pulido (más precisamente "bruñido"). Se subdividen en 4 subgrupos, resultado de la aplicación de pastillaje e incisiones configurando pequeñas "caritas" que se ubican en un lado del cuello. La mayor o menor complejidad de ellas ha derivado en la denominación de los subgrupos (B1, B2, B4). Poseen asas lisas doble adheridas en el cuello. El cuello puede ser recto, evertido o invertido. Todas son de cuerpo globular y base recta - son "botellones"- . El subgrupo B3, tendría las mismas características, pero corresponde a 
Figura 1

AGRUPACION CERAMICA POR ANALISIS DE CORRESPONDENCIA

Ejes $N^{O S} 1$ y 2


OHE. JUDITH OLIVA CARL 
Figura 2

AGRUPACION CERAMICA POR ANALISIS DE CORRESPONDENCIA

Ejes NOS 3 y 4

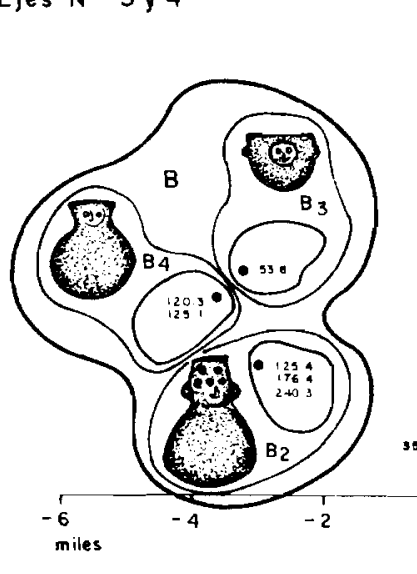

$$
\text { Eje } 4
$$
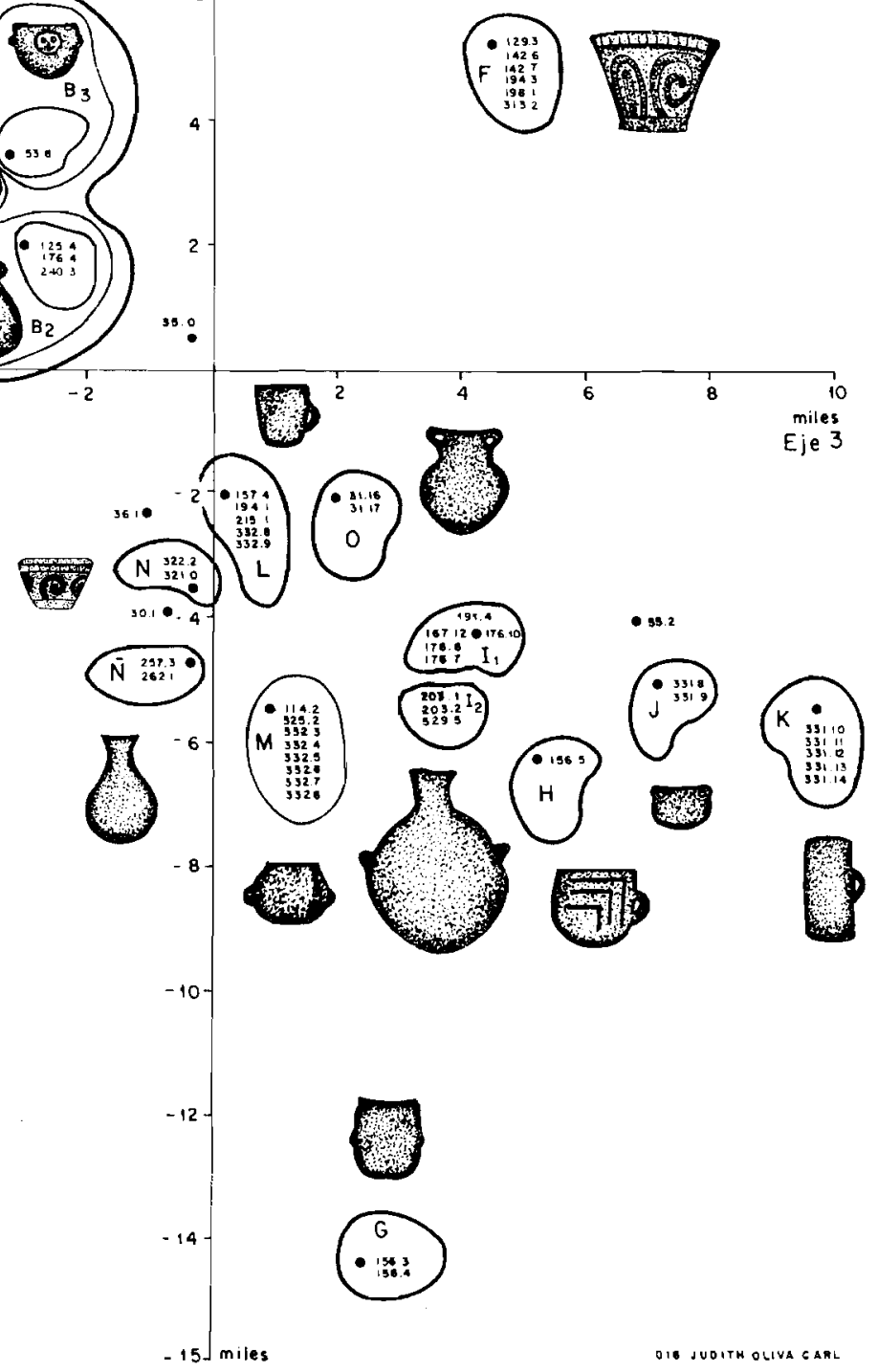

Imiles

$\because$

6.
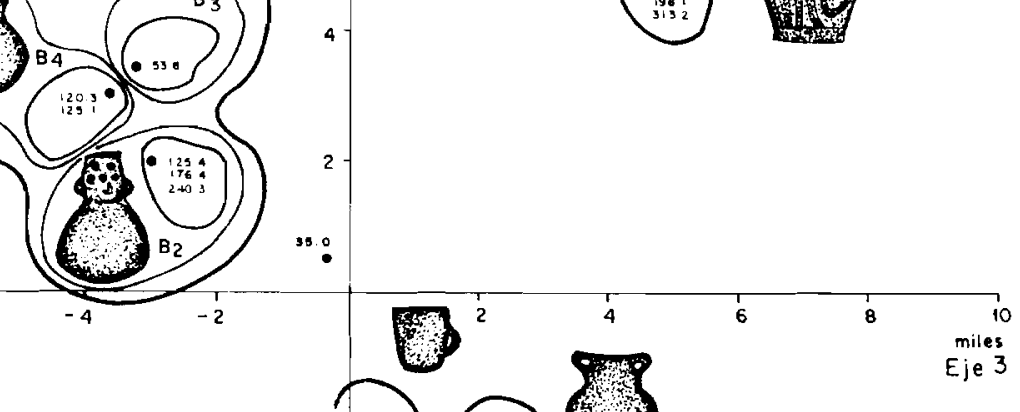
Figura 3

AGRUPACION CERAMICA POR ANALISIS DE CORRESPONDENCIA

Ejes NOS 1 Y 3

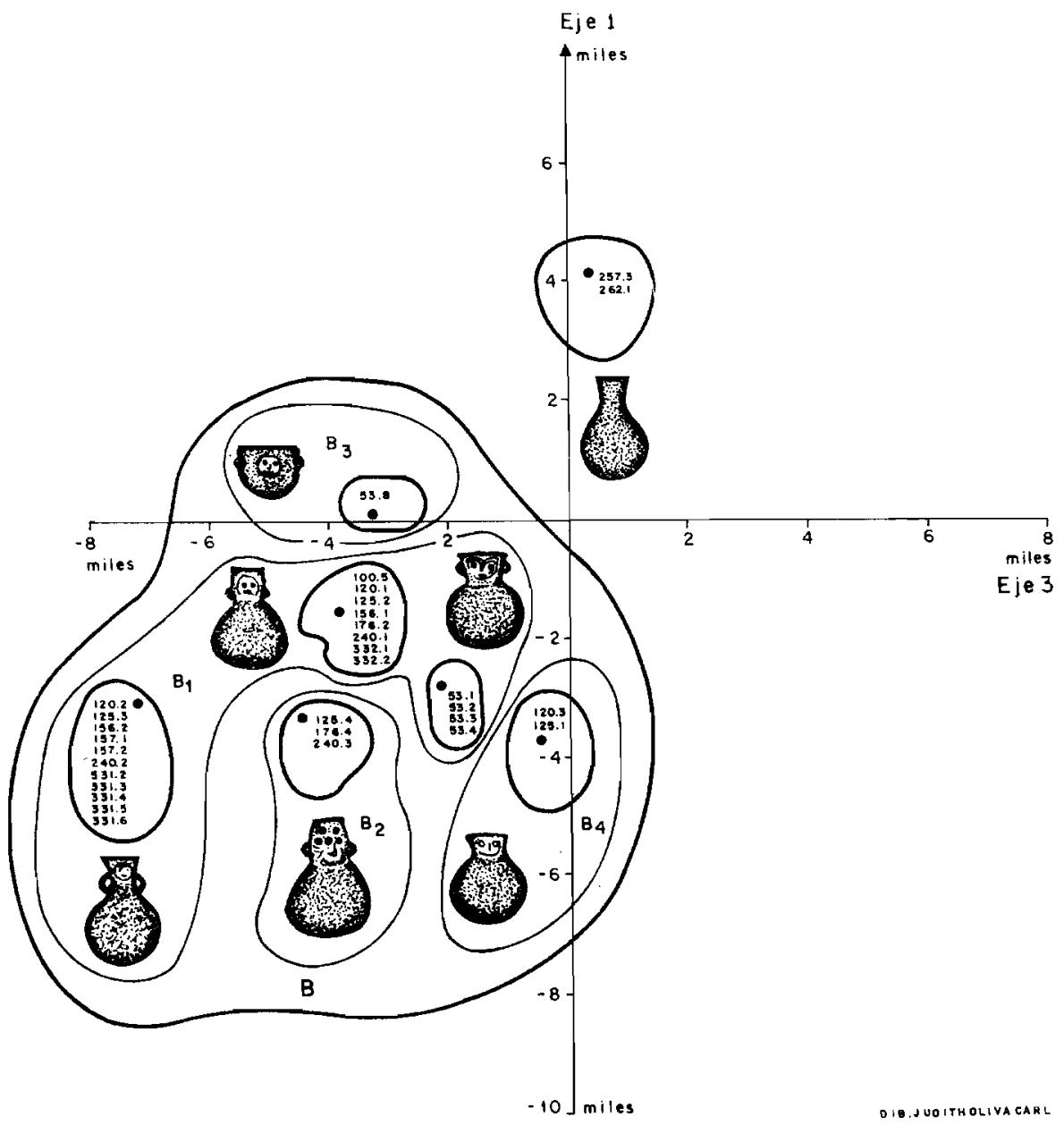




\section{Figura 4}

AGRUPACION CERAMICA POR ANALISIS DE CORRESPONDENCIA

Ejes NOS 2 Y 4


9



$\overbrace{\substack{2517 \\ 23 i, T}}^{2321}$

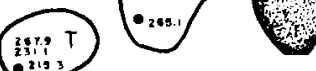
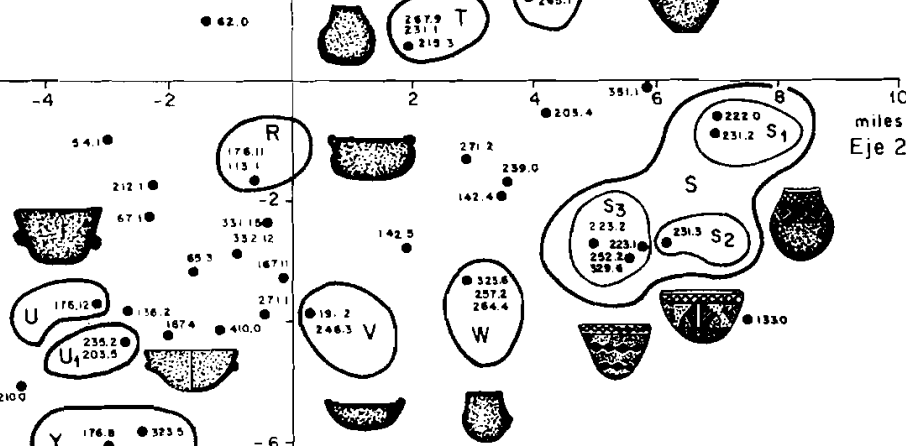

4176,100 
una "escudilla honda". Según Tarragó, han sido definidas como "formas negropulidas decoradas A y B" (cf. 1976).

Grupo C: Son vasijas no restringidas de contornos simples. De color negro y alisadas, sus lados son evertidos con respecto a la base que es recta. Corresponde a los tipos denominados por Le Paige "cuasi o casi pulido", por la naturaleza de la pasta (gruesa) y tratamiento de superficie (cf. 1964).

Grupo D: Vasijas no restringidas, de contornos simples. De color negro y tratamiento bruñido ${ }^{2}$ sus lados son casi rectos de labios evertidos y base recta. Posee dos asas cintas laterales doble adheridas, ubicadas transversalmente en el cuerpo. Corresponde a uno de los tipos denominados por Le Paige "negro pulido".

Grupo E: Vasija no restringida, de contorno simple. Alta, pintada gris con líneas negras cruzadas en el cuello. Labios evertidos y base recta. Correspondería a una de las formas cerámicas extranjeras presentes en la región de San Pedro de Atacama.

Grupo F: Son vasijas no restringidas, de contornos complejos, ya que su perfil está definido por dos puntos angulares o de inflexión (base y labio). Son vasijas de color gris, grabadas con líneas rectas y puntos en su cuello y base. El cuerpo lo definen grandes formas geométricas en forma de volutas y puntos blancos. Han sido denominados por Le Paige como vasos tronco cónicos-grabados (cf. 1964) y por Munizaga como del tipo "San Pedro Negro lnciso" (cf. 1963).

Grupo G: Corresponden a vasijas restringidas simples e independientes, de contornos simples. Son de color negro y tratamiento bruñido, su base es cóncava, cuerpo casi recto y labio ev́ertido. Poseen dos pequeñas asas laterales, lisas doble adherida en el cuerpo de la vasija. Han sido también definidas por Le Paige (cf. 1964) como pertenecientes a las formas del tipo "negro pulido".

Grupo $H$ : Corresponde al grupo de vasijas no restringidas de contornos compuestos. Pintada de color rojo y sobre éste se han diseñado líneas negras quebradas. Poseen lados rectos, labio recto y base convexa, en el cuerpo se inserta un asa cinta doble adherida. Corresponde a una forma extranjera.

Grupo I: Son vasijas restringidas independientes de contornos compuestos, son de color negro alisadas y se presentan otras negras con un leve polvo rojo encima. De cuerpo globular, base apuntada, cuello recto y labio evertido. Poseen dos asas macizas en la parte superior del cuerpo. Algunas de ellas pueden ser definidas como "urnas".

${ }^{2}$ Se estima oportuno, por las evidencias observadas, reemplazar el término "pulido" por el de "bruñido" en relación al tratamiento de superficie de la cerámica clásica de San Pedro. Este rasgo "bruñido" ya fuera destacado por Tarragó (cf. 1968: 127).

En adelante, se utilizará, en el contexto, el término "bruñido" en referencia a la cerámica en cuestión, salvo cuando se cite algún autor. 
Grupo J: Está configurado por vasijas restringidas simples y dependientes de contornos simples - son de color negro pulida y poseen dos asitas lisas doble labio adheridas-, corresponden a unas de las formas del tipo denominado por le Paige "negro pulido" (cf. 1964).

Grupo K: Grupo que corresponde a las vasijas no restringidas de contornos simples. Son de color negro bruñido, de paredes, labio y base recta. Poseen un asa lisa doble adherida en solo un lado del cuerpo.

Miriam Tarragó las clasificó dentro de la "forma I, negro pulido" (cf. 1976).

Grupo L: Vasijas no restringidas de contornos simples. Son de color negro y tratamiento bruñido. Sus lados son evertidos con respecto a la base que es recta. Poseen un asa lisa doble adherida en uno de los lados. Ha sido definida por Tarragó como perteneciente a la "forma xI, negro pulido" (cf. op. cit.).

Grupo $M$ : Formas de vasijas restringidas simples y dependientes de contornos complejos. Son de color negro, tratamiento bruñido, de base recta, labio evertido y poseen dos pequeñas asitas lisas doble adheridas en el cuerpo medio de ella. Tarragó las catalogó como la "forma viI, negro pulido" (cf. op. cit.).

Grupo N: Vasijas no restringidas de contornos complejos; su perfil se define por dos puntos de inflexión (base y labio). Su color es rojo; son grabadas con líneas rectas y puntos (cuello y base), están caracterizadas por grandes formas geométricas en forma de volutas y con incisiones de puntos de color blanco. Tarragó las agrupa en los "tipos rojo grabado, forma I" (cf. op. cit.).

Grupo $\bar{N}$ : Conformado por vasijas restringidas, independientes, de contornos inflexionados; su color es negro y su tipo de tratamiento de superficie es bruñido. Forma globular de base convexa y cuello-labio evertido.

Son botellones que corresponden a la "forma vi, negro pulido" de Tarragó (cf. op. cit.).

Grupo O: Vasijas restringidas independientes, de contornos simples. Son "urnas" de color café-negro y tratamiento alisado, cuerpo subglobular de base apuntada, cuello y labio evertido. Poseen dos grandes asas lisas doble labio adheridas.

Grupo P: Está conformado por vasijas restringidas independientes de contornos compuestos, están pintadas de color violáceo, tienen base recta y labio evertido. Dos grandes asas cintas doble adheridas se ubican en el cuerpo.

Es reconocido por Le Paige como una de las formas del tipo "concho de vino" (cf. 1964).

Grupo $Q$ : Lo configuran vasijas no restringidas de contornos simples, de base y paredes rectas, son bruñidas y de color negro, son consideradas por Le Paige como una de las formas del tipo "negro pulido" (cf. 1964).

Grupo $R$ : Son vasijas restringidas simples y dependientes de contornos simples. 
Son bruñidas de color negro, su base es recta, su cuerpo levemente inflexionado con dos asas lisas, labio doble, adheridas. Le Paige las define como una de las formas características del tipo "negro pulido" (cf. 1964).

Grupo $S$ : Se subdivide en tres grupos:

S1 : Vasijas restringidas independientes de contornos inflexionados, de color negro, están grabadas en el cuello con líneas y reticulados. Tienen labio evertido y base convexa. Corresponde, según Le Paige (cf. 1963: 230), al grupo negro pulido inciso tipo 5 .

S2 : Vasijas no restringidas de contornos simples. De color negro, con dibujos grabados de líneas rectas, curvas, reticulados y puntos. Base convexa y cuello labio recto.

Corresponden al tipo denominado por Le Paige (1963: 229) como una de las formas incisas con "Juego de colas" y al tipo "negro grabado A" de Tarragó (cf. 1976).

S3 : Vasijas no restringidas de contornos simples, de color negro, con dibujos grabados de líneas rectas, rombos y reticulados en todo el cuerpo. Mantienen la base convexa y cuello labio evertido.

Según Tarragó, corresponden al tipo "negro grabado B" (cf. 1976).

Grupo T: Se trata de vasijas restringidas independientes, de contornos inflexionados. Son de color gris negro de tratamiento alisado. Su base es recta, cuerpo subglobular y cuello labio levemente evertido. Por su tratamiento corresponden a uno de los tipos denominados por Le Paige como "casi o cuasi pulida" (cf. 1964).

Grupo $U$ : Vasijas no restringidas de contornos simples, de tratamiento bruñido y color negro. Tienen base recta y cuerpo evertido. Poseen dos asas cintas doble adheridas en el cuerpo medio. Según Tarragó corresponden al tipo "negro pulido, forma 111" (cf. 1976).

Grupo $U_{1}$ : Son vasijas no restringidas de contornos simples. De color negro y tratamiento bruñido, base convexa y cuerpo semiesferoide. Labio recto evertido y poseen dos asas lisas adheridas en el cuerpo medio. Corresponden, según Tarragó, al "tipo negro pulido, forma iv" (cf. op. cit.).

Grupo V: Vasijas no restringidas de contornos simples. Son de color negro y tratamiento bruñido. Base recta, paredes rectas labio evertido. Poseen dos asas lisas labio adheridas.

Grupo W: Son vasijas restringidas independientes de contornos inflexionados, de color gris negro y tratamiento bruñido. Base cóncava, cuerpo subglobular y labio evertido. Posee en un lado del cuerpo una pequeña protuberancia.

Grupo X: Son vasijas restringidas simples y dependientes y de contornos compuestos. De tratamiento alisado y color café-negro. Poseen base recta, cuello 
labio invertido y dos asas lisas se adhieren en el labio. Han sido denominadas por Le Paige como "urnas" (cf. 1963).

Grupo $Y$ : Pertenecen al grupo de vasijas no restringidas de contornos simples. Son de color rojo pintado. De la base recta surgen las paredes en forma divergente.

Grupo Z: Vasijas restringidas simples y dependientes, de contornos simples, de color negro y tratamiento bruñido. Base recta y cuerpo levemente invertido al labio que es invertido. Tienen dos asitas en el medio del cuerpo adheridas. Según Tarragó corresponden a la forma "negro pulido II" (cf. 1976).

Grupo $Z_{I}$ : Vasijas restringidas simples y dependientes, de contornos compuestos, son bruñidas de color negro. Poseen la base recta, cuerpo semiesférico inflexionado, cuello recto y labio evertido. Poseen dos asas lisas cuerpo doble adheridos. Tarragó las agrupa dentro de la “forma Ix, negra pulida” (cf. 1976).

\subsection{Cerámica extranjera}

Además de las formas y grupos cerámicos tratados por manejo computacional, se ha observado en el área de San Pedro la presencia relevante de otras formas cerámicas de procedencia trasandina y boliviana. Dichas formas se describen a continuación, aunque no se trata de información resultante de un proceso teórico-cuantitativo (Figura 5, q.v.):

$H_{1}$ : Vasijas restringidas, de contornos simples cuerpo semiesférico, poseen dos asas cintas a ambos costados, doble adheridas, decoración consistente de líneas negras cruzadas encerradas por líneas paralelas del mismo color pintadas sobre el fondo rojo natural de la greda. En el borde superior sobre el labio va una decoración de líneas negras paralelas.

Identificación: Arellano (cf. 1983) lo identificó como oriundo de la zona de Potosí de Lipez.

$\mathbf{H}_{2}$ : Vasijas restringidas simples y dependientes, cuerpo ovoide inflexionado de cuello y labio evertido. Sobre un fondo rojo va una serie de líneas negras cruzadas enmarcadas en un rectángulo del mismo color, el motivo se dispone en forma vertical desde el extremo superior de la vasija hasta el centro de ella.

Arellano (cf. 1983) lo identifica como oriundo de la zona de Potosí Lipez.

$\mathbf{H}_{3}$ : Vasijas restringidas simples y dependientes de contornos complejos, con un asa lateral. Decoradas con líneas negras, onduladas, que se descuelgan desde el borde hasta el tercio inferior de la vasija. Al lado opuesto del asa, una zona decorada de círculos concéntricos pintados en negro y separados por puntos negros, enmarcados en líneas del mismo color. Todos los motivos están sobre el fondo natural de la greda.

Arellano (cf. 1983) identificó este tipo en forma genérica como altiplánico. 
Figura No5 CERAMICA EXTRANJERA EN SAN PEDRO DE ATACAMA.

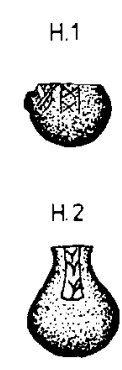

H.3

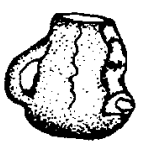

H. 4
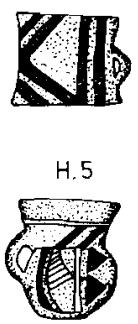

H. 5



H. 8

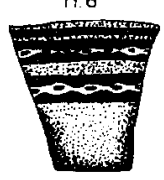

NOTA

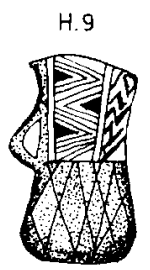

H. 10

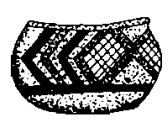

H.91



Hi. 12

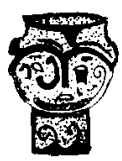

H.13

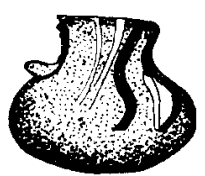

H. 14

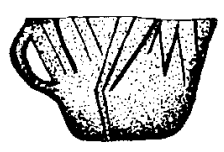

H. 27

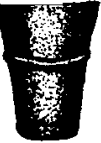

H.15
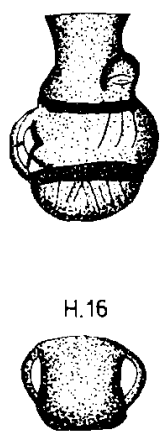

H. 17
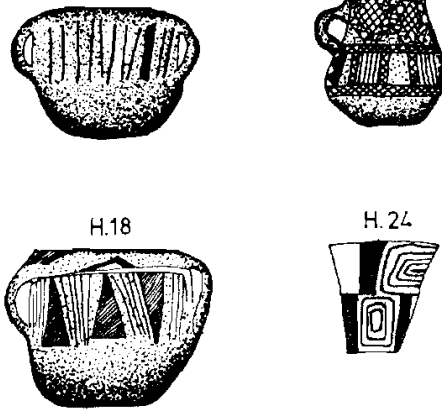

H. 25
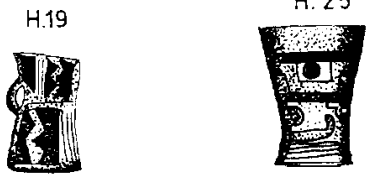

H. 26

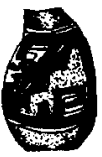


$\mathrm{H}_{4}$ : Vasijas restringidas de contornos simples con un asa al centro del cuerpo. Decoración de líneas negras gruesas sobre fondo rojo formando ya sea líneas paralelas o líneas paralelas que se cortan en ángulos, que se incluyen el uno al otro (cf. 1983).

Identificado por Arellano (cf. 1983) como tipo que puede ubicarse en el valle Mesotermo de Bolivia.

$\mathrm{H}_{5}$ : Vasijas restringidas independientes de contornos compuestos, de cuerpo globular y cuello-labio evertido posee un asa a un costado. Decoración: Sobre un engobado rojo, se disponen líneas negras paralelas, o ángulos también negros, segmentados por líneas del mismo color. Se disponen líneas de ángulos rellenos en negro unidos en la base por una línea del mismo color.

Una zona en el 1/3 inferior del cuello de fondo blanco, se decora con líneas oblicuas paralelas.

Identificación: Tarragó (cf. 1983) Le Paige: Tipo Isla.

Arellano (cf. 1983): Tipos observados en el área de Tarija.

$\mathrm{H}_{6}$ : Vasijas no restringidas de contornos simples con asa que comienza en el 1/3 superior y termina en la mitad de la vasija, decoración de líneas paralelas negras, y paralelas quebradas en su tercio superior, del mismo color, sobre fondo engobado rojo.

Identificación: Arellano (cf. 1983) como altiplánico genérico.

$\mathrm{H}_{8}$ : Vasijas no restringidas de contornos simples. Sobre un fondo gris, se despliegan paralelamente tres zonas de motivos que comprometen todo el contorno de la vasija. Una primera zona consiste en dos líneas paralelas ondulantes de color sepia. La segunda consistente en líneas ondulantes negras rellenas y en oposición, dejan al centro semicírculos que son a su vez decorados por óvalos negros rellenos.

La tercera zona es idéntica a la anteriormente descrita. Esta zonificación de decorado ocupa la mitad de la vasija.

Identificación: Arellano (cf. 1983). Tipo observado en Chuquisaca.

$\mathrm{H}_{9}$ : Vasijas no restringidas de contornos simples, asa cinta lateral ubicada al centro. Decoración: La mitad inferior sobre un fondo rojo pulido una serie de rombos en sepia cubren todo el contorno de la vasija. En la mitad superior, a partir de la inserción inferior del asa, sobre un fondo blanco se despliega una serie de paralelos decorados en sepia. Uno de ellos está compuesto de triángulos rellenos de una sepia más oscura, el cual está enmarcado por una serie de líneas oblicuas paralelas del mismo color. Un segundo panel y paralelo al asa consiste de una serie de paralelos verticales en sepia. Un tercer panel consiste de líneas paralelas verticales sepias que enmarcan líneas en sepia dispuestas en forma de ángulos que se contienen unos a otros formando una espiga invertida. El asa recubierta también con slip blanco en su lado externo está decorada con líneas cruzadas.

Identificación: Arellano (cf. 1983): Tarija. 
$\mathrm{H}_{10}$ : Vasijas no restringidas de contornos simples. Decoración negro y rojo sobre slip ante la cual cubre los 2/3 superiores de la pieza. Enmarcados sobre dos líneas paralelas la superior roja y la inferior negra. Una serie de ángulos alternados negros y rojos enmarcan dos losanges unidos por uno de los vértices. Al interior de cada uno de los losanges hay un reticulado compuesto de líneas rojas. El tercio inferior de la vasija está pintado de rojo. El borde superior. El labio de la vasija está segmentado cada cierta distancia por líneas gruesas rojas. Identificación: No hay.

$\mathbf{H}_{11}$ : Vasijas no restringidas de contornos simples. Decoración: Entre 2 líneas paralelas negras que se disponen cercanas al borde, una serie de líneas cruzadas del mismo color se desarrollan entre las paralelas antes dichas. De la línea límite inferior se desprenden 2 grupos de líneas paralelas oblicuas que no se cruzan y llegan hasta la mitad de la vasija cuyo fondo es la pasta rosada de la greda.

Identificación: Arellano (cf. 1983): Tarija al Oeste.

$\mathrm{H}_{12}$ : Vasija no restringida de contornos compuestos. Decoración: modelada y pintada. La propia subdivisión de su contorno da como resultado un cuello compuesto por la parte inferior de la vasija y una cabeza compuesta por la parte superior de la vasija. Tanto las orejas que hacen las veces de asas, como los ojos, nariz, ceja y boca son producto de aplicación de pastillaje. La totalidad de la vasija esta decorada con pintura negra semejando un tatuaje tanto en la cara y cabeza como en el cuello. Los principales motivos son líneas paralelas de la cual surgen ángulos rellenos negros, líneas onduladas paralelas. Volutas que parten de ángulos rellenos negros. Volutas en oposición enmarcadas por líneas negras en forma de L. También encontramos series de puntos.

Identificación: Arellano (cf. 1983), Uruquilla al borde de la montaña por Rosario del Inga (Tarija).

$\mathrm{H}_{13}$ : Vasijas restringidas simples y dependientes de contornos inflexionados. Decoración: líneas gruesas paralelas de pintura roja oscura y brillante se enmarcan en líneas negras gruesas en forma de S. Esta decoración está sobre un fondo pintado rojo violáceo. En un costado en donde comienza una inflexión presenta un asa, la cual remata en el borde superior.

Identificación: No hay.

$\mathrm{H}_{14}$ : Vasijas no restringidas de contornos simples con asa lateral que parte desde el borde y se desarrolla hasta el centro de la vasija sobre un fondo ante, una serie de amplias líneas sepias se entrecruzan formando ángulos, hacia el borde interior se desarrollan una serie de ángulos contrapuestos. Identificación: Arellano (cf. 1983): Tarija al Oeste.

$\mathrm{H}_{15}$ : Vasijas restringidas simples y dependientes, de contornos complejos con asa lateral al centro del cuerpo. Decoración pintada y modelada, una serie de líneas negras sepias pintadas adorna en forma de ángulos la parte superior del cuello. En el cuerpo cerca de la inflexión del cuello dos líneas 
rojas paralelas se desarrollan a lo largo del contorno del ceramio, y de la línea paralela inferior se desprenden algunas líneas verticales paralelas de color negro sepia.

En el tercio inferior del cuerpo se desarrollan otras líneas paralelas de color rojo la superior y negra la inferior y de ésta se desprenden líneas verticales de color negro sepia en forma paralela pero desordenadas.

A la altura del cuello, aplicaciones de greda han modelado el típico rostro compuesto por gruesas cejas, nariz aguileña y a ambos lados de la nariz el típico ojo "grano de café".

Identificación: Le Paige: Candelaria.

Arellano (cf. 1983): Tarija al Este (Rosario del Inga).

$\mathrm{H}_{16}$ : Vasijas no restringidas de contorno simple, con asas a ambos costados que parten de los labios de la vasija y se adhieren en el $1 / 3$ inferior de ella. Decoración: cubierta de un slip color blanquecino amarillento.

Identificación: Arellano (1983): 'Tarija.

$\mathrm{H}_{17}$ : Vasijas no restringidas de contorno simple con dos asas laterales que parten de los labios y se adhieren en la mitad del cuerpo de la vasija. Decoración: slip blanco amarillento. En la mitad superior de la vasija se observa una zona compuesta de líneas paralelas, vértices anchos y delgados de color sepia y limitadas por dos líneas paralelas horizontales de igual color.

Identificación: No hay.

$\mathrm{H}_{18}$ : Vasijas no restringidas de contornos simples con asas laterales que nacen desde el labio de la vasija y se adhieren en la parte final del $1 / 3$ superior de ella. Decoración: slip blanco ceniciento. Se nota una zonificación en que se insertan triángulos opuestos alternados con líneas paralelas. Esta zonificación de decoración se desarrolla en la mitad superior de la vasija.

Identificación: Arellano (1983): Zona Tarija al Oeste.

$\mathrm{H}_{19}$ : Vasijas no restringidas de contornos simples con un asa adherida al centro del cuerpo de la vasija. Decorado: Sobre un engobado blanco amarillento se distinguen dos sectores decorados: la decoración adopta zonas alternadas, dividida por dos líneas paralelas de color negro, una superior compuesta de líneas negras verticales paralelas y la otra zona de triángulos negros rellenos que adoptan una forma aserrada, dejando al centro un grueso zig-zag del mismo color blanco amarillento. El sector inferior tiene la misma decoración pero el desplazamiento de las zonas hace que se contrapongan. El borde interno del ceramio está decorado con una serie de líneas negras cruzadas.

Identificación: Arellano (1983): Zona Tarija.

$\mathrm{H}_{20}$ : Vasijas no restringidas de contornos simples, con asa a medio cuerpo. Decorado: Se distinguen dos sectores en la vasija: Uno superior, el cual presenta un slip blanco, y otro que ocupa los dos tercios inferiores; los dos sectores están delimitados por dos líneas: una roja superior y otra negra 
inferior. Todo el cuerpo está pintado con líneas negras que forman un reticulado.

Identificación: Arellano (1983): Tarija.

$\mathrm{H}_{21}$ : Vasijas no restringidas de contorno simple con asa lateral ubicada a mitad del cuerpo. Decoración: fondo rojo engobado decorado con líneas paralelas anchas de color negro.

Sin identificación.

$\mathrm{H}_{22}$ : Vasijas no restringidas de contorno simple, con asa lateral, ubicada a mitad de cuerpo. Decorado: sobre fondo rojo, grecas paralelas, en número de tres, unas contenidas en la otra, se desarrollan en torno a la vasija finalizando cerca del asa. Una línea negra decora todo el borde superior de la vasija. Sin identificación.

$\mathrm{H}_{23}$ : Vasijas restringidas simples y dependientes de contornos complejos, con un asa lateral. Se distinguen en estas vasijas dos sectores: un sector correspondiente al inferior, rojo engobado, y un sector correspondiente a los dos tercios, medio y superior con un fondo compuesto por slip blanco. Sobre este sector se desarrollan dos zonas decoradas en la zona correspondiente al tercio superior, está compuesto por dos losanges enmarcados con gruesas líneas negras un enrejado en rojo. La segunda zona, enmarcada en dos líneas gruesas de color negro forman paneles verticales decorados con líneas negras, que se alternan con paneles del color base (slip y con paneles que contienen triángulos negros rellenos que conforman un aserrado). Indentificación: Arellano (1983): Tarija.

$\mathrm{H}_{24}$ : Vasijas no restringidas de contornos simples. Decorado sobre un fondo gris de la vasija se distinguen dos zonas de decoración, en la mitad superior se distinguen 2 paneles separados por una línea negra gruesa vertical, uno de los paneles exhibe el fondo gris de la vasija y en otro desarrolla una serie de figuras rectangulares inclusives, configurado por una línea negra que se repliega en sí misma terminando en el centro, con un rectángulo que incluye una cruz central del mismo color.

En la mitad inferior se desarrollan los mismos temas, estando sí descentrados los paneles de modo que ellos se contrapongan.

Identificación: Arellano (1983): Chuquisaca, Mojocolla.

$\mathrm{H}_{25}$ : Vasija no restringida de contorno simple. Decorado: sobre un engobe rojo y entre una línea horizontal negra que se desarrolla en toda la vasija a la altura del tercio superior y una serie de líneas paralelas amarillas se desarrolla una serie de grecas negras que contienen la típica cabeza de cóndor con el círculo blanco.

Identificación: Arellano (1983): Tiahuanaco decadente, pieza importada de acuerdo a la pasta.

$\mathrm{H}_{26}$ : Vasijas restringidas independientes de contorno compuesto.

Sobre un engobado rojo, los dos tercios del cuerpo están decorados con un escalonado en líneas gruesas. El interior del escalerado contiene una voluta 
conformada de líneas rectas, en el centro de la vasija entre dos líneas negras verticales paralelas se dispone una serie de líneas onduladas blancas paralelas. Separan estos motivos del tercio inferior dos líneas paralelas horizontales negras.

Identificación: Arellano (1983): Tiahuanaco decadente.

$\mathrm{H}_{27}$ : Vasijas no restringidas de contornos simples. Decoradas en el $1 / 3$ superior con una "media caña" superficial negra bruñida.

Identificación: Podría ser una adaptación de formas extranjeras (H25) adaptadas en la localidad. Sin embargo, dada su escasa frecuencia se considerará por el momento como una forma extranjera más.

$\mathrm{H}_{28}$ : Vasijas restringidas simples y dependientes de contornos inflexionados, su tratamiento es (asimétrica) sin decoración su tratamiento es café alisado. Identificación: Posiblemente esta forma asimétrica corresponda a tipos similares ilustrados por Bennet, para los sitios de Rinconada e lsla (Argentina). No se han descrito aquí otros ceramios de procedencia extranjera, dado que no se conocen con precisión sus relaciones contextuales.

\subsection{Ordenamiento en fases de los tipos cerámicos postulados por Miriam Tarragó}

Por otra parte, retomando a Miriam Tarragó (cf. 1976), se aplicó a los datos consignados en su artículo (con respecto a la cerámica negra pulida y sus relaciones con el rojo pulido y negro grabado) un test de asociación —correlación de perfil cuya fórmula se consigna en el acápite (q.v.). Los resultados obtenidos permitieron identificar cuatro fases definidas por diversas formas cerámicas interrelacionadas. Ellas son las siguientes:

\section{Fase A}

con dos modalidades:

1. Tipo negro pulido: Formas I - 111 - Decorado A y formas de excepción.

2. Tipo rojo pulido: Todas las formas.

Fase $B$

Tipo negro pulido: Formas II - iv y decorado B.

Fase $C$

Con tres modalidades:

1. Tipo negro pulido: Formas VI - VII y Ix.

2. Tipo negro grabado: Todas las formas.

3. Tipo rojo grabado: Todas las formas.

Fase $D$

Tipo negro pulido: Formas v - v111 - x - xII y xIII. 


\section{ANÁlisis}

\subsection{Homologación de la información}

Por agregación de los datos consignados por Miriam Tarragó (cf. 1976: 48-5256-59) y los resultados de la revisión de colecciones realizada (ya mencionada en acápites anteriores) se construyó la base de datos a la cual se recurre en el desarrollo de esta investigación y que se presenta en el Anexo $\mathrm{N}^{\circ} \mathbf{l}$ (q.v.)

La matriz que aparece en este anexo está configurada por una serie de filas que corresponden al total de los sitios del área de San Pedro de Atacama, considerados por el presente artículo. Las columnas de dicha matriz son referentes de todos los tipos cerámicos pesquisados para el área en cuestión, tanto aquellos consignados por Tarragó, como aquellos que sólo aparecen de la revisión de las colecciones del Museo de San Pedro de Atacama.

Cuando corresponde, en el encabezamiento de la fila aparece la denominación utilizada por Tarragó como asimismo su correspondiente de acuerdo a los resultados del análisis multivariado realizado por los autores del presente artículo, en relación a tipos cerámicos asociados a tabletas de rapé.

Si se trata de formas cerámicas no consignadas por Tarragó, sólo aparece la denominación resultante del análisis multivariado referido en el acápite 5.1.

\subsection{Formulación de Supuestos}

Para el área en estudio se reconoce un período temprano ubicado en sus inicios alrededor del 900 a.C. (cf. BENAVENTE, 1982: 22), especialmente por la presencia en la localidad de Poconche, Tulor y Sequitor de cerámica corrugada y algunas otras formas de las selvas orientales del NW argentino. Sin embargo, es posible para fechas posteriores visualizar otros tipos posiblemente vinculados al Horizonte gris monócromo que están presentes en San Pedro y que podemos también incluirlos en fases sucesivas de este período. Específicamente se hace referencia a cerámica pulida fina de color gris o café, que también se ha encontrado en Turi y que podrían ser antecedentes de la cerámica San Pedro Negro Pulido, ubicable alrededor del 200 d.C., de acuerdo con Orellana (cf. 1963: 33), quien fecha urnas, sobre una capa de alfarería del tipo San Pedro Negro Pulido, en $1650 \pm 150 \mathrm{~B}^{\mathrm{P}}$.

Partiendo del 100 d.C. y prolongándose hasta el 1200 d.C. puede postularse un período intermedio, en el cual se ubica el material cerámico analizado por Miriam Tarragó (cf. 1976). En éste, indiscutiblemente, dominan las formas del Negro Pulido y sus diversas asociaciones. Se hace concluir este período en el 1200 d.C., por la presencia de algunas formas cerámicas extranjeras perfectamente ubicadas como son Huruquilla procedentes del altiplano y Yura, Tilcara-Yavi procedentes de la vertiente trasandina. Asociación postulada por Tarragó para el 1300 d.C. (cf. 1968: 141). A este período (100 d.C. 1200 d.C.) se circunscribe el desarrollo del presente trabajo. 
Además a partir del 900 d.C. se reconoce la introducción en la zona de formas cerámicas típicas de más al Norte y conocidas en la literatura como los tipos Dupont (cf. Núñez 1965), Pukara de Chiu-Chiu (cf. Thomas, Benavente 1974), (cf. Thomas 1978), Lasana il (cf. Pollard 1971) y formas reconocidas para Río Salado como los tipos Ayquina (negro y gris café) (cf. Orellana, 1968).

Volviendo a la data menejada por Tarragó, y considerando las diversas asociaciones del tipo Negro Pulido, inferidas a partir del análisis de "correlación de perfil", es válido subdividir tentativamente el período intermedio en las siguientes fases ya descritas en el acápite anterior:

Fase A (100 d.C. - 400 d.C.)

Fase $B$ (400 d.C. - 600 d.C.)

Fase $C$ (600 d.C. - 900 d.C.)

Además de los tipos que, del análisis de los datos manejados por Tarragó, pertenecerían a esta fase, deben agregarse todas aquellas formas que Le Paige denomina "casi o cuasi pulidas" (1964), mencionadas también por Tarragó (cf. 1976: 50; cf. 1968: 132).

Fase D (900 - 1200 d.C.)

Es valido postular cronológicamente como límite terminal de la fase $\mathrm{A}$ la fecha 400 d.C. dando crédito al fechado obtenido por Le Paige (cf. Núñez, 1976: 74) en Quitor 6 de $1700 \pm 150 \mathrm{~B}^{\mathrm{P}}$, siendo además un rasgo significativo el que éste sitio manifieste la ausencia de las formas tradicionales de la cerámica Roja Pulida.

Por otra parte, puede suponerse como fecha terminal de la fase B el $600 \mathrm{~d}$.C. Esta suposición se basa en el fechado ( $1195 \pm 100 \mathrm{~B}^{\mathrm{P}}$ ) obtenido en el sitio "Nin̄o Korin" (Bolivia). Si bien este sitio se encuentra alejado del área en estudio, están presentes en él elementos del complejo de rapé que lo vinculan de algún modo al problema en cuestión.

En dicho sitio se encontraron algunas tabletas de rapé, labradas en madera, muy similares a las encontradas en San Pedro de Atacama y que los análisis, realizados por quien escribe, las identificaron como integrantes del grupo $\mathrm{F}$ (cf. Thomas Benavente, 1984: 172).

Cabe señalar la yuxtaposición entre tabletas del grupo $\mathrm{F}$ y cerámica de los tipos grabados, elementos referentes de la expansión de Tiwanaku en la zona, que se produciría con posterioridad al 600 d.C. Ayuda a la consistencia de esta suposición la serie de fechas obtenidas por Ponce Sanginés, las que por su promedio aritmético se ordenan alrededor del 667 (cf. 1972: 78), como asimismo algunas formas cerámicas ilustradas por Wallace (1950: 285b), estas últimas muy semejantes a los tipos cerámicos grabados ya mencionados. Finalmente puede postularse como fecha terminal de la fase C e inicio de la fase D el $900 \mathrm{~d}$.C. Confirman esta postulación los fechados obtenidos por el Padre Le Paige, en los cementerios de Solor 4 (980 \pm 75 d.C.) y Quitor 9 (1050 \pm 80 d.C.). 


\subsection{Asociación entre grupos cerámicos y construcción de secuencia}

Para lograr un ordenamiento de la alfarería de San Pedro, en términos cronológicos relativos, se recurrió a la base de datos que se consigna en el anexo 1.

A esta información se aplicó, de acuerdo a la metodología propuesta, el test de correlación de perfil para medir el grado de asociación entre las diferentes formas cerámicas registradas para el área de San Pedro de Atacama en correspondencia al período que definiéramos como intermedio en el acápite anterior.

El test de correlación de perfil es referido por la siguiente expresión:

$$
Q \mathrm{ij}=1-\frac{\mathrm{D}_{\mathrm{ij}}^{* 2}}{2}
$$

donde:

$$
D_{i j}^{* 2}=\frac{\sum(X i-X j)^{2}-k(M i-M j)^{2}-(S i-S j)^{2}}{(S i) *(S j)}
$$

donde:

i. Cuyo valor varía de 1 a 82 , identifica los primeros ochenta y dos grupos cerámicos contenidos en el anexo $\mathrm{N}^{\circ} 1$.

j. Cuyo valor varía de 2 a 83 , identifica los últimos ochenta y dos grupos cerámicos contenidos en dicho anexo.

Xi. Designa la frecuencia de ceramios pertenecientes al grupo i en cada uno de los 32 sitios considerados por el estudio.

$\mathrm{Xj}$. Designa la frecuencia de ceramios pertenecientes al grupo j en cada uno de los 32 sitios considerados por el estudio.

k. Designa el número de dimensiones de los perfiles i y j (32, en este caso, dado el número de sitios en estudio).

Mi. Valor medio de perfil i.

$\mathrm{Mj}$. Valor medio de perfil j.

$\mathrm{Si}$ Dispersión del perfil i.

Sj. Dispersión del perfil j.

Estas últimas medidas de dispersión se obtienen a través de la expresión genérica:

$$
S=\sqrt{\Sigma(x-M)^{2}}
$$

Aplicado el test, se asumió como parámetro, para aceptar como relevante una asociación entre dos grupos cerámicos, el valor de 0.7260 .

De la aplicación del test mencionado se obtuvieron las siguientes asociaciones relevantes: 
Tabla 1

COEFICIENTES DE CORRELACION DE PERFIL ENTRE FORMAS CERAMICAS

\begin{tabular}{|c|c|c|c|c|c|}
\hline \multicolumn{2}{|c|}{$\begin{array}{c}\text { Formas cerámicas } \\
\text { Asociadas }^{3}\end{array}$} & \multirow{2}{*}{$\begin{array}{c}\begin{array}{c}\text { Coeficiente de } \\
\text { correlación de perfil }\end{array} \\
0.9752\end{array}$} & \multicolumn{2}{|c|}{$\begin{array}{c}\text { Formas Cerámicas } \\
\text { Asociadas }^{3} \\
\end{array}$} & \multirow{2}{*}{$\begin{array}{c}\begin{array}{c}\text { Coeficiente de } \\
\text { correlación de perfil }\end{array} \\
0.7642\end{array}$} \\
\hline Uo & $\mathrm{U}$ & & NcP2 & mNR & \\
\hline Uo & A2 & 0.9782 & NcP2 & E26 & 0.7643 \\
\hline Uo & RNt & 0.9174 & NcP2 & E28 & 0.7643 \\
\hline \multirow[t]{2}{*}{ Uo } & NB 14 & 0.7580 & & & \\
\hline & & & RNt & NB 14 & 0.7322 \\
\hline $\mathrm{U}$ & A2 & 0.9978 & & & \\
\hline $\mathrm{U}$ & RNt & 0.9416 & NB 1 & NB2 & 0.7266 \\
\hline $\mathrm{U}$ & NB 14 & 0.8178 & NB 1 & NB4 & 0.8267 \\
\hline \multirow[t]{2}{*}{$\mathrm{U}$} & NB 18 & 0.7469 & NB 1 & NBD1 & 0.8026 \\
\hline & & & MB I & RP1 & 0.8898 \\
\hline Al & NB 10 & 0.7905 & MB 1 & RP2 & 0.8815 \\
\hline Al & NB 11 & 0.9043 & NB 1 & RP4 & 0.8432 \\
\hline $\mathrm{Al}$ & NBD2 & 0.7792 & NB 1 & RP5 & 0.8248 \\
\hline Al & NBD4 & 0.9035 & NB I & E14 & 0.8432 \\
\hline Al & NB 15 & 0.7956 & NB I & E 19 & 0.8432 \\
\hline Al & NB 17 & 0.9035 & NB I & E20 & 0.8432 \\
\hline Al & NG4 & 0.7956 & & & \\
\hline Al & E10 & 0.9035 & NB2 & NB4 & 0.7934 \\
\hline Al & E12 & 0.9035 & NB2 & NB9 & 0.7292 \\
\hline A2 & RNt & 0.9450 & NB2 & NBD 1 & 0.9559 \\
\hline A2 & NB 14 & 0.7811 & NB2 & NBD2 & 0.9066 \\
\hline \multirow[t]{2}{*}{ A2 } & NB 18 & 0.7512 & NB3 & NB4 & 0.8042 \\
\hline & & & NB3 & NB7 & 0.7557 \\
\hline $\mathrm{NcPl}$ & NcP2 & 0.7814 & NB3 & NB9 & 0.7794 \\
\hline $\mathrm{NcPl}$ & NBD3 & 0.9087 & NB3 & $\mathrm{Ng} 2$ & 0.7622 \\
\hline $\mathrm{NcPl}$ & $\mathrm{mRN}$ & 0.7931 & & & \\
\hline $\mathrm{NcPl}$ & Ng6 & 0.7767 & NB4 & NB 7 & 0.8240 \\
\hline $\mathrm{NcPl}$ & E26 & 0.9087 & NB4 & NB9 & 8.8225 \\
\hline \multirow[t]{2}{*}{$\mathrm{NcPl}$} & E28 & 0.9087 & NB4 & NBDI & 0.7896 \\
\hline & & & NB4 & NBD2 & 0.7555 \\
\hline $\mathrm{NcP} 2$ & NBD & 0.7643 & NB4 & Ng2 & 0.8040 \\
\hline
\end{tabular}

${ }^{3}$ Tanto M. Tarragó como los resultados del análisis multivariado de la cerámica asociada a tabletas de rapé utilizan nomenclaturas distintas para identificar tipos cerámicos similares. Esto ha hecho necesario uniformar la denominación de las formas. A partir de este acápite se utilizará esta nueva denominación.

l.a correspondencia entre las diferentes nomenclaturas se consigna en el Anexo 2. 


\begin{tabular}{|c|c|c|}
\hline \multicolumn{2}{|c|}{$\begin{array}{l}\text { Formas Cerámicas } \\
\text { Asociadas }^{3}\end{array}$} & \multirow{2}{*}{$\begin{array}{c}\begin{array}{c}\text { Coeficiente de } \\
\text { correlación de perfil }\end{array} \\
0.8313\end{array}$} \\
\hline NB7 & NB9 & \\
\hline NB7 & $\mathrm{Ng} 2$ & 0.9059 \\
\hline NB8 & NB 12 & 0.7754 \\
\hline NB9 & NB 11 & 0.7432 \\
\hline NB9 & Ng2 & 0.7476 \\
\hline NB 10 & NBD4 & 0.7912 \\
\hline NB 10 & NB 15 & 0.8307 \\
\hline NB 10 & NB 17 & 0.7912 \\
\hline NB 10 & $\mathrm{Ng} 4$ & 0.7695 \\
\hline NB 10 & E10 & 0.7912 \\
\hline NB 10 & E12 & 0.7912 \\
\hline NB 11 & NBD2 & 0.7677 \\
\hline NB 11 & NBD4 & 0.7262 \\
\hline NB 11 & NB 17 & 0.7262 \\
\hline NB 11 & Ry & 0.7694 \\
\hline NB 11 & E10 & 0.7262 \\
\hline NB 11 & E12 & 0.7262 \\
\hline NB 13 & NB20 & 0.8916 \\
\hline NB 13 & RP3 & 0.9717 \\
\hline NB 13 & E13 & 1 \\
\hline NBD 1 & NBD2 & 0.8070 \\
\hline NBD 1 & RP1 & 0.7512 \\
\hline NBDI & RP2 & 0.7441 \\
\hline NBD 1 & RP4 & 0.7387 \\
\hline NBD1 & E14 & 0.7387 \\
\hline NBD1 & E19 & 0.7387 \\
\hline NBD 1 & E20 & 0.7387 \\
\hline NBD2 & NBD4 & 0.7933 \\
\hline NBD2 & NB 15 & 0.7456 \\
\hline NBD2 & NB 17 & 0.7933 \\
\hline NBD2 & $\mathrm{Ng} 4$ & 0.7531 \\
\hline NBD2 & E10 & 0.7933 \\
\hline NBD2 & E12 & 0.7933 \\
\hline NBD3 & E.26 & 1 \\
\hline
\end{tabular}

\begin{tabular}{|c|c|c|}
\hline \multicolumn{2}{|c|}{$\begin{array}{l}\text { Formas Cerámicas } \\
\text { Asociadas }^{3}\end{array}$} & \multirow{2}{*}{$\begin{array}{c}\begin{array}{c}\text { Coeficiente de } \\
\text { correlación de perfil }\end{array} \\
1\end{array}$} \\
\hline NBD3 & E28 & \\
\hline NBD4 & NB 15 & 0.8916 \\
\hline NBD4 & NBl 7 & 1 \\
\hline NBD4 & $\mathrm{Ng} 4$ & 0.8916 \\
\hline NBD4 & E10 & 1 \\
\hline NBD4 & E12 & 1 \\
\hline NB 15 & NB 17 & 0.8916 \\
\hline NB 15 & Ng3 & 0.7317 \\
\hline NB 15 & $\mathrm{Ng} 4$ & 0.7881 \\
\hline NB 15 & E10 & 0.8916 \\
\hline NB 15 & E 12 & 0.8916 \\
\hline NB 16 & Rs & 0.8294 \\
\hline NB 16 & E16 & 0.8266 \\
\hline NB 16 & E17 & 0.8266 \\
\hline NB 16 & E18 & 0.8266 \\
\hline NB17 & $\mathrm{Ng} 4$ & 0.8416 \\
\hline NB 17 & E 10 & 1 \\
\hline NB 17 & E12 & 1 \\
\hline NB20 & RP3 & 0.9275 \\
\hline NB20 & E.13 & 0.8916 \\
\hline RP1 & RP2 & 0.9250 \\
\hline \multirow[t]{4}{*}{ RP1 } & RP4 & 0.9424 \\
\hline & RP5 & 0.9473 \\
\hline & E14 & 0.9424 \\
\hline & E20 & 0.9424 \\
\hline RP2 & RP4 & 0.9458 \\
\hline RP2 & RP5 & 0.8106 \\
\hline RP2 & E14 & 0.9458 \\
\hline RP2 & E19 & 0.9458 \\
\hline RP2 & E20 & \\
\hline RP3 & E13 & 0.9716 \\
\hline RP4 & RP5 & 0.7964 \\
\hline
\end{tabular}




\begin{tabular}{|c|c|c|c|c|c|}
\hline \multicolumn{2}{|c|}{$\begin{array}{c}\text { Formas Cerámicas } \\
\text { Asociadas }^{3}\end{array}$} & \multirow{2}{*}{$\begin{array}{c}\begin{array}{c}\text { Coeficiente de } \\
\text { correlación de perfil }\end{array} \\
1\end{array}$} & \multicolumn{2}{|c|}{$\begin{array}{c}\text { Formas Cerámicas } \\
\text { Asociadas }^{3}\end{array}$} & \multirow{2}{*}{$\begin{array}{c}\begin{array}{c}\text { Coeficiente de } \\
\text { correlación de perfil }\end{array} \\
1\end{array}$} \\
\hline RP4 & E14 & & E2 & E3 & \\
\hline RP4 & E19 & 1 & E2 & E5 & 1 \\
\hline RP4 & E20 & 1 & E2 & E21 & 1 \\
\hline RP5 & E14 & 0.7964 & E2 & E24 & 1 \\
\hline RP5 & E19 & 0.7964 & E3 & E5 & 1 \\
\hline \multirow[t]{2}{*}{ RP5 } & E20 & 0.7964 & E3 & E21 & 1 \\
\hline & & & E3 & E24 & 1 \\
\hline Rg 1 & Rg3 & 0.8733 & & & \\
\hline Rg 1 & E8 & 0.8733 & E5 & E21 & 1 \\
\hline Rg 1 & E9 & 0.8733 & E5 & E24 & 1 \\
\hline Rg3 & E8 & 1 & E8 & E9 & 1 \\
\hline \multirow[t]{2}{*}{ Rg3 } & E9 & 1 & & & \\
\hline & & & E10 & E 12 & 1 \\
\hline Rs & E16 & 0.9933 & & & \\
\hline Rs & E17 & 0.9933 & Ell & E15 & 1 \\
\hline \multirow[t]{2}{*}{ Rs } & E18 & 0.9933 & & & \\
\hline & & & E14 & E 19 & 1 \\
\hline $\mathrm{Ng} 3$ & $\mathrm{Ng} 4$ & 0.7317 & E14 & E20 & 1 \\
\hline $\mathrm{Ng} 4$ & E10 & 0.8916 & E16 & E17 & 1 \\
\hline $\mathrm{Ng}^{4}$ & E12 & 0.8916 & E16 & E 18 & 1 \\
\hline $\mathrm{Ng} 5$ & E2 & 1 & E17 & E18 & 1 \\
\hline $\mathrm{Ng} 5$ & E3 & 1 & & & \\
\hline $\mathrm{Ng} 5$ & E5 & 1 & E19 & E20 & 1 \\
\hline Ng5 & E21 & 1 & & & \\
\hline Ng5 & E24 & 1 & E21 & E24 & 1 \\
\hline El & E7 & 0.7317 & E26 & E28 & 1 \\
\hline
\end{tabular}

A partir de estos resultados, y considerando todos los antecedentes documentales, de gabinete y teóricos descritos, se construyó la secuencia cerámica cuya presentación gráfica se consigna en la Figura 6 "secuencia cerámica y correspondencia con tabletas para el área de San Pedro de Atacama” (q.v.). 
Luego se procedió a chequear la bondad de la secuencia construida. Dicho chequeo se realizó por comparación con los últimos fechados disponibles -Termoluminiscencia- (cf. Román, Deza, Berenguer, Llagostera, 1985).

Los resultados de tal comparación, los que verifican la secuencia presentada en este artículo, se consignan en la siguiente tabla:

TABLA II

COMPARACION ENTRE FECHADOS POR TERMOLUMINISCENCIA Y CRONOLOGIA RELATIVA OBTENIDA

\begin{tabular}{|c|c|c|c|c|}
\hline Sitio ${ }^{\prime}$ & $\begin{array}{l}\text { Identi- } \\
\text { ficación' }\end{array}$ & $\begin{array}{c}\text { Grupo } \\
\text { o forma }\end{array}$ & $\begin{array}{c}\text { Fecha } \\
\text { termoluminiscencial }\end{array}$ & $\begin{array}{l}\text { Cronología relativa } \\
\text { (Cr.) por secuencia }{ }^{2}\end{array}$ \\
\hline Quitor-5 & $\begin{array}{l}3397-V \\
2245-V \\
\text { S.N.-II }\end{array}$ & $\begin{array}{l}\text { Casi Pulido } \\
\text { Casi Pulido } \\
\text { Rojo Pulido }\end{array}$ & $\begin{array}{l}340 \mathrm{dC}-440 \mathrm{dC}-540 \mathrm{dC} \\
600 \mathrm{dC}-710 \mathrm{dC}-820 \mathrm{dC} \\
210 \mathrm{AC}-40 \mathrm{aC}-130 \mathrm{dC}\end{array}$ & $\begin{array}{r}600-900 \text { d.C. } \\
600-900 \text { d.C. } \\
\text { Cr. } 100-400 \text { d.C. }\end{array}$ \\
\hline Quitor-6 & $\begin{array}{l}288 \text { I-IV-V } \\
0035-\text { VII } \\
0054-\text { VII }\end{array}$ & $\begin{array}{l}\text { Rojo Grabado } \\
\text { Dupont } \\
\text { Dupont }\end{array}$ & $\begin{array}{l}440 \mathrm{dC}-580 \mathrm{dC}-680 \mathrm{dC} \\
070 \mathrm{dC}-1140 \mathrm{dC}-1210 \mathrm{dC} \\
810 \mathrm{dC}-940 \mathrm{dC}-1070 \mathrm{dC}\end{array}$ & $\begin{array}{l}600-900 \text { d.C. } \\
900-1200 \text { d.C. } \\
900-1200 \text { d.C. }\end{array}$ \\
\hline $\begin{array}{l}\text { Toconao } \\
\text { Oriente }\end{array}$ & $\begin{array}{l}4340-1 \\
4534-\text { IV } \\
4383-\text { IILIV } \\
4383-\text { III/IV } \\
4607-\text { II/III }\end{array}$ & $\begin{array}{l}\text { Rojo Pulido } \\
\text { Negro Bruñido } 4 \\
\text { N. Bruñido 1? } \\
\text { N. Bruñido 3? } \\
\text { Gris Pulido }\end{array}$ & $\begin{array}{l}350 \mathrm{aC}-170 \mathrm{aC}-10 \mathrm{dC} \\
360 \mathrm{dC}-740 \mathrm{dC}-850 \mathrm{dC} \\
150 \mathrm{dC}-310 \mathrm{dC}-470 \mathrm{dC} \\
150 \mathrm{dC}-310 \mathrm{dC}-470 \mathrm{dC} \\
100 \mathrm{dC}-240 \mathrm{dC}-380 \mathrm{dC}\end{array}$ & $\begin{array}{l}\text { Cr. } 100-400 \text { d.C. } \\
300-750 \text { d.C. } \\
100-400 \text { d.C. } \\
300-750 \text { d.C. } \\
\text { No considerado en } \\
\text { el estudio. }\end{array}$ \\
\hline & 4240-II/III & Gris Pulido & $35 \mathrm{dC}-150 \mathrm{dC}-265 \mathrm{dC}$. & $\begin{array}{l}\text { No considerado en } \\
\text { el estudio }\end{array}$ \\
\hline & $\begin{array}{l}\text { 4448-IVIII } \\
4274-\text { II/III } \\
4432-\text { IV }\end{array}$ & $\begin{array}{l}\text { Umas Varias } \\
\text { Gris Pulido }\end{array}$ & $\begin{array}{r}90 \mathrm{dC}-220 \mathrm{dC}-350 \mathrm{dC} \\
220 \mathrm{dC}-350 \mathrm{dC}-480 \mathrm{dC}\end{array}$ & $\begin{array}{l}\text { Cr. } 100-300 \text { d.C. } \\
\text { No considerado en } \\
\text { el estudio. } \\
300-750 \text { d.C. }\end{array}$ \\
\hline
\end{tabular}

Fuentes: ${ }^{1}$ Román, A., A. Deza, J. Berenguer y A. Llagostera. Pontificia Universidad Católica de Chile TL dates, I984 (III).

2Elaboración propia.

${ }^{3}$ Tarració, Miriam. Secuencias culturales de la etapa agroalfarera de San Pedro de Atacama (Chile) I968. 


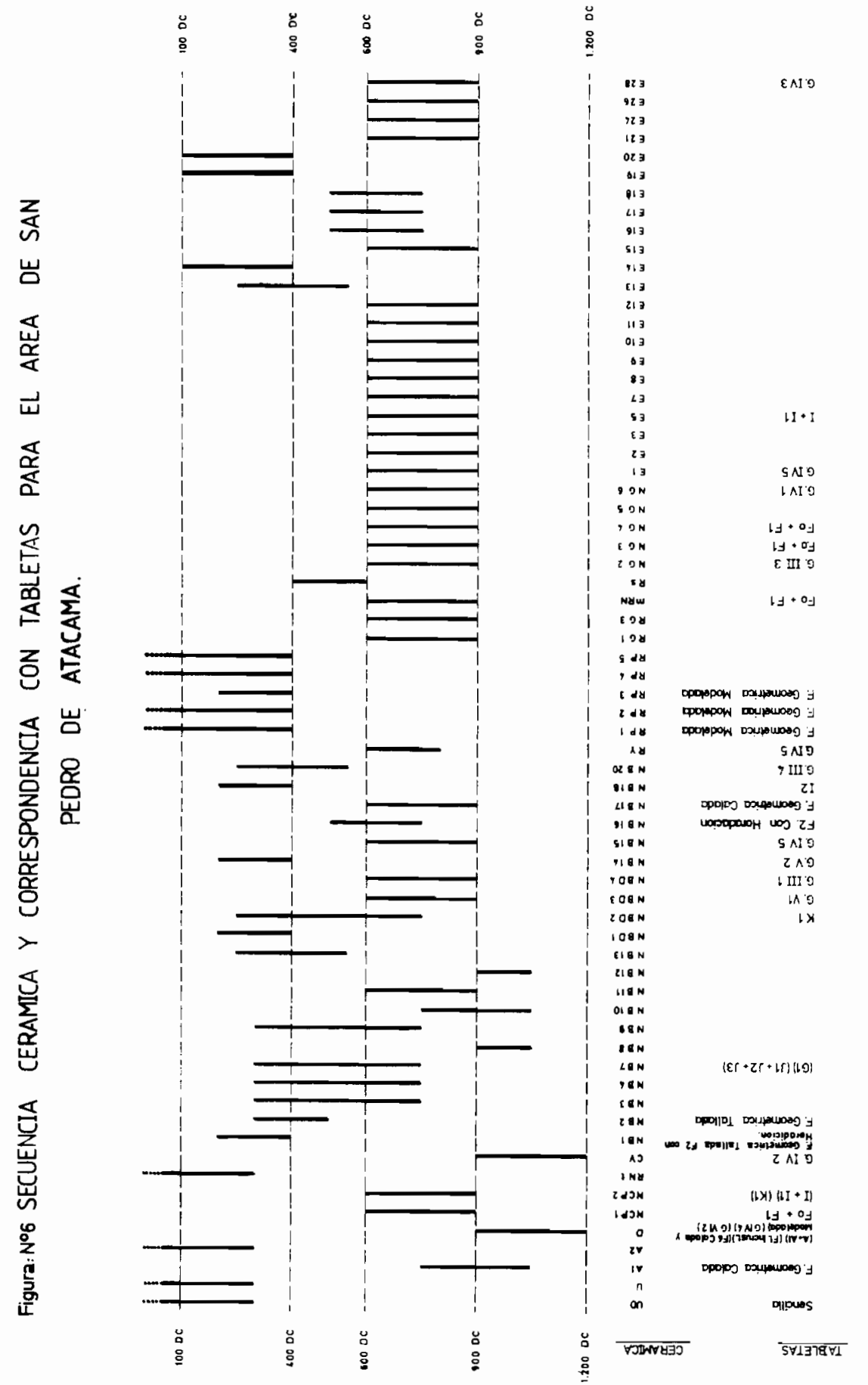




\subsection{Ubicación cronológica relativa de los grupos de tabletas de rapé}

Con miras a dar cuenta del segundo objetivo general de la presente investigación se procedió al análisis de los siguientes conjuntos de tabletas de rapé consignados en publicaciones anteriores de los autores, bajo el rótulo de grupo A, B, C, D, E, F, G, H, I, J y K (cf. Thomas, Benavente, 1984).

Se cruzaron estos grupos (como asimismo los subgrupos que los configuran) con las diferentes formas cerámicas manejadas en este estudio. Se obtuvo de este modo una tabla de contingencia que da cuenta del número de yuxtaposiciones que manifiesta cada grupo o subgrupo de tabletas de rapé con cada una de tales formas cerámicas (Figura 7 q.v.).

A dicha tabla se aplicó la prueba de contingencia de chi-cuadrado dada por la fórmula general siguiente:

$$
x^{2}=\sum \frac{(\mathrm{O}-\mathrm{E})^{2}}{\mathrm{E}}
$$

Donde:

$\boldsymbol{x}^{2}=$ Valor observado de chi-cuadrado.

$\mathrm{O}=$ Valores observados en relación a las yuxtaposiciones que se están analizando.

$\mathrm{E}=$ Valores esperados en relación a las yuxtaposiciones que se estén analizando.

Dicho test se aplicó con el debido factor de corrección (cf. MAXwelL, 1966) y se asumió como parámetro, para aceptar como relevante una correspondencia entre un determinado grupo de tabletas y una forma cerámica determinada, el valor de 3.841 .

Los coeficientes de chi-cuadrado de contingencia obtenidos son los siguientes:

Tabla III

VALORES DE CHI-CUADRADO OBSERVADOS

QUE COMPRUEBAN

LA CORRESPONDENCIA

ENTRE GRUPO DE TABLETAS

Y FORMA CERAMICA

\begin{tabular}{llc}
\hline Tabletas & Cerámica & $\begin{array}{c}\text { Coeficiente de } \\
\text { contingencia }\end{array}$ \\
\hline Sencilla & Uo & 14.45 \\
Sencilla & RPn & 4.21 \\
$\mathrm{~A}+\mathrm{Al}$ & $\mathrm{D}$ & 9.63 \\
$\mathrm{~A}+\mathrm{Al}$ & $\mathrm{NCP}$ & 4.51 \\
Fo + F 1 & Ux & 5.59
\end{tabular}




\begin{tabular}{|c|c|c|}
\hline Tabletas & Cerámica & $\begin{array}{l}\text { Coeficiente de } \\
\text { contingencia }\end{array}$ \\
\hline $\mathrm{Fo}+\mathrm{Fl}$ & NCPl & 4.52 \\
\hline Fo $+F l$ & $\mathrm{mRN}$ & 7.05 \\
\hline $\mathrm{Fo}+\mathrm{Fl}$ & NG3 & 5.59 \\
\hline$F_{0}+F_{1}$ & NG4 & 5.59 \\
\hline F2 con Horadación & NB 16 & 18.25 \\
\hline F. Geom. Calada & Al & 5.75 \\
\hline F. Geom. Calada & NB 17 & 3.94 \\
\hline F. Incrustaciones & $\mathrm{D}$ & 4.38 \\
\hline F. Geom. Tallada & NB 1 & 18.19 \\
\hline F. Geom. Tallada & NB2 & 18.19 \\
\hline F. Geom. modelada & RPl & 24.58 \\
\hline F. Geom. modelada & RP2 & 11.84 \\
\hline F. Geom. modelada & RP3 & 11.84 \\
\hline F. Geom. caladas & Al & 7.93 \\
\hline GlIII & NBD4 & 6.95 \\
\hline GIII3 & NGl & 11.92 \\
\hline GIII4 & NB6 & 3.89 \\
\hline GIII4 & NB20 & 3.89 \\
\hline GIV 1 & NG6 & 4.59 \\
\hline GIV2 & NCP3 & 8.75 \\
\hline GIV3 & E28 & 14.45 \\
\hline GIV4 & $\mathrm{D}$ & 4.38 \\
\hline GIV5 & NB 15 & $29.3 \mathrm{I}$ \\
\hline GIV5 & RY & 13.29 \\
\hline GIV5 & El & 29.31 \\
\hline GI & NB7 & 10.11 \\
\hline GV 1 & NBD & 8.75 \\
\hline GV2 & NB 14 & 4.21 \\
\hline GVI & NB 19 & 4.59 \\
\hline GVI2 & $\mathrm{D}$ & 4.09 \\
\hline $1+12$ & NCP2 & 5.50 \\
\hline$I+I 1$ & E5 & 11.92 \\
\hline 12 & NB 18 & 37.25 \\
\hline $\mathrm{J} 1+\mathrm{J} 2+\mathrm{J} 3$ & NB7 & 11.29 \\
\hline KI & NCP2 & 4.59 \\
\hline K 1 & NBD2 & 5.75 \\
\hline
\end{tabular}

Fuente: Elaboración propia. 


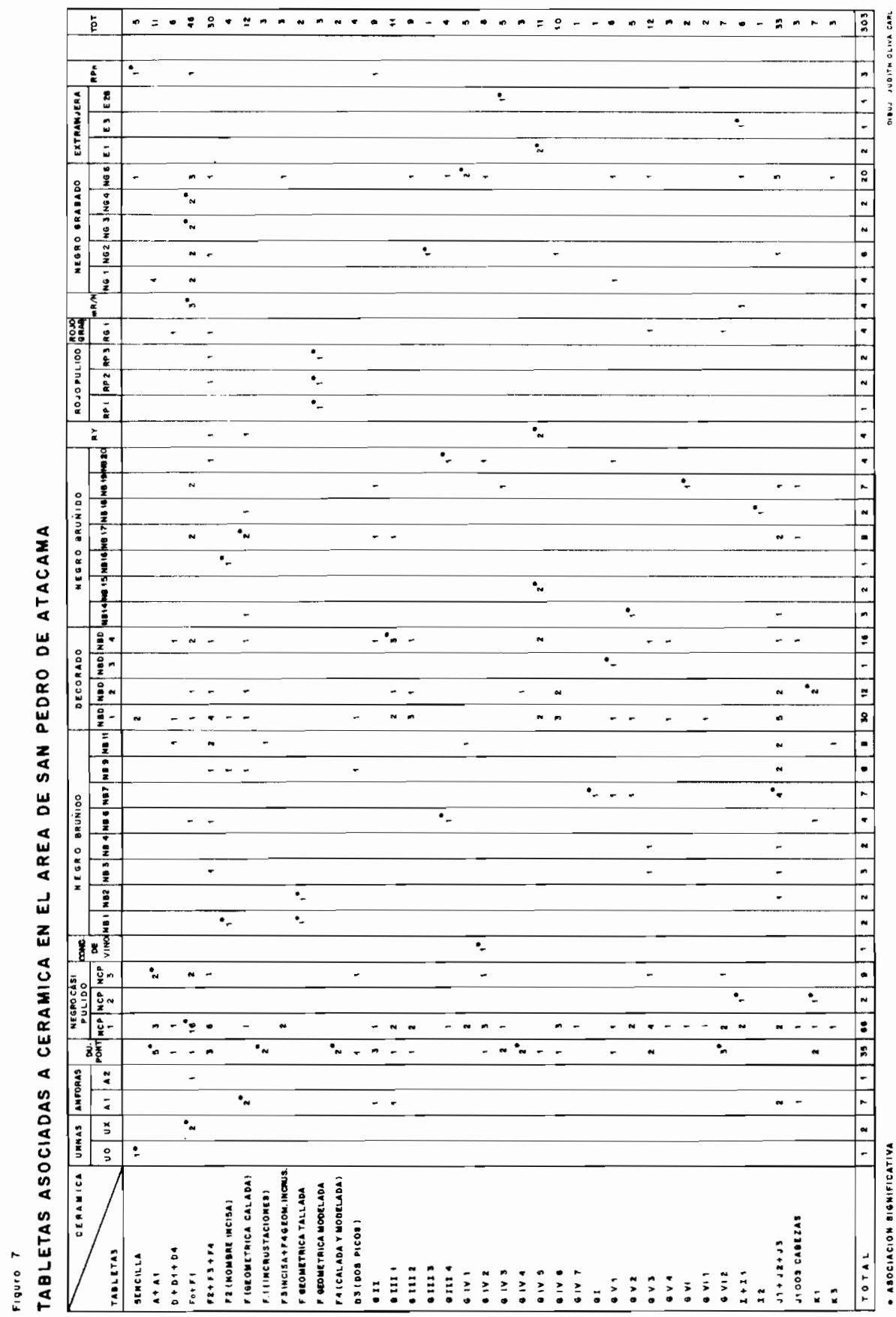


A continuación se describen los grupos y subgrupos de tabletas de rapé consignados en la tabla anterior.

A : Corresponde a tabletas con recipiente rectangular y mango claviforme.

$A_{1}$ : Son tabletas de recipiente rectangular y mango tallado en forma de semicírculo.

Fo : Considera las tabletas de receptáculo rectangular y mango de forma trapezoidal.

$\mathrm{F}_{\mathrm{I}}$ : $\quad$ Grupo de tabletas de receptáculo rectangular y mango trapezoidal.

$\mathrm{F}_{2}$ : $\quad$ Son consideradas aquí las tabletas de receptáculo rectangular, mango trapezoidal anguloso con motivos grabados e incisos que representan figuras de la "Puerta del Sol".

F Geométrica modelada: Tableta de receptáculo rectangular mango trapezoidal redondeado con figuras geométricas en forma de volutas y semicírculos en su parte superior.

F Geométrica calada: Grupo de tabletas de receptáculo rectangular mango de forma trapezoidal con calados que representan diversas formas geométricas.

F Geométrica tallada: Grupo de tabletas de receptáculo rectangular, mango de forma trapezoidal con incisos tallados de diversas formas geométricas.

F Con horadación: Tabletas de receptáculo rectangular, mango trapezoidal con una horadación en el centro.

F Con incrustaciones: Tabletas de receptáculo rectangular y mango trapezoidal con pequeñas incrustaciones de malaquita, azurita, conchas u otros.

GI : Grupo de tabletas de recipiente rectangular sin mango.

GIII $_{1}$ : Son tabletas rectangulares y mango con dos personajes tallados: felinos encontrados.

GIIIs : Grupo de tabletas rectangulares y mango que representa dos personajes zoomórficos tallados: cóndores hembra.

GIII $_{4}$ : Conformado por tabletas de recipiente rectangular y mango tallado con dos personajes: cabeza de peces.

GIV : Grupo de tabletas rectangulares de mango tallado de un individuo antropomorfo que representa un sacrificador.

$\mathrm{GIV}_{2}$ : Tabletas de recipiente rectangular y mango que representa un individuo antropomorfo de posición hierática.

$\mathrm{GIV}_{3}$ : Grupo de tabletas de recipiente rectangular y mango trapezoidal redondeado que representa una figura con un gran tocado.

GIV $_{4}$ : Tabletas de recipiente rectangular con un individuo antropomorfo: sacrificador con máscara a modo de mango.

GIV $_{5}$ : Grupo de tabletas con mango que representa un individuo antropomorfo con tocado y recipiente rectangular.

$\mathrm{GV}_{1}$ : Tabletas rectangulares de mango tallado en forma de un animal de perfil: felino. 
$\mathrm{GV}_{2}$ : Grupo de tabletas rectangulares y mango tallado en forma de animal de lado con máscara humana.

$\mathrm{GVI}_{2}$ : Tabletas rectangulares y mango tallado en forma de camélido.

I : Está constituido por tabletas de receptáculo rectangular con mango tallado en forma apuntada.

$I_{1} \quad$ : Grupo de tabletas de receptáculo rectangular y mango tallado en dos formas apuntadas.

$I_{2}$ : Lo conforman un grupo de tabletas de receptáculo rectangular y mango estrecho tallado en forma rectangular.

$\mathrm{J}_{1} \quad$ : Está constituido por tabletas de receptáculo rectangular de mango con motivos antropomorfos de dos individuos idénticos.

$\mathrm{J}_{2} \quad$ : Grupo de tabletas rectangulares y mango tallado que representa tres individuos idénticos.

$\mathrm{J}_{3} \quad$ : Está constituido por tabletas rectangulares y mango que representa cuatro individuos idénticos.

$\mathrm{K}_{1} \quad$ : Este grupo está conformado por tabletas de recipiente rectangular con motivo zoomórfico de un individuo: felino tallado sobre la superficie horizontal con la cabeza en dirección al recipiente.

Trasladando las correspondencias relevantes observadas a la secuencia cerámica ya construida se observan los siguientes resultados:

a) El grupo de tabletas $\mathrm{F}$ manifiesta una extensiva distribución en el tiempo, durante un lapso definible entre el 200 d.C. y el 1200 d.C. Este grupo es correspondiente con quince formas cerámicas, entre las cuales destacan aquellas que configuran los tipos cerámicos característicos del área en estudio, a saber: Rojo Pulido, Negro Bruñido, Negro casi Pulido, Negro Grabado y Dupont genérico. Durante un momento más temprano aparecen con clara correspondencia a formas cerámicas, primero un subgrupo con decoraciones geométricas modeladas, luego un subgrupo con decoraciones geométricas talladas y finalmente un subgrupo cuya decoración está dada por una horadación esférica. Este último subgrupo revela una mayor duración en el tiempo llegando probablemente hasta cerca del $700 \mathrm{~d} . \mathrm{C}$.

Entre el 600 d.C. y el 900 d.C. surgen dos nuevos subgru pos: el primero, que reúne aquellas tabletas que manifiestan un receptáculo rectangular y mango trapezoidal anguloso, siendo, al parecer, las más difundidas en el área de San Pedro de Atacama; el segundo, configurado por tabletas que evidencian decoraciones geométricas talladas. Ambos subgrupos presentan una evidente correspondencia a formas cerámicas características de ese lapso. El último de dichos subgrupos manifestará correspondencia con nuevos tipos cerámicos entre el 900 d.C. y el 1050 d.C., aproximadamente.

Cabe señalar que entre el 600 d.C. y el 900 d.C. aparece un subgrupo de tabletas con mango trapezoidal anguloso con motivos grabados e incisos, los cuales constituyen un referente cierto de una influencia con marcado carác- 
ter ideológico procedente del ámbito Tiwanakota. Permite hacer esta afirmación el hecho que tales motivos grabados e incisos son representaciones de figuras de la "Puerta del Sol" en Tiwanaku. Sin embargo, el subgrupo en cuestión no manifiesta correspondencia cierta con alguna de las formas cerámicas específicas del lapso que se está tratando, más bien aparece yuxtapuesto a diversas formas cerámicas, lo que estaría denotando su gran difusión y la fuerza de la dependencia ideológica del área de San Pedro con respecto al ámbito Tiwanakota, durante el lapso 600 d.C. 900 d.C.

Con posterioridad al 900 d.C. y hasta el 1200 d.C. la presencia del grupo F de tabletas de rapé está corroborada por la aparición de los subgrupos de tabletas, decoradas con incrustaciones o decoradas con motivos geométricos calados y modelados, en correspondencia a un nuevo tipo cerámico que, en este escrito, se ha denominado Dupont genérico.

b) Asimismo, la forma de tabletas $\mathrm{J} 1+\mathrm{J} 2+\mathrm{J} 3$ puede consignarse a un rango temporal equivalente al lapso que va desde el 300 d.C. hasta el 750 d.C., aproximadamente. Esta forma de tabletas está caracterizada por mangos decorados con motivos antropomorfos de 2,3 y 4 personajes, presenta una correspondencia relevante con la forma NB7 del tipo cerámico negro bruñido.

c) Por su parte, el grupo de tabletas GIII puede asimilarse a dos lapsos separados. Entre el 250 d.C. y el 550 d.C., se observa la presencia de un subgrupo de tabletas rectangulares y mango con dos personajes zoomorfos en correspondencia sobresaliente con la forma NB20 del tipo cerámico negro bruñido. Luego durante el lapso 600 d.C. 900 d.C. aparece nuevamente el grupo en cuestión con formas de tabletas en correspondencia relevante con la forma NBDI del tipo cerámico negro bruñido y con la forma NG2 del tipo cerámico negro grabado, sin embargo, cambian los temas de los motivos, aunque estos últimos siguen siendo antropomorfos o zoomorfos.

d) El grupo de tabletas GIV aparece durante el lapso 600 d.C. 900 d.C., fundamentalmente en correspondencia sobresaliente con formas características de ese momento, a saber: la forma NG6 de tipo Negro Grabado, la forma extranjera denominada El, procedente del área Potosí-Lipez, la forma rojo pintada RY y la forma NB15 del tipo negro bruñido.

La correspondencia de este grupo de tabletas con una forma boliviana altiplánica, como la señalada, pareciera indicar el probable origen bolivianoaltiplánico de los motivos antropomorfos de la decoración de las tabletas pertenecientes al grupo GIV.

Entre el 900 d.C. y el 1200 d.C. surgen nuevas formas propias del grupo de tabletas en cuestión. Estas se encuentran en correspondencia significativa con dos tipos cerámicos que caracteriza ese lapso: Dupont Genérico y Concho de vino. 
e) El grupo de tabletas GV, rectangulares de mango tallado con forma de un animal de perfil aparece en dos momentos separados en el tiempo, pero siempre en correspondencia sobresaliente con formas cerámicas propias del tipo negro bruñido. Durante el lapso 200 d.C. 400 d.C., una de las formas configuradoras del grupo de tabletas GV se encuentra en correspondencia con la forma cerámica NB 14. Entre el 600 d.C. y 900 d.C. otra de las formas configuradoras del grupo de tabletas en cuestión se muestra en correspondencia con la forma cerámica NBD3.

f El grupo de tableta GIV, rectangular, de mango tallado con forma de camélido estilizado, tiene su expresión modal durante el lapso 900 d.C. 1200 d.C. Es entonces cuando una de las formas configuradoras de dicho grupo de tabletas se encuentra en correspondencia con el tipo cerámico que caracteriza el lapso en cuestión: Dupont Genérico.

g) Las formas de tableta I2, GI, A + AI constituyen un conjunto de tabletas sencillas (respectivamente tabletas con mango claviforme o tallado en forma semicircular).

Están presentes a lo largo de todo el segmento temporal analizado en este escrito. Entre el 200 d.C. y el 750 d.C. se observa la correspondencia relevante entre la forma de tableta Gl y la forma cerámica NB7 del tipo Negro Bruñido. Asimismo, entre el 200 d.C. y el 400 d.C. se aprecia la correspondencia significativa entre la forma de tableta $\mathbb{I}_{2}$ y la forma cerámica NB 18 del tipo Negro Bruñido.

Estas formas simples de tabletas sin duda deben tener algún grado de relación con las tabletas consignadas por Le Paige como "sencillas" - sin mayores antecedentes descriptivos (cf. N/D: passim)--, las que presentan una correspondencia sobresaliente con la forma UO del tipo Urnas que temporalmente se ubican desde antes del 100 d.C. hasta el 200 d.C.

Posteriormente, entre el 900 d.C. y el 1200 d.C., surge la forma A + Al referente de un modelo de tableta sencilla con recipiente rectangular y mango claviforme, manifestando una correspondencia relevante con uno de los tipos cerámicos característicos del lapso en cuestión: el Dupont Genérico.

h) La forma I + Il constituida por tabletas de receptáculo rectangular con mangos tallados en una o dos formas apuntadas está referida al lapso que va del 600 d.C. al 900 d.C. en correspondencia con la forma NcP2 de uno de los tipos característicos de dicho transcurso de tiempo: el Negro Casi Pulido.

i) La forma $\mathrm{KI}$ configurada por tabletas de recipiente rectangular con motivo de un único personaje (e.g. felino encontrado al sentido de la tableta), debe remitirse al transcurso de tiempo comprendido entre el 200 d.C. y el 900 d.C., ya que manifiesta correspondencia significativa tanto con la forma cerámica NBD2 de tipo negro bruñido, como con la forma NCP2 del tipo negro casi pulido. 
SISTEMATIZACION DE LA ALFARERIA DE.L AREA DE SAN PEDRO DE. ATACAMA

Flgura 8

CORRESPONDENCIA ENTRE FORMA CERAMICAS Y TIPOS DE TABLETAS

CERAMICAS

TABLETAS

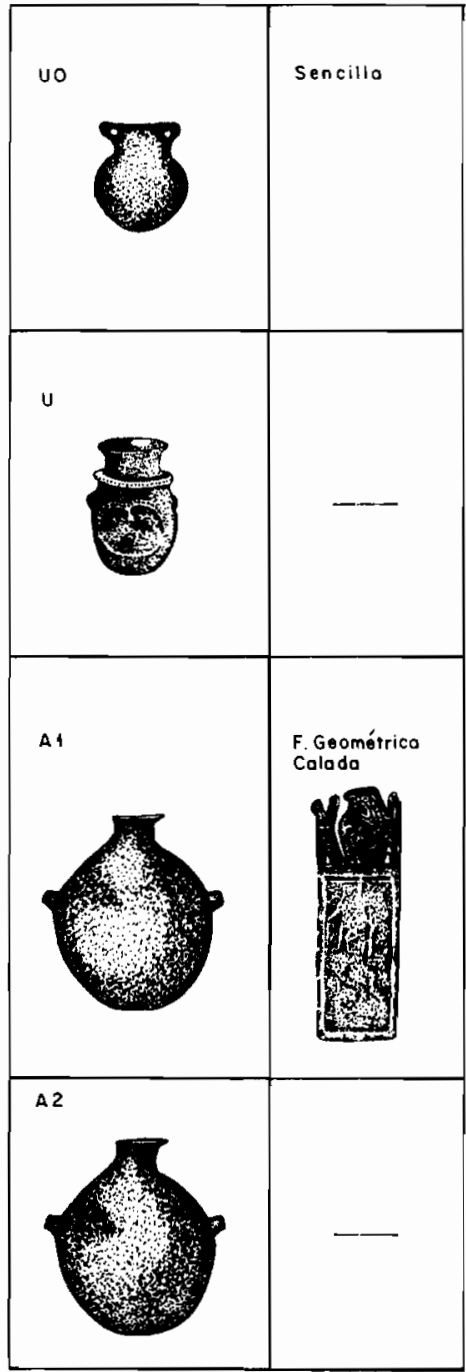

CERAMICAS TABLETAS

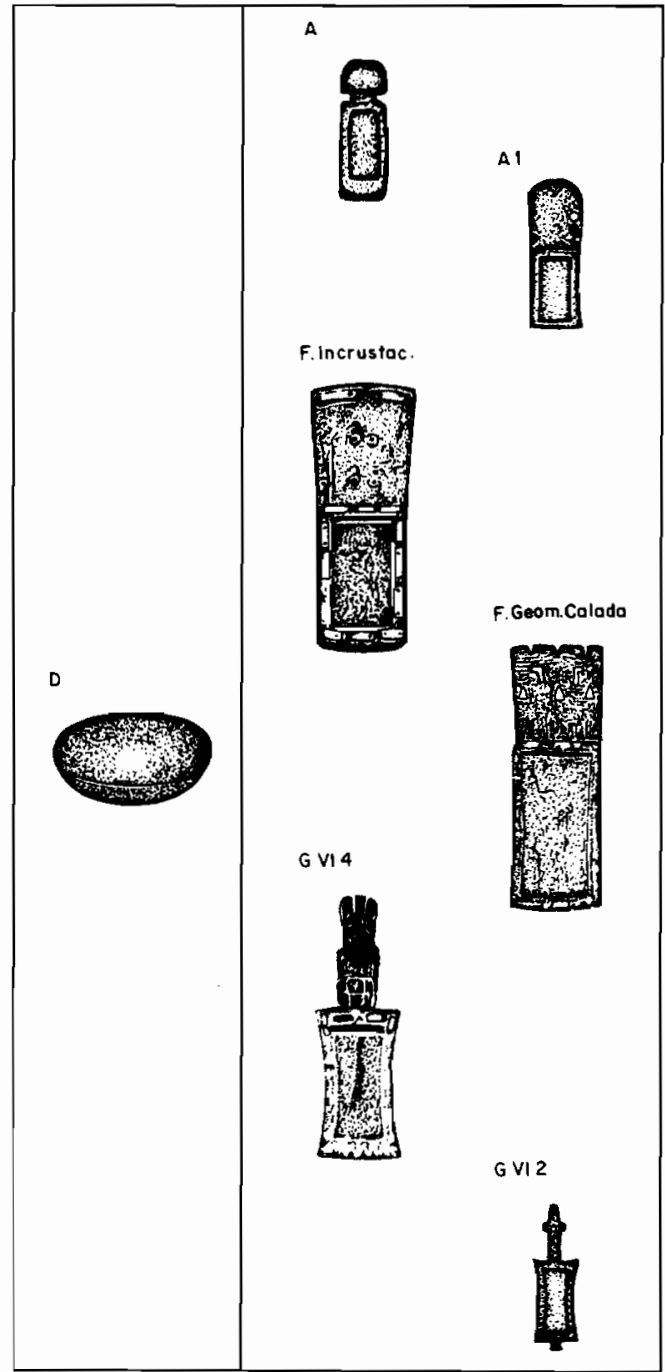


continuación CORRESPONDENCIA ENTRE FORMA CERAMICAS Y TIPOS DE TABLETAS

CERAMICAS

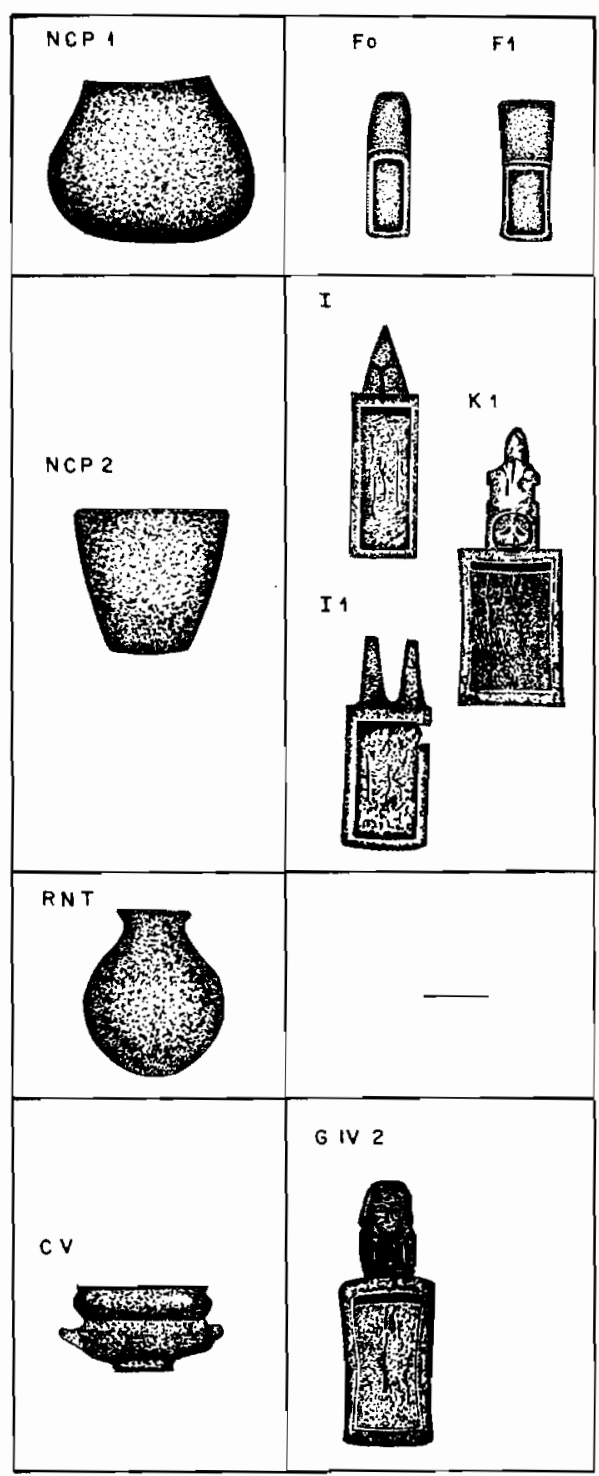

CERAMICAS

TABLETAS

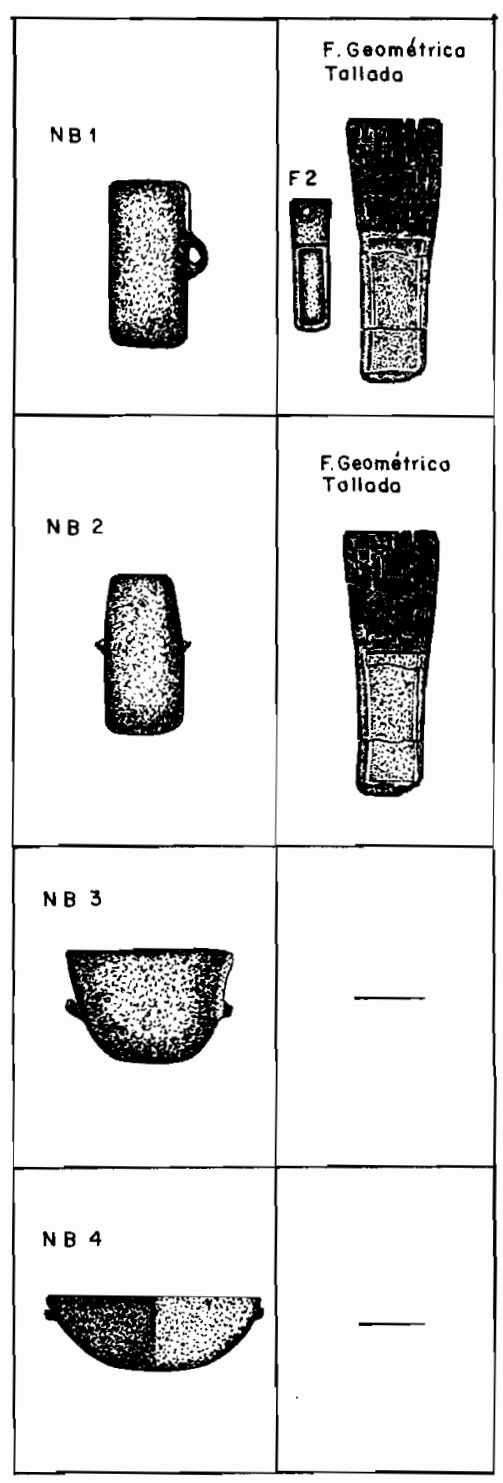


continuoción

CORRESPONDENCIA ENTRE FORMA CERAMICAS Y TIPOS DE TABLETAS

CERAMICAS

TABLETAS

CERAMICAS

TABLETAS
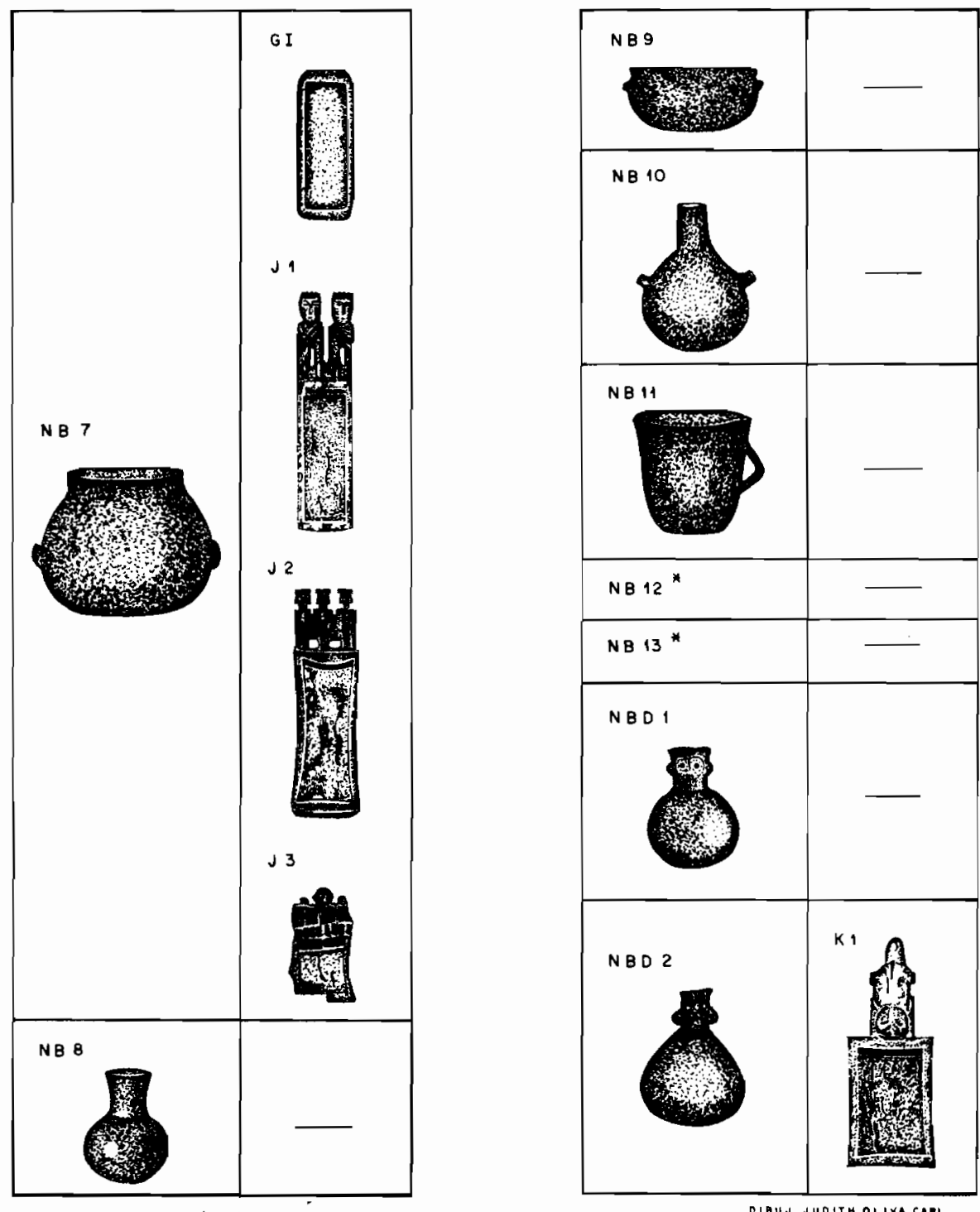

* Forma sin representoción grática en fuentes consultodos y no obsevodos por DIBUJ JUDTTH OLIVA CARL los autores. 
Continuación

CORRESPONDENCIA ENTRE FORMA CERAMICAS Y TIPOS DE TABLETAS

CERAMICAS

TABLETAS

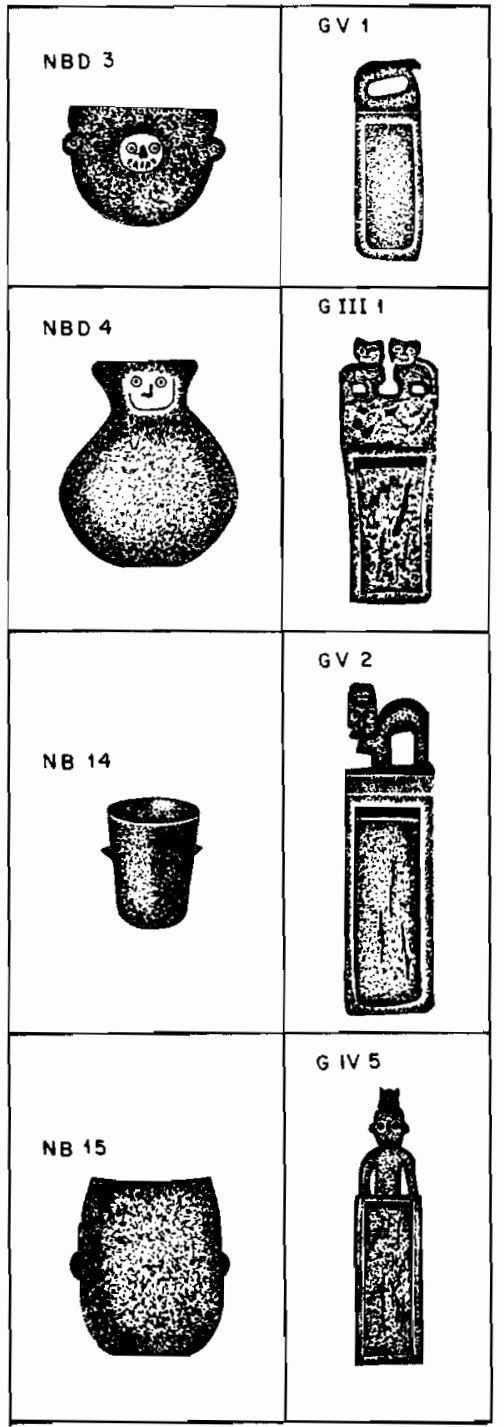

CERAMICAS

TABLETAS

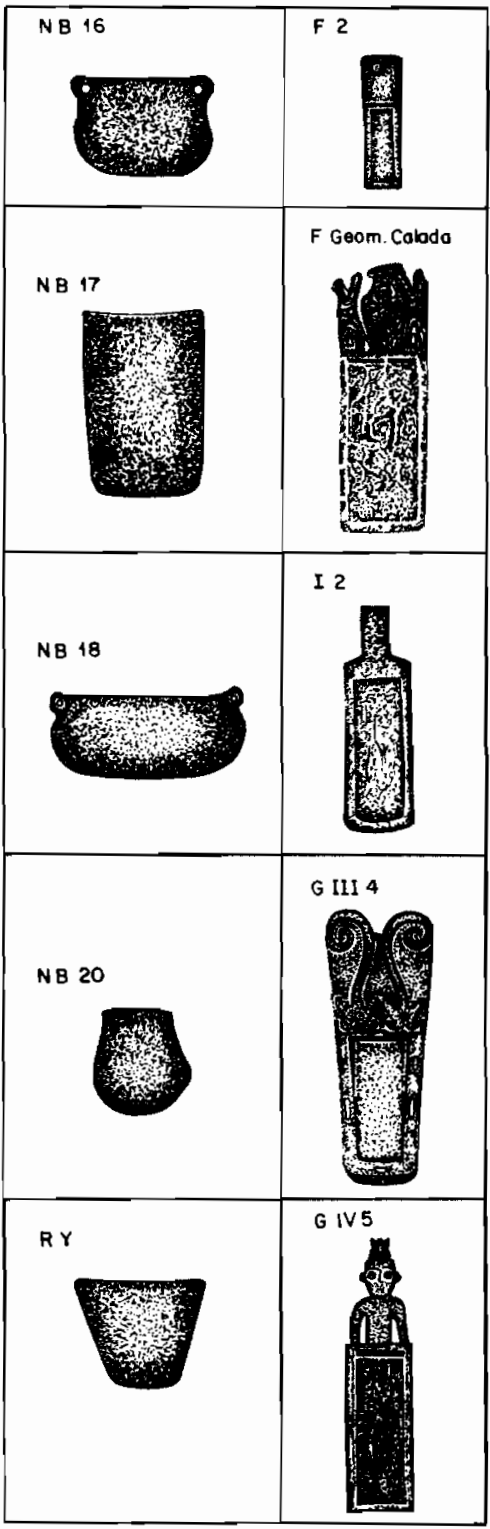

OIB. JUDITH OLIYA CAAL 
continuoción

CORRESPONDENCIA ENTRE FORMA CERAMICAS Y TIPOS DE TABLETAS

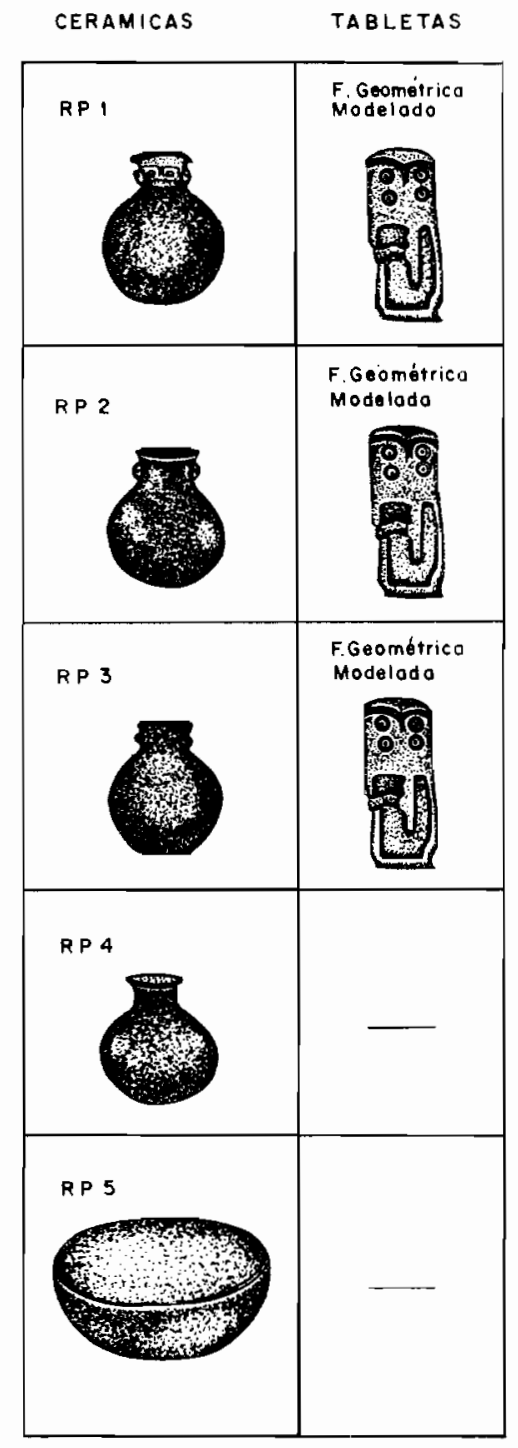

CERAMICAS

TABLETAS

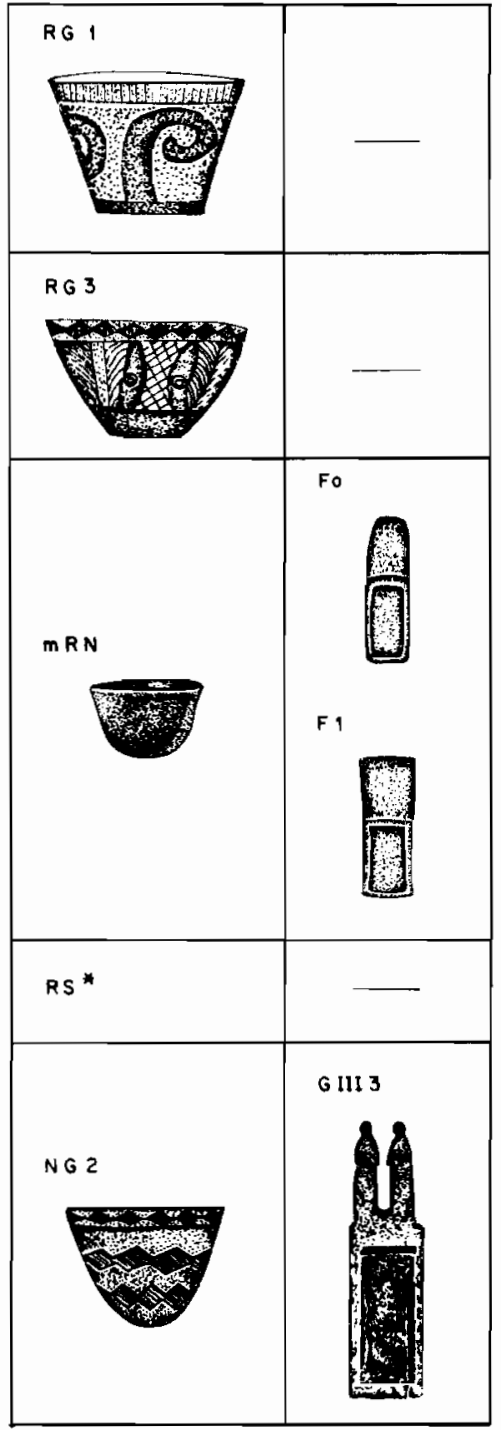

$x$ Solamente ceprosentado par fragmentog. 
Confinuación

CORRESPONDENCIA ENTRE FORMA CERAMICAS Y TIPOS DE TABLETAS

CERAMICAS

TABLETAS

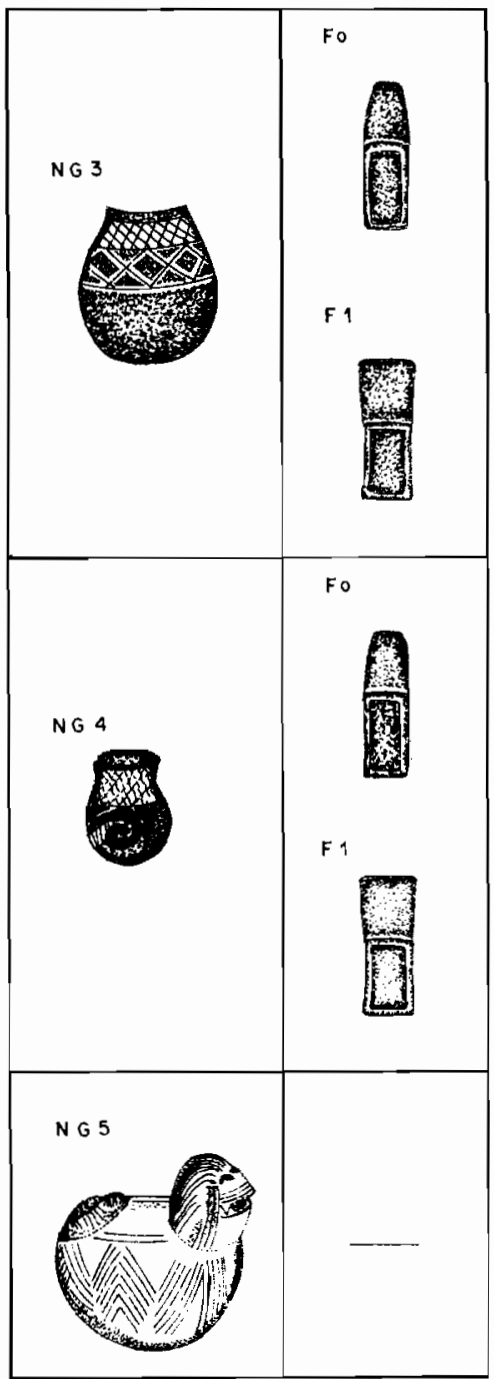

CERAMICAS

TABLETAS

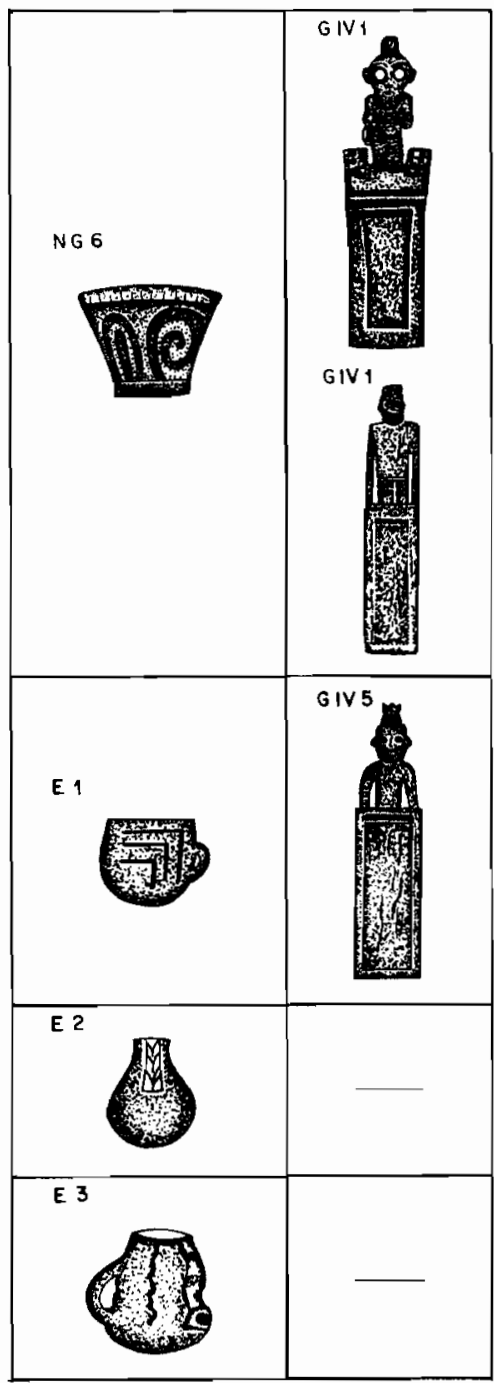

DIG. JUDITH OLIVACARL 
SISTEMATIZACION DE LA ALFARERIA DEL AREA DE SAN PEDRO DE ATACAMA

continuación

CORRESPONDENCIA ENTRE FORMA CERAMICAS Y TIPOS DE TABLETAS

CERAMICAS

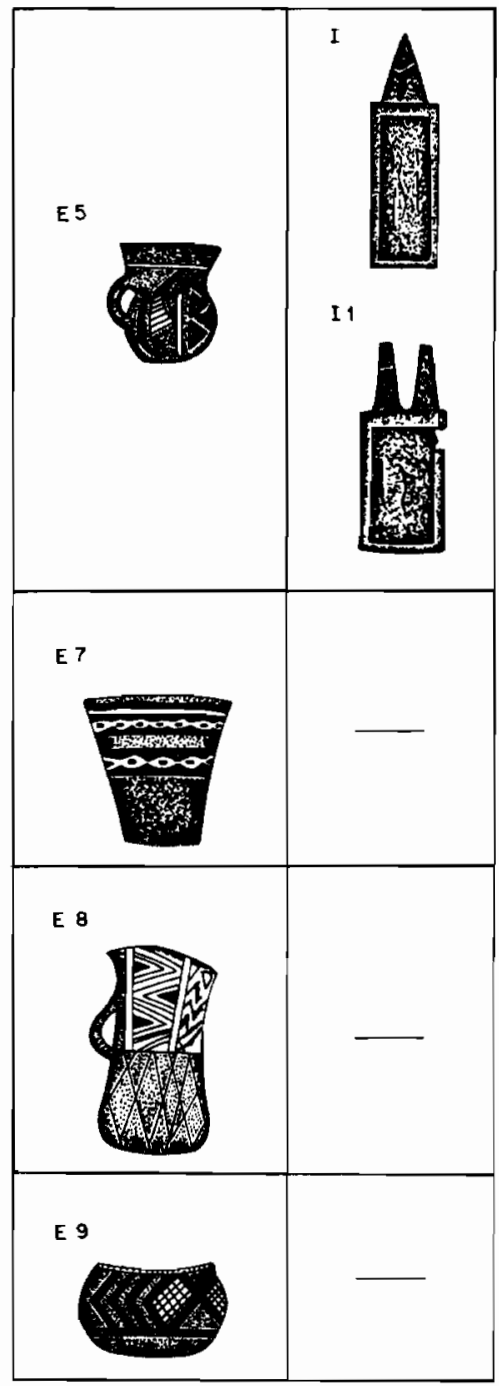

CERAMICAS

TABLETAS

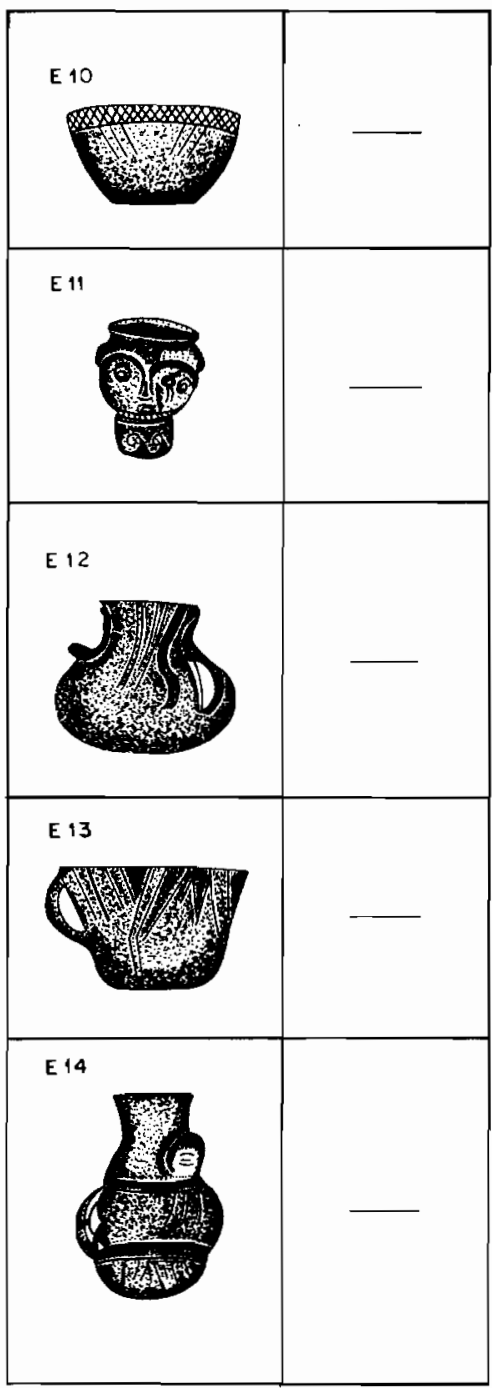

DIE JUDITH OLIVA CARL 
Continuación

CORRESPONDENCIA ENTRE FORMA CERAMICAS Y TIPOS DE TABLETAS

CERAMICAS

TABLETAS

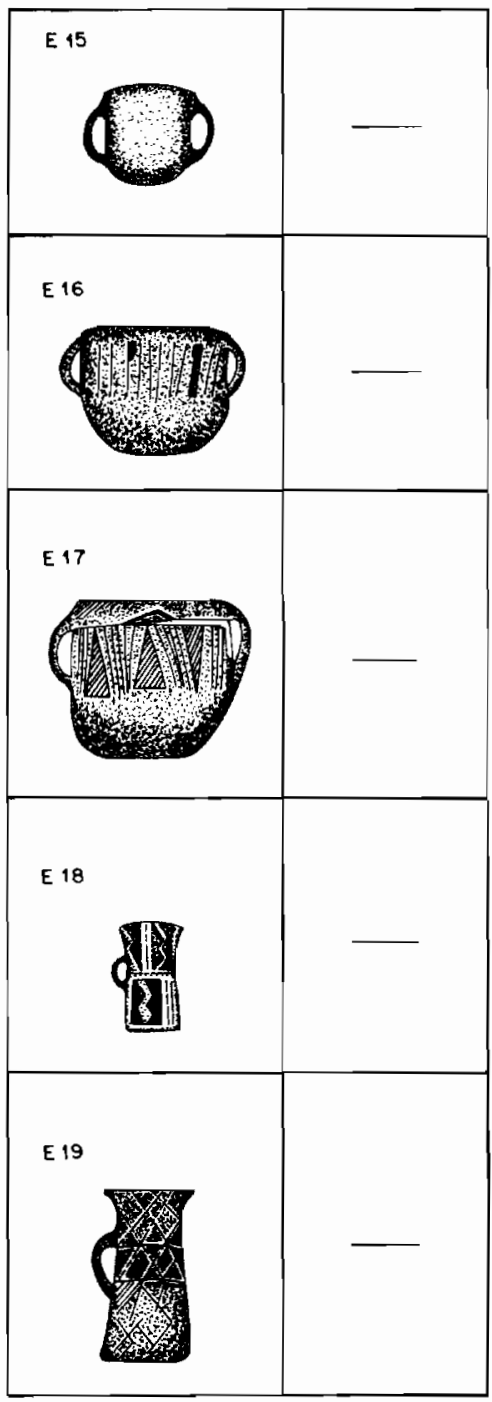

CERAMICAS

TABLETAS

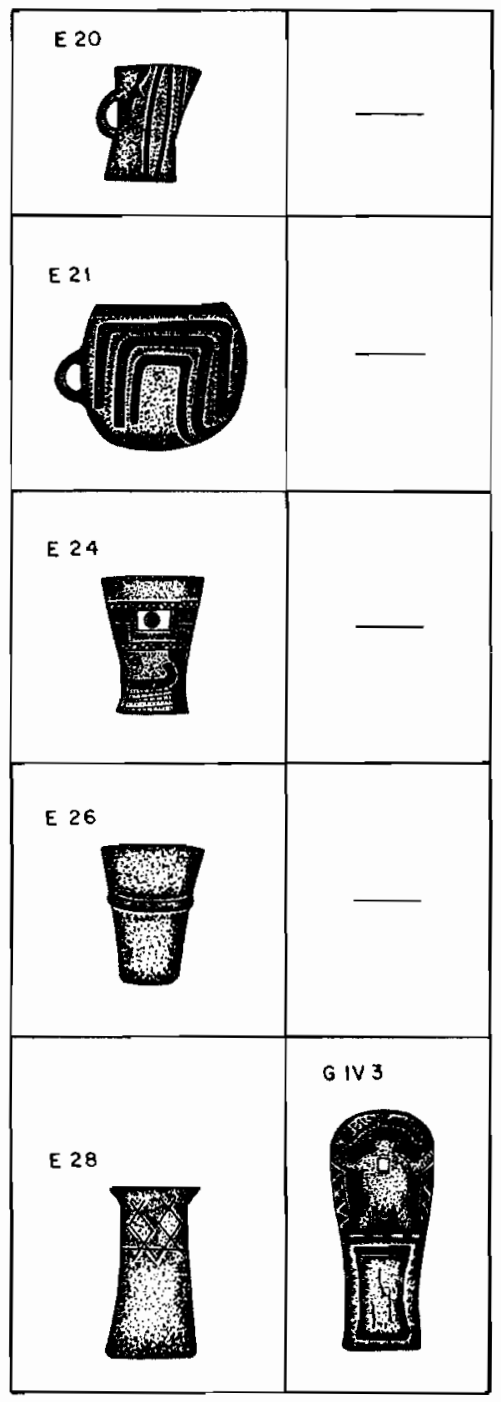

D:O JUDITH OLIVA CARL 


\section{Discusión de resultados}

Dado que por discusión se entenderá la argumentación y el razonamiento sobre los resultados del análisis expuesto, con el propósito de colegir ratificaciones sistemáticas acerca de tales resultados, se procederá primero a una síntesis metodológica de lo desarrollado, recurriendo para tal efecto a la terminología analítico-sistemática de Clarke (cf. 1978) y de Dunnell (cf. 1971), según corresponda.

La información que sirvió de base para el presente estudio puede resumirse, por una parte, como un conjunto de formas analíticas que sistematizan materiales arqueológicos tales como tabletas de rapé y ceramios, en su mayoría reputados como propios del área de San Pedro. Dichas formas analíticas son el resultado sea de procesos de agrupación mediante técnicas cuantitativas, consignados en anteriores publicaciones de los autores (cf. ThOMAs y BENAVENTE, 1984), sea de procesos agrupatorios cuantitativos que sirvieron para generar una base de datos teórica para el presente estudio (e.g. cerámica) correlacionada (arqueológicamente) a tabletas de rapé.

Por otra parte, se dispone de un conjunto de formas sintéticas que ordenan materiales arqueológicos tales como ceramios, unos reputados como característicos del área en estudio, y otros identificados como evidencia de la presencia extranjera en dicha área. Tales formas sintéticas son el resultado de investigaciones de otros autores sobre el particular —e.g. ceramios característicos del área (cf. TARrago, 1976) - y de descripciones desarrolladas para construir la base de datos de esta investigación -e.g. cerámica extranjera presente en el área de San Pedro. Sean esos resultados, sean esas descripciones se recabaron mediante el manejo paradigmático tradicional de atributos arqueológicos.

Por último, la base de datos del presente estudio consulta un ordenamiento por fases del material cerámico manejado por Tarragó (cf. 1976). Cruzado este ordenamiento con algunos supuestos relativos a la ubicación temporal se obtuvo el conjunto de parámetros que permitió la construcción de asociaciones entre formas cerámicas analíticas y sintéticas, y de correspondencias entre formas de tabletas y formas cerámicas, como asimismo su ubicación temporal.

Sobre este conjunto de resultados presentados en las páginas anteriores se discutirá en este acápite desde una perspectiva sistémica (cf. HAwLeY; 1966) con miras a definir fases del sistema arqueológico estudiado a partir de las cuales, a nivel de conclusiones, se intentará definir etapas de desarrollo cultural para el área y lapso estudiado.

La noción de "fase" aquí empleada corresponde a la formulada por Dunnell, para quien ésa es "una clase paradigmática de ocupaciones definidas por tipos y/o formas" (cf. 197 l: 200s). Por "ocupación" debe entenderse aquí toda "agrupación (cluster) espacial de objetivos discretos, en los que pueden asumirse como el producto de un determinado grupo de personas de una... "unidad geográfi- 
ca"... determinada y depositada allí después de continua residencia, comparable con otras ocupaciones como unidades del mismo estudio"4 (op. cit.: 200s).

Llevando estos conceptos a una perspectiva sistémica, la noción de "fase" puede analogarse con la de "estado de sistema", mientras que la de "ocupación" es análoga al "conjunto de elementos configuradores de un sistema, o subsistema" espacialmente acotado aunque sea en su punto focal.

De acuerdo con estos criterios es posible caracterizar los siguientes estados sistémicos y cambios sucesivos:

\subsection{Fase I (antes del 100 d.C. - 200 d.C.)}

El material analizado permite identificar dos claros subsistemas cerámicos. Uno que se denominará de "Urnas" y otro de la "Cerámica Roja Pulida".

Los elementos que componen el primer sistema son: dos formas de urnas (Uo y $\mathrm{U}$ ), una forma de ánfora $\left(\mathrm{A}_{2}\right)$ y una forma cerámica roja y negra $(\mathrm{RNt})$ que se conoce como transicional. En correspondencia a uno de los elementos cerámicos de este sistema Uo, se observa la asociación de una tableta de forma "Sencilla".

El segundo subsistema está configurado por cuatro formas de cerámica roja pulida (RP1, RP2, RP4 y RP5) y tres formas cerámicas procedentes del exterior del área de San Pedro y más precisamente del Noroeste argentino (E14, E19, E20).

El sistema "Cerámica Roja Pulida" aparece más complejo tanto por la masa de población cerámica como por el número de relaciones estructurales -yuxtaposiciones en un mismo sitio- entre las diversas formas cerámicas que lo componen.

Se reconoce el sistema "Cerámica Roja Pulida" como característico del área de Sequitor, mientras que el sistema "Urnas" es característico de Toconao. Si bien originariamente dichos sistemas deben haber identificado de manera excluyente las ocupaciones de Sequitor y Toconao, durante esta fase se encuentran interactuando en diferentes localidades al interior del área de estudio.

Es por esta razón que, considerando mancomunadamente los dos sistemas cerámicos definidos, se identifican dos puntos focales para el área de San Pedro durante esta fase. El primero, Sequitor al Norte de Salar de Atacama, y Toconao, el segundo próximo a los márgenes centro-orientales del Salar. Cabe señalar que si bien Toconao se caracteriza por elementos propios del sistema "urnas", asimismo manifiesta, en menor medida, elementos del sistema "cerámica roja pulida".

4 Desde el punto de vista operativo esta definición es concordante con el proceso de análisis desarrollado, ya que ella maneja conceptos tales como "cluster" y "objeto discreto" intimamente asociados con el manejo cuantitativo de los datos. Se cambió el término "localidad", de la definición original, por el de "unidad geográfica" por estar más ajustado a la perspectiva de análisis localizacional al que parece apuntar Dunnell al hablar de “...agrupamiento (cluster) espacial...". 
Viceversa Sequitor, que se caracteriza por elementos propios de este último sistema, evidencia, en menor medida, componentes del sistema "urnas".

\subsection{Cambio sistémico y fase il (200 d.C. - 300 d.C.)}

El sistema "urnas" experimenta un cambio por evolución morfológica. Dentro de este sistema la forma cerámica roja y negra transición, elemento clave significativamente asociado a cada uno de los otros componentes, genera una nueva forma cerámica diversificada: la cerámica negra bruñida.

Esta cerámica presenta dos formas: NB14 y NB18. De ésta, la primera constituye el elemento cerámico más significativo en el área en estudio al menos en términos de cantidad.

Esta predominancia de formas negras bruñidas se torna en el eiemento externo que genera el cambio en el sistema "cerámica roja pulida".

Sin duda este cambio se produce por la interacción observada entre ambos sistemas. Surgen así dos formas negras bruñidas: NB l y NBDl. Rápidamente éstas se transforman en el elemento cerámico numéricamente más significativo no sólo en el sistema "cerámica roja pulida" sino en toda el área.

El proceso de cambio en el sistema "cerámica roja pulida" es dramático. Implica un crecimiento del tamaño de la comunidad, al menos en el área de Sequitor, produciendo una escisión en dos segmentos territoriales:

a) Sequitor acequia.

b) Sequitor alambrado.

Ambos segmentos se especializan. Sequitor acequia se caracteriza por una mayor presencia de formas cerámicas negras bruñidas y una menor presencia de rojas pulidas. En Sequitor alambrado se da lo inverso. Surge înclusive una nueva forma roja pulida (RP3) que se transforma en el elemento rojo pulido numéricamente más significativo dentro del área estudiada. La cerámica negra bruñida está presente, en Sequitor alambrado, en sólo dos formas poblacionalmente muy escasas: NB20 y NB13. Llama la atención, sin embargo, que en este sitio se encuentre asociada, a la forma NB20, una tableta de rapé de recipiente rectangular y mango tallado con dos cabezas de peces (G. III 4), sin duda referente del manejo socio-territorial dual en la localidad de Sequitor. II:

Dado este proceso de cambio, pueden reconocerse tres sistemas para la Fase

a) Sistema "Negro Bruñido y Urnas" cuyos componentes son: dos formas negras bruñidas (NB 14 y NB 18), dos formas de urnas (Uo y U), una forma cerámica rojo y negra de transición ( $\mathrm{RNt}$ y una forma de ánfora $\left(\mathrm{A}_{2}\right)$, más la correspondencia con la forma de tableta "sencilla". En correspondencia al elemento NB 14 se observa asimismo la presencia de tableta GV2. Del mismo modo el elemento cerámico NB18 evidencia asociación con la forma de tableta $\mathbf{I}_{\mathbf{2}}$. 
b) Sistema "Negro Bruñido y Rojo Pulido" configurado por dos formas negras bruñidas (NB 1 y NBD1), cuatro formas rojas pulidas (RP1, RP2, RP4 y RP5) y tres formas cerámicas extranjeras asimilables al Noroeste argentino (E14, E19 y E20).

En correspondencia al elemento NB 1 de este sistema se observa la asociación de dos formas de tabletas F geométrica tallada y F2 con horadación.

c) Sistema "Rojo Pulido" compuesto por una forma rojo pulida (RP3), dos formas negras bruñidas (NB13 y NB20), una forma cerámica extranjera (E13) asimilable al Sur Boliviano (Tarija) y una forma de tableta de rapé (G.II14).

Tal como sucedía con los sistemas identificados en correspondencia a la Fase I, estos tres sistemas de la Fase 1 I manifiestan una fuerte interacción espacial dentro del área estudiada. Considerando este hecho, y tomando conjuntamente los tres sistemas, se identifican tres puntos focales para el área que se mencionan en orden jerárquico: Toconao, primero, y, con un peso igual, Sequitor Acequia y Sequitor Alambrado.

Sin duda, reafirmando la posición jerárquica primada de Toconao se observa en esta localidad una tableta de receptáculo rectangular, mango trapezoidal redondeado con figuras geométricas en forma de volutas y semicírculos en su parte superior (F. Geométrica Modelada), asociada a tres ceramios de forma rojo pulida (RP1, RP2, RP3).

\subsection{Cambio sistémico y fase III (300 d.C. - 400 d.C.)}

El impacto del negro bruñido como agente de cambio se maximiza en esta fase, especialmente en el sistema "Negro Bruñido y Rojo Pulido". En este sistema, se diversifica la cerámica negra bruñida. A las formas ya existentes se suman seis nuevas formas (NB2, NB3, NB4, NB7, NB9, NBD2).

El mismo hecho produce un cambio significativo en el sistema "Negro Bruñido y Urnas", reduciéndolo a su expresión más simple, ya que desaparecen los elementos "urnas", "ánforas" y "cerámica roja y negra de transición". lido".

El único que no experimenta modificación alguna es el sistema "Rojo Pu-

Como resultante de este proceso se reconocen tres sistemas cerámicos para la fase en cuestión:

a) Sistema "Negro Bruñido Originario", que denominaremos así ya que está configurado solamente por las dos primeras formas cerámicas negras bruñidas (NB14 y NB18) aparecidas en el área de San Pedro de acuerdo con los datos disponibles y con el análisis realizado con miras a una cronología relativa, más las asociaciones de formas de tabletas ya señaladas anteriormente.

b) Sistema "Negro Bruñido y Rojo Pulido", que manifiesta clara tendencia hacia la diversificación y la expansión. Sus componentes son: ' ocho formas 
negras bruñidas (NB 1, NB2, NB3, NB4, NB7, NB9, NBDl y NBD2); cuatro formas rojas pulidas (RP1, RP2, RP4, RP5) y tres formas extranjeras asimilables al Noroeste argentino (E14, E19 y E20). Las formas cerámicas NB2 y NBD2 manifiestan correspondencia con las formas de tableta de rapé $F$ Geométrica tallada y $\mathrm{Kl}$, respectivamente. La forma cerámica NBl sigue manifestando la misma correspondencia con forma de tableta señalada anteriormente. La forma NB7 presenta asociación con las formas Gl y Jl + $\mathrm{J} 2+\mathrm{J} 3$ cuyo significado se detalla más adelante.

c) Sistema "Rojo Pulido" que no presenta ninguna alteración respecto a su estado en la fase anterior.

La interacción entre tales sistemas se extiende cada vez más a las diversas entidades de poblamiento existente en el área. Se torna cada vez más difícil asignar un sistema cerámico a un determinado lugar poblado. Sin embargo, considerando conjuntamente los tres sistemas en cuestión, se observa que los centros focales para el área siguen siendo los mismos, y en igual ordenamiento jerárquico, de la fase anterior.

Reafirma este hecho la proliferación en el área de una forma de tableta de rapé con receptáculo rectangular y con mango tallado con motivos antropomorfos (2, 3 ó 4 individuos). Sin duda estas tabletas son el referente de la segmentación del manejo socio-territorial del área en relación a los centros Sequitor Acequia, Sequitor Alambrado y Toconao. Es más, reafirmando la posición jerárquica de Toconao se observa allí la asociación significativa de tabletas con cerámica negra bruñida de la forma NB7.

\subsection{Cambio sistémico y fase IV (400 d.c. - 500 d.C.)}

Como ulterior resultado del proceso de cambio asociado al desarrollo de las formas cerámicas negras bruñidas, se produce, por una parte, la especialización de los sistemas hacia dichas formas y, por la otra, una pérdida de complejidad de los sistemas.

El sistema "Negro Bruñido Originario" desaparece. De igual forma, ya no se observan los componentes rojos pulidos y sus relaciones con cerámica extranjera del Noroeste argentino. Asimismo desaparecen algunas de las formas más antiguas del negro bruñido.

Como resultante de este proceso se observan ahora, en el área, dos sistemas (ocupaciones) con cierto grado de diferenciación espacial:

a) "Negro Bruñido Solor 3 - Quitor 6 - Sequitor Acequia", cuyas formas componentes son NB2, NB3, NB4, NB7, NB9, NBD2.

b) "Negro Bruñido Sequitor Alambrado", configurado por las formas NB 13 y NB20 y por la forma extranjera E13 que sigue manifestando la relación entre este sistema y el sur boliviano (Tarija). 
Cabe señalar que el peso de este último sistema, en términos de población cerámica, es casi nulo.

Ambos sistemas siguen manifestando correspondencia entre formas de tabletas señaladas anteriormente con elementos cerámicos negro bruñido.

\subsection{Cambio sistémico y fase v (500 d.C. - 600 d.C.)}

Como resultado del, al parecer, continuo proceso de segmentación surge una nueva forma negra bruñida (NB 16), probablemente como resultado de la evolución de la forma NB7, ateniéndose a los resultados del análisis de correspondencia de Benzecri y Fenelón. Cabe señalar la correspondencia de esta forma cerámica con una forma de tableta F2 con horadación.

En torno a esta forma se organiza un nuevo sistema cerámico cuyos componentes manifiestan una clara influencia del Sur boliviano (Tarija).

Por otra parte, el sistema "Negro Bruñido Solor 3 - Quitor 6 - Sequitor Acequia" sigue en un proceso de reducción y especialización hacia algunas formas negras bruñidas.

Por su parte el sistema "Negro BruñidoSequitor Alambrado" sigue manifestando las mismas características que en la fase anterior.

Es así como para la fase $\mathrm{v}$ se observan los siguientes sistemas cerámicos ordenados de acuerdo con su grado de complejidad:

a) "Negro Bruñido y Cerámica Rosada" configurado por la nueva forma negra bruñida NB16, una forma cerámica rosada, probablemente extranjera, y tres formas cerámicas extranjeras $(\mathrm{E} 16, \mathrm{E} 17, \mathrm{E} 18)$ asimilables al Sur boliviano (Tarija).

b) "Negro Bruñido Solor 3 - Quitor 6 - Sequitor Acequia" estructurado ahora en torno a las formas NB3, NB4, NB7 y NB9.

c) "Negro Bruñido Sequitor Alambrado" sin cambio respecto a su anterior estado.

Si bien en términos de población cerámica el sistema que más pesa es el "Negro Bruñido Solor 3 - Quitor 6 - Sequitor Acequia", el sistema "Negro Bruñido y Cerámica Rosada" aparece como un elemento competitivo dentro del área dada su complejidad de interrelaciones.

\subsection{Cambio sistémico y fase vo (600 d.C. - 750 d.C.)}

El peso, en términos de población cerámica, manifestado en la fase anterior por el sistema "Negro Bruñido Solor 3 - Quitor 6 - Sequitor Acequia" supone un volumen demográfico significativo. Esto produce una nueva segmentación sistémica.

Por evolución de formas negras bruñidas aparece una nueva forma cerámica: el negro casi pulido. En torno a esta nueva forma diversificada (NCP1 y NCP2) se estructura un nuevo sistema cerámico. Este, para poder enfrentar 
exitosamente la situación de competencia insinuada en la fase anterior, recurre a una serie de aportes extranjeros más precisamente altiplánicos.

Puede decirse que es en este momento cuando se aprecia, en el área de San Pedro, una influencia Tiwanaku mediatizada a través del aporte de otras localidades bolivianas como Potosí, Lipez, Chuquisaca y Tarija.

Uno de los productos relevantes de esta influencia es la generación de formas cerámicas grabadas negras y rojas.

La situación competitiva produce la expansión y complejización del sistema "Negro Bruñido Solor 3 - Quitor 6 - Sequitor Acequia”. Surgen nuevas formas negras bruñidas. Formas negras grabadas pasan a integrar el sistema. Se teje una trama de relaciones que implican tipos cerámicos extranjeros (Tarija, PotosíLipez, Chuquisaca).

Este proceso de revitalización del sistema e indudable característica de complejo dominante en el área está denotado por la presencia de una tableta de rapé de recipiente rectangular con mango que representa un personaje antropomorfo con tocado (G.IV5) asociada a una forma cerámica roja (RY), la cual a su vez se correlaciona con una forma negra bruñida (NB11).

Como resultante de este proceso se observan, durante la fase vI, los siguientes sistemas cerámicos ordenados de acuerdo a su importancia:

a) Sistema “Negro Bruñido y Negro Grabado" configurado por nueve formas de cerámica negro bruñida (NB3, NB4, NB7, NB9, NB11, NB15, NB17, NBD2 y NBD4), tres formas de cerámica negro-grabada (NG2, NG3, NG4), cuatro formas extranjeras (E10 - Tarija -; E12 - Tarija -; E1 - Potosí/Lipez-; E7 - Chuquisaca), una forma de cerámica roja (RY) y una tableta de rapé cuyo mango representa un individuo antropomorfo con tocado.

b) Sistema "Negro Casi Pulido y Negro Grabado" estructurado en torno a dos formas de cerámica negro casi pulida (NCP1, NCP2), dos formas de cerámica negro-grabada (NG5, NG6), siete formas cerámicas extranjeras (E2 Potosí/Lipez -; E3 - Altiplánica genérica -; E5 - Tarija/Isla -; E21 - Negro Postcocción -; E24, E26, E28 - Tiwanakoide -), una forma cerámica negra bruñida (NBD3) y una forma cerámica rojo y negra (mRN).

c) Sistema "Rojo Grabado", constituido por dos formas de cerámica roja grabada (RG1, RG3) y dos formas cerámicas extranjeras (E8 y E9 - Tarija Policromo).

Cabe señalar que el sistema "Negro Bruñido y Cerámica Rosada" durante esta fase se encuentra en proceso de desarticulación habiendo desaparecido la cerámica rosada. Los restos de este sistema desaparecen en torno al 750 d.C.

Proyectando a una dimensión espacial los sistemas identificados se observa que los focos gravitacionales del sistema "Negro Bruñido y Negro Grabado" se encuentran en las localidades Solor 3 y Quitor 6. Por su parte el sistema "Negro Casi Pulido y Negro Grabado" presenta tres focos gravitacionales en las localidades Solcor, Sequitor Alambrado y en la localidad primada Coyo Oriente. 
Dado que la localidad focal del sistema "Rojo Grabado" es Solor 3, y que este sistema no presenta asociaciones significativas con el sistema "Negro Bruñido y Negro Grabado" que comparte Solor 3 como localidad focal primada, hace suponer que los elementos configuradores del sistema "Rojo Grabado" son indicadores de status en la localidad de Solor.

Retomando nuevamente el sistema "Negro Bruñido y Negro Grabado" y el sistema "Negro Casi Pulido y Negro Grabado" se observa una fuerte polarización sistémica. Referente de este hecho es la asociación de tabletas de rapé de la forma $I_{1}$ (con mango tallado en dos formas apuntadas) asociada a cerámica Negra Casi Pulida.

Desde una perspectiva localizacional, esta polarización se manifiesta abiertamente competitiva. Se observa el sistema "Negro Casi Pulido y Negro Grabado" materializado en un eje (Coyo - Sequitor - Solcor) que trunca en dos segmentos (Solor y Quitor) el antiguo eje Solor - Sequitor - Quitor del sistema, "Negro Bruñido".

Sin embargo, esta situación de competencia se yuxtapone a una situación de intercambio entre los dos sistemas, ya que en relación a ambos se observa un gran número de tabletas de la forma Fo + F1 (receptáculo de forma rectangular y mango trapezoidal y/o anguloso).

Por estas evidencias de intercambio es válido suponer que esta situación competitiva no desembocó en un proceso de abierto conflicto.

Llama la atención el hecho de que al aparecer esta situación de competencia, aparece en el sistema del Negro casi pulido una tableta asociada a negro grabado (NG6) de la forma GIV1 (tableta con mango tallado en forma de personaje antropomorfo que representa un sacrificador).

Este sería un elemento el cual junto con la cerámica extranjera ya señalada, reafirma la dependencia y la influencia tiwanacota al que está sometido el sistema "negro casi pulido y negro grabado" que penetra al área en estudio vía los ayllus de Solcor, Sequitor y Coyo Oriente.

Asimismo son referentes de esta influencia una serie de tabletas decoradas con motivos "Puerta del Sol" (F2 - F3 y F4), las que tienen significación de status por ser de número menor frente a las no decoradas (Fo y F1) y no aparecen significativamente asociadas a ningún tipo de cerámica. Asimismo llama la atención del comparecimiento de una serie de tabletas exornadas en su mango con personajes hieráticos, sin duda referentes de la situación descrita, con alusión a poder.

\subsection{Proceso de cambio y fase viI (750 d.C. a 900 d.C.)}

Frente a la situación anterior el sistema "Negro Bruñido" y "Negro Grabado" presenta una disminución de la población cerámica al sustituir algunas formas por otra nueva (NB10).

Los sistemas "Rojo Grabado" y "Negro casi Pulido, Negro Grabado" no manifiestan modificaciones respecto a la fase anterior. 
Para esta fase el sistema "negro bruñido" y "negro grabado" queda conformado por 5 formas bruñidas (NB 10 - NB 11 - NB 17 - NBD4), dos formas Negro Grabadas (NG4, NG3), cuatro formas extranjeras (E1, E7, E10, E12, cuya procedencia ya señalaremos), una forma roja ( $R Y)$.

$\mathrm{Al}$ parecer la nueva forma negra bruñida generada NB 10 se adapta mejor a un medio en el cual está perdiendo fuerza la influencia tiwanacota.

\subsection{Proceso de cambio y fase vIII (900 d.C. en adelante)}

El declinar de la influencia altiplánica hace que el sistema "Negro casi Pulido, Negro Grabado" desaparezca alrededor del 900 d.C.

Asimismo desaparece el sistema "Rojo Grabado" y todas las formas grabadas existentes en el sistema que para la fase anterior llamamos "Negro Bruñido" y "Negro Grabado". Al parecer desaparece de este sistema todo elemento que evidencia influencia extranjera, como las descritas, salvo en la decoración de formas de tabletas de rapé. Es más, en correspondencia a las nuevas formas cerámicas Dupont y Concho de Vino se observan formas de tabletas con mango decorado representando figuras antropomorfas que representan sea personajes hieráticos, sea sacrificadores.

Queda así al inicio de esta fase un sistema "Negro Pulido" cuyos puntos focales son Quitor 6 y 5 y cuyas formas cerámicas "Negras Bruñidas" son NB8, NB 10 y NB 12 .

Simultáneamente se observan dos formas cerámicas nuevas independientes entre sí ("Dupont y Concho de Vino"), que se tornan en las poblaciones cerámicas más significativas del área, teniendo como punto focal respectivamente Coyo Oriente y Solor 4.

El sistema "Negro Bruñido" desaparece alrededor del 1050 d.C.

Como se vio, hacia el 900 d.C. desaparecen las influencias significativas Tiwanakotas en la región de San Pedro. Sin embargo no se pierde la polaridad dual que caracterizó desde sus inicios el lapso estudiado. Desaparecidas las formas terminales del tipo negro bruñido, las nuevas formas cerámicas asumen una distribución espacial que recuerda el patrón dicotómico observado durante el transcurso de tiempo entre el 600 d.C. y el 900 d.C.

Coyo Oriente es el lugar focal de la ocu pación caracterizada por la presencia del tipo cerámico que se ha denominado "Dupont Genérico". Esta cerámica manifiesta además el mayor número de correspondencias con los residuos de la supuesta influencia Tiwanakota tales como las formas de tabletas GIV4 y GVI2, sin contar la correspondencia con formas de tabletas sencillas como A + A 1 y decoradas como Fl con incrustaciones y F4 Calada y modelada.

En oposición, el otro polo ocupacional se localiza en el área de Solor. En Solor 4 se da la frecuencia modal del tipo cerámico "Concho de Vino", la que revela la correspondencia con una sola forma de tableta la GIV2.

Obviamente, tanto por tamaño de población cerámica, como por correspon- 
dencia con formas de tabletas, el sistema "Dupont Genérico" se visualiza como la ocupación primada, en el área de San Pedro, por sobre el sistema "Concho de Vino".

Sintetizando lo expuesto, puede decirse que, para el lapso en estudio, se ha identificado una serie de sistemas asimilables al concepto de "ocupación", configurados por elementos cerámicos propios del área en estudio, por relaciones con áreas externas a la estudiada connotadas por la presencia de ceramios extranjeros y por las formas de tabletas de rapé en correspondencia a dichos elementos cerámicos.

De la constitución de las ocupaciones (sistemas) identificadas, se infiere, para el transcurso de tiempo estudiado, la presencia de dos tradiciones cuya dilatada distribución en el tiempo (cf. DunNell, 1971: 200ss.) es producto de evolución sistémica de dichas ocupaciones. Dichas tradiciones, que manifiestan un carácter politético, son: el tipo cerámico negro bruñido y el grupo de tabletas $\mathrm{F}$ de receptáculo rectangular y mangos trapezoidales angulosos o redondeados.

En un momento determinado dentro del lapso en estudio (600 d.C. - 900 d.C.), la tradición de formas de tabletas $\mathrm{F}$ es interceptada por un horizonte-estilo (cf. Dunnell, 1971) extensiva a todas las ocupaciones (sistemas) cerámicos, dado por la decoración repetitiva de motivos Tiwanaku en los mangos de las tabletas de rapé. Es este horizonte-estilo el referente de la influencia ideológica que entrelaza las distintas entidades de poblamiento del área de San Pedro en una trama de dependencia en relación al centro de Tiwanaku que caracteriza a toda el área altiplánica surandina.

Al desaparecer el impacto de dicha influencia connotada por ese horizonteestilo, sigue por algún tiempo la tradición cerámica negra bruñida hasta desaparecer, mientras que la tradición de tabletas del grupo $F$, por entonces más consistente, entronca sistémicamente con las nuevas formas cerámicas que se difunden por el área de estudio.

\section{CONCLUSIONES}

La discusión de los resultados, producto de la sistematización a nivel regional de la cerámica de San Pedro, ha proporcionado una visión bastante detallada de la trayectoria recorrida por las diversas ocupaciones observadas en dicha área. $\mathrm{Ha}$ sido posible reconocer ocho "estados" sistémicos que se suceden durante el transcurso de esa trayectoria que, en el tiempo, abarca un lapso de 1.000 años aproximadamente.

Una serie de conclusiones pueden desprenderse de ese análisis. Una de las más importantes parece ser el poder visualizar ciertas etapas del desarrollo cultural del área de San Pedro y, consiguientemente, poder identificar los factores principales que influyen en ese desarrollo. 
Una primera etapa, que se ha denominado de "síntesis de Tradiciones", comprende las tres primeras de dichas fases, estando ubicadas entre los primeros años de nuestra era hasta el $400 \mathrm{~d}$.C.

En esta primera etapa se han podido distinguir dos sistemas cerámicos interactuantes, claramente localizados, que son representantes de dos tradiciones cerámicas diferentes. El primero de ellos denominado de "Urnas y Anforas", se deriva de aquella tradición cerámica proveniente de las Selvas Occidentales (N.W. argentino y S.S.E. boliviano), ya que algunos de sus elementos, especialmente ornamentaciones, tales como adornos modelados, caras antropomorfas, narices protuberantes aguileñas, caras aplicadas con técnica de pastillaje y ojos redondos u oblicuos, decoran, también en San Pedro, los componentes de dicho sistema. Cabe señalar que esta tradición de Selvas Occidentales manifiesta una fuerte y amplia distribución en el N.W. argentino, estando documentada en relación al área de Tafi y de Arroyo del Medio (cf. González, 1963: 5 l-52, apud. lbarra Grasso, 1967: 591; cf. Serrano fide loc. cit.), llegando incluso, de acuerdo con Rex González (cf. op. cit.), hasta el área de San Pedro de Atacama.

La extensión de esta tradición ha sido objetivamente ubicada, a nivel regional, en el N. de Chile, y su antigüedad ha sido fechada en la zona de Chiu-Chiu, al Norte de San Pedro (cf. Benavente, 1982).

Orellana, en Turi (cf. 1968), y Núñez, en esta misma localidad y, también, en Caserones (cf. 1975), registran rasgos ceramiológicos de dicha tradición, señalando, ese último, la frecuencia sobresaliente, en Toconao, de dichos rasgos.

Sobre esta tradición de Selvas Occidentales, se superponen temporalmente también en un momento temprano ot ros elementos cerámicos, los cuales pueden tentativamente provenir, por sus formas y tratamiento de superficie, de la región valliserrana trasandina, o surboliviana. Tales elementos se caracterizarían por su monocromía (negro, gris, café rojiza, etc.). Estos se encontrarían, además, en la región de San Pedro, en la localidad de Tulor y, más al Norte, en la localidad de Turi.

Esta superposición se puede, además, fundamentar en la siguiente cita de Rex González:

"El elemento más característico y mejor conocido (de la cultura de La Candelaria) son los tipos cerámicos urnas, alfarerías de color rojo y negro. ...El color de la superficie externa de estas urnas es gris rojizo o negruzco. ...Los vasos de cerámica pulida y brillante están decorados con... modelados...

Lo que nosotros denominamos La Candelaria debe ser, en realidad, un grupo grande de tipos cerámicos que tienen por común denominador el uso de alfarería negro o gris, la abundancia de vasos efigies y el predominio de urnas" (GONZALEZ, 1971: 43).

Asimismo, en relación a este supuesto, Tarragó compara ceramios de la forma NB1 de San Pedro con jarros similares que pueden encontrarse en Tebenquiche en el N.W. argentino (cf. 1976). 
De la superposición antedicha y de la interacción de esos dos sistemas cerámicos, surgen las primeras formas que, junto a otras, caracterizarán, en fases siguientes, la tradición cerámica propia de San Pedro de Atacama, hasta reemplazar, al final de la fase iı, el sistema cerámico Rojo Pulido y de Urnas y formas asociadas.

En esta etapa, a través de la observación de los distintos elementos que configuran el sistema, se puede también visualizar la segmentación territorial de la localidad Sequitor (en Sequitor Acequia y Sequitor Alambrado), lo cual ocurre entre el 200 d.C. y el 300 d.C. Es decir, se está, ya, frente a la generación y desarrollo de los distintos ayllus, como, asimismo, frente a la generación y desarrollo de la distinta configuración que adoptan los diferentes elementos que conforman los grupos cerámicos observados para el área. Corrobora esta segmentación, la asociación de una tableta de mango decorado con dos peces con formas cerámicas de escasa frecuencia en Sequitor Alambrado. Durante la fase II, se observa, también, que las ocupaciones del área de San Pedro han expandido sus contactos externos y, por tanto, además de mantener relaciones con el N.W. argentino (como lo atestigua la presencia de las formas cerámicas E14, E19, E20), se evidencian contactos con la región de Tarija al W., connotados por la aparición de una nueva forma cerámica extranjera (E13), cuya procedencia ha sido reconocida como perteneciente a dicha región de Tarija.

Es interesante anotar que, aun cuando el elemento pipa no ha sido considerado en este trabajo, pareciera que él debe haber sido un elemento importante en el sistema de Toconao, donde su número de recurrencias en el registro, correspondiente a la primera fase, $\mathrm{e}$ incluso anteriores a ella, es sobresaliente. De aquí que se pueda pensar, con cierto grado de fiabilidad, que el elemento tableta, que recién comienza a aparecer en el inventario, puede haber sido un componente aportado por la tradición valliserrana trasandina o surboliviana.

Etapa II: ésta se ha denominado de "Consolidación de Ocupaciones" del área de San Pedro. Ella comprende desde la fase IV, en sus inicios (400 d.C.), hasta el término de la fase v $(600 \mathrm{~d}$.C.). Lo que caracteriza esta etapa es el afianzamiento, en el área, del tipo cerámico denominado, en este escrito, "Negro Bruñido" y su orientación sostenida, en lo que a relaciones externas se refiere, hacia el área de Tarija, dada la presencia, en este transcurso de tiempo, de formas cerámicas extranjeras cuyo origen apunta hacia dicha localidad surboliviana.

Otro carácter que, también, debe ponerse en relieve es aquel de la segmentación territorial sucesiva, que se observa a través de los distintos "sistemasocupaciones" cerámicos; fenómeno que ya se empezó a percibir en la última fase (III) de la etapa anterior.

Cada segmentación, o polarización, del sistema cerámico, en relación a una determinada localidad geográfica, pareciera estar denotada por la presencia de tabletas de la forma J (dos o más personajes), cuya presencia en las localidades 
focales del sistema estaría enumerando la cantidad de linajes primados interrelacionados existentes en el área.

Por otra parte, cabe destacar la importancia de la presencia de cerámica extranjera, la cual, a lo largo de todas las fases analizadas, pareciera ser el elemento que favorece la continuidad de los sistemas en el tiempo y, por ende, de la posición jerárquica de los linajes.

De este modo, hasta el 600 d.C., los sistemas dominantes parecerían estar sujetos a su mayor o menor capacidad —de uno o más linajes- para establecer relaciones de tipo familiar con algunos de los grupos extranjeros representados por la cerámica Tarija.

La etapa 1II, que se ha denominado de "Penetración Masiva de Rasgos Foráneos" en el área de San Pedro, es testigo de cambios notables en el comportamiento de los sistemas hasta ahora descritos.

Es así como la ocupación de cerámica "Negra Bruñida”, que tiene sus puntos focales en las localidades de Solor y Quitor, ve amagadas sus pretensiones hegemónicas por la aparición de un nuevo sistema, aquel de la cerámica "Negra Casi Pulida" con su foco modal en Coyo Oriente.

Este nuevo sistema se basa en múltiples relaciones con el extranjero, más precisamente con el área altiplánica, y dichas relaciones, sin duda, van más allá de la simple alianza entre linajes. Específicamente cabe pensar que esta nueva estructura de alianzas denota un fuerfe carácter ideológico. Es contemporáneo a la aparición de este nuevo sistema, el proceso de crecimiento y diversificación de formas cerámicas y de tabletas, como asimismo, la aparición de nuevas formas cerámicas anteriormente desconocidas en el área.

Es más, entre las diferentes formas de tabletas, que logran una mayor difusión en el área de San Pedro, se encuentran las formas F1 (tabletas de receptáculo rectangular y mango trapezoidal anguloso) y F2 (tabletas de receptáculo rectangular, mango trapezoidal anguloso con motivos grabados e incisos que representan figuras de la "Puerta del Sol" de Tiwanaku). Es la presencia de estas formas y estas decoraciones, típicas de la inconografía de dicha "Puerta del Sol", la que permite afirmar que la nueva estructura de alianzas sobrepasa los límites regionales y familiares, comprometiendo el área de San Pedro de Atacama con la fuerza doctrinal representada por el centro hegemónico de Tiwanaku.

Es sólo en este momento, ubicable entre el 600 d.C. y el 900 d.C., cuando se aprecia, en el área de San Pedro de Atacama, una clara influencia Tiwanaku, si bien mediatizada a través del aporte de otras localidades bolivianas como Potosí, Lipez, Chuquisaca y, también en cierta medida, Tarija. Esta verificación, a la que ha llegado el trabajo que se presenta en estas líneas, corrobora las hipótesis que, sobre el particular, expresara Orellana (cf. 1983).

En respuesta a esta nueva forma de alianza, el sistema cerámico “Negro Bruñido", representado por Solor y Quitor como sus localidades focales, expande su estructura de relaciones externas al área de San Pedro de Atacama. Estos vínculos no se limitan —como había sido tradicional— sólo al área de Tarija; 
también apuntan hacia el altiplano, más precisamente hacia Potosí, Lipez y Chuquisaca.

Esta situación se traduce en un estado de competencia entre linajes territoriales, que se resuelve, en el lapso entre el 750 d.C. y el 900 d.C., con la paulatina pérdida de predominancia del sistema "Coyo" y la supervivencia del sistema "Negro Bruñido" de Quitor y Solor, que al final de ese lapso sólo manifiesta características locales, sin mantener - al menos de acuerdo con las evidencias cerámicas - relaciones sustantivas ni con Tarija, ni con el Altiplano en general.

Con respecto a las tabletas de rapé — tanto aquellas que manifiestan correspondencia con elementos del sistema "Negro Bruñido", como aquellas que lo hacen en relación al sistema "Negro Casi Pulido"-, es necesario manifestar que, durante el período en cuestión, penetra, en el área de San Pedro, un conjunto de motivos los cuales, dado que están inscritos en un antiguo corpus de creencias, hacen suponer que ellas experimentan una transformación a nivel sincrético. Los temas ya conocidos, como aquellos que connotaban el manejo socioterritorial, se ven enriquecidos con motivos referentes a un culto de la cabeza trofeo, a un personaje identificado como "El Sacrificador", y a personajes con cetros, todo lo cual connota cierta jerarquización de la estructura social, más allá de la simple jefatura de linajes.

Etapa IV: denominada de "Integración Regional" (900 d.C. en adelante). Algunos elementos cerámicos del sistema "Negro Bruñido" persisten durante esta etapa hasta alrededor del 1000 d.C. Para esta fecha se observa la consolidación, en el área, de dos nuevas formas cerámicas: una que se ha denominado genéricamente "Dupont" y otra "Concho de Vino".

Estas nuevas formas cerámicas, que constituyen un patrón popular en localidades más al Norte, como Calama, Chiu-Chiu, Lasana y Río Salado, entran al área de San Pedro y se yuxtaponen al único elemento superviviente de las ocupaciones que caracterizaron dicha área en las etapas anteriores: la tableta de rapé.

Al respecto, cabe destacar la polarización, en Coyo Oriente, del tipo cerámico denominado "Dupont Genérico"; mientras que el tipo "Concho de Vino", minoritario en términos de población cerámica, se focaliza en el área de Solor. A nivel regional, este hecho está corroborado por similar patrón de distribución de elementos ceramológicos en el área del Loa Medio (Chiu-Chiu/Lasana). Allí, el "Dupont Genérico" caracterizaría a Chiu-Chiu, y el "Concho de Vino" a Lasana. Esta dicotomía, con antecedentes regionales, viene a reafirmar la dualidad en el manejo socioterritorial del área de San Pedro, como una constante registrada desde la Etapa I ya descrita.

La forma de tableta GIV 4 (representando un personaje con máscara: el sacrificador) en correspondencia con elementos del tipo cerámico "Dupont", y la forma de tableta GIV 2 (simbolizando un personaje hierático) en relación con elementos del tipo cerámico "Concho de Vino" _- entre otras formas de tabletas yuxtapuestas de manera relevante con dichos tipos cerámicos-estarían signifi- 
cando que el cambio en la esfera ideológica, que se produjera en la etapa anterior, habría alcanzado una gran profundidad en el área de San Pedro. Dicho cambio habría sido internalizado de tal manera, por el contexto simbólico, que se habría mantenido, por sobre cambios funcionales y sociales, una forma de representación (cuyo origen está asociado a la influencia mediatizada de Tiwanaku, desaparecida, como se ha visto, alrededor del 900 d.C.) la cual seguirá connotando, en esta Etapa iv, la complejización ceremonial y social ya observada en la etapa anterior.

\section{COMPENDIO}

A la luz de lo observado, puede reconocerse, para el área en estudio, la presencia de una "Cultura San Pedro", tal como señalara Orellana (cf. I963), a lo largo de casi todo el transcurso de tiempo analizado -desde el 200 d.C. hasta el 1200 d.C.- denotada por la correspondencia politética entre la tradición cerámica "Negra Bruñida" y la tradición del grupo $\mathrm{F}$ de tabletas de rapé.

Revisando el tamaño poblacional y la procedencia de los elementos asignables a dicha cultura, es posible subdividir su extensión temporal en los siguientes tres períodos que engloban tanto las etapas de desarrollo, como las fases sistémicas descritas:

1. Trasandino Prototípico ${ }^{4} /$ San Pedro Temprano (200 d.C. - 600 d.C.).

2. San Pedro Modal (600 d.C. - 900 d.C.).

3. San Pedro Prototípico (900 d.C. - 1200 d.C.).

En cada uno de dichos períodos, tanto el material cerámico como las tabletas de rapé son referentes, en un plano organizativo-funcional, de una tradición de manejo socioterritorial dual. Los polos de esta dualidad son, durante un gran lapso, los mismos. Durante el primer período, Toconao y Sequitor son dichos polos. A lo largo de los dos períodos siguientes, Solor y Quitor, por una parte, y Coyo, por la otra, son las dos focalidades que refieren dicha dicotomía en el patrón de asentamiento del área estudiada. En un plano normativo-cultural, dicha polaridad, al menos en los últimos dos períodos, connota pautas ideales constantes en relación al ceremonial y a la organización social.

Este modelo, recabado de la investigación a nivel regional del área de San

${ }^{4}$ Se habla de un "Trasandino Prototípico" en función del ámbito geográfico de referencia de la documentación más abundante, en torno a las tradiciones cerámicas que : habrían originado la tradición "Negro Bruñido". Sin embargo, puede constituir una hipotesis de trabajo el precisar espacialmente la difusión de esas tradiciones que, al parecer, podrían extenderse (o incluso provenir) del S. boliviano y, específicamente, del área Tarijeña.

Por otra parte, empleando otra acepción del término "prototipo", se consigna un período "San Pedro Prototípico" caracterizado por la presencia residual de los dos elementos identificadores de la cultura en cuestión: la tableta de rapé decorada y la cerámica negra brun̄ida. 
Pedro presentada en este artículo, constituye la hipótesis de trabajo que, en próximos estudios, se someterá a contrastación mediante un estudio particularizado y un análisis de sensibilidad de dicho modelo a nivel de localidad.

Este artículo es parte de un proyecto patrocinado por el Departamento de Investigación y Bibliotecas de la Universidad de Chile, en relación con el cual se agradece la colaboración de Agustín Llagostera, Director del Museo de San Pedro de Atacama.

ANEXO 1

Cuadro

CERAMICA DEL AREA DE SAN PEDRO DE ATACAMA

Urnos $(1,2,3)$, Anforos $(4,5)$, Dupont (6), Negrocosi pulido $(7,8,9)$, Transición rojo y negro $(10)$, Concho de vino(11)

\begin{tabular}{|c|c|c|c|c|c|c|c|c|c|c|c|c|}
\hline & & (1) & (2) & (3) & (4) & 131 & (6) & $(7)$ & (B) & |9| & $(10)$ & (t1) \\
\hline $\begin{array}{c}\text { FILAS } \\
\text { TARRAGO } \\
\text { \#ШT }\end{array}$ & $\begin{array}{l}\text { SITIOS } \\
\text { I.D. }\end{array}$ & $\frac{1}{0}$ & ${ }^{2}-$ & $\frac{3}{\text { varias }}$ & $\overline{I_{1}}$ & $\frac{5}{12}$ & oupont & $7_{A}^{7}$ & $\frac{8}{c}$ & ${ }^{9}-$ & $\frac{10}{R / N}$ & ${ }^{11}-$ \\
\hline &  & $\begin{array}{l}5 \\
1 \\
1\end{array}$ & $\begin{array}{r}4 \\
1 \\
25 \\
11\end{array}$ & 13 & 3 & 3 & $\begin{array}{r}8 \\
5 \\
12 \\
1 \\
6 \\
1 \\
5 \\
1 \\
25 \\
3 \\
7 \\
5 \\
3 \\
8 \\
1 \\
2 \\
2 \\
1 \\
\end{array}$ & $\begin{array}{c}11 \\
1 \\
19 \\
16 \\
2 \\
1 \\
1 \\
64 \\
5 \\
13 \\
1 \\
1 \\
2 \\
2 \\
3\end{array}$ & $\begin{array}{c}1 \\
5 \\
1 \\
10 \\
1 \\
1 \\
3 \\
1 \\
1 \\
1\end{array}$ & $\begin{array}{l}1 \\
2\end{array}$ & 2 & 16 \\
\hline
\end{tabular}


CERAMICA DEL AREA DE SAN PEDRO DE ATACAMA

Negro pulido $(1,2,3,4,5,6,7,8,9,10,11)$

\begin{tabular}{|c|c|c|c|c|c|c|c|c|c|c|c|c|}
\hline $\begin{array}{c}\text { FILAS } \\
\text { TARRAGO } \\
\text { BNT }\end{array}$ & $\begin{array}{l}\text { SITIOS } \\
\text { I.D. }\end{array}$ & $\frac{(1)}{-}$ & \begin{tabular}{|l}
121 \\
12 \\
1 \\
$k$
\end{tabular} & $\frac{(3)}{13} \begin{array}{c}13 \\
Z\end{array}$ & 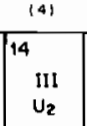 & 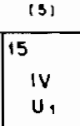 & $\begin{array}{c}(6) \\
16 \\
v \\
-\end{array}$ & \begin{tabular}{|c|}
$\mid 71$ \\
$\frac{17}{\mathrm{~V}}$ \\
$\bar{N}$
\end{tabular} & $\frac{181}{\mid \begin{array}{c}18 \\
V I I \\
M\end{array}}$ & $\begin{array}{c}191 \\
\frac{19}{\mathrm{VIII}} \\
-\end{array}$ & 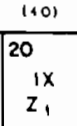 & 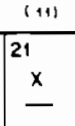 \\
\hline & 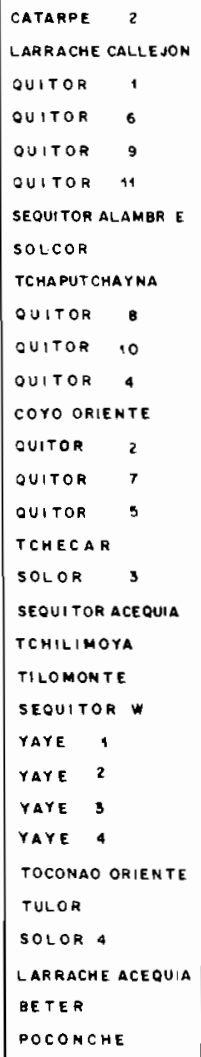 & & $\begin{array}{r}3 \\
22 \\
15 \\
22 \\
2 \\
25 \\
71\end{array}$ & $\begin{array}{r}20 \\
2 \\
18 \\
8 \\
39\end{array}$ & $\begin{array}{r}4 \\
20 \\
53 \\
67 \\
2 \\
93 \\
46\end{array}$ & $\begin{array}{r}3 \\
4 \\
12 \\
33 \\
3 \\
30 \\
63\end{array}$ & $\begin{array}{l}2 \\
3\end{array}$ & $\begin{array}{l}1 \\
3 \\
4 \\
7\end{array}$ & $\begin{array}{r}9 \\
24 \\
36 \\
2 \\
104 \\
34\end{array}$ & $\begin{array}{r}1 \\
7 \\
41 \\
3 \\
2 \\
4\end{array}$ & $\begin{array}{r}10 \\
3 \\
19 \\
1 \\
31 \\
21\end{array}$ & 4 \\
\hline
\end{tabular}


CERAMICA DEL AREA DE SAN PEDRO DE ATACAMA

Negro pulido $(1,2,3,4,5,6,7,8,9,10,11)$

\begin{tabular}{|c|c|c|c|c|c|c|c|c|c|c|c|c|}
\hline $\begin{array}{l}\text { FILAS } \\
\text { TARRAGO } \\
\text { OMT }\end{array}$ & $\begin{array}{l}\overline{\text { SITIOS }} \\
\text { I.D. }\end{array}$ & $\frac{111}{22}$ & $\begin{array}{c}|2| \\
23 \\
x \mid 1\end{array}$ & 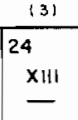 & $\begin{array}{c}141 \\
25 \\
\text { Decor.A } \\
89\end{array}$ & $\begin{array}{c}151 \\
26 \\
\text { Decor. B } \\
\mathrm{B}_{2}\end{array}$ & $\frac{(6)}{\frac{27}{-B_{3}}}$ & $\frac{171}{\frac{28}{84}}$ & $\frac{(\text { a) }}{29}$ & $\frac{191}{\frac{30}{6}}$ & $\begin{array}{l}1101 \\
\frac{31}{3}\end{array}$ & $\frac{1911}{\frac{32}{0}}$ \\
\hline & 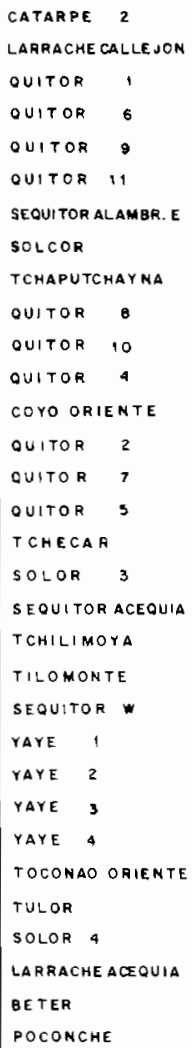 & ' & 1 & 1 & $\begin{array}{r}4 \\
14 \\
14 \\
4 \\
32 \\
3 \\
25 \\
7 \\
65\end{array}$ & $\begin{array}{r}8 \\
3 \\
16 \\
9 \\
32\end{array}$ & 1 & 1 & $\begin{array}{r}1 \\
24 \\
2 \\
8\end{array}$ & 2 & 2 & 4 \\
\hline
\end{tabular}




\section{CERAMICA DEL AREA DE SAN PEDRO DE ATACAMA}

Negro pulido $(1,2,3)$, Rojo pintado $(4,10)$, Rojo pulido $(5,6,7,8,9)$, Rojo grabodo (11)

\begin{tabular}{|c|c|c|c|c|c|c|c|c|c|c|c|c|}
\hline & & (11) & (2) & (3) & $(4)$ & (3) & 161 & 171 & $\{0\}$ & $(9)$ & $(10)$ & (11) \\
\hline $\begin{array}{l}\text { FILAS } \\
\text { TARRAEO } \\
\text { BMT }\end{array}$ & $\begin{array}{l}\overline{S 1 T 10 S} \\
1.0\end{array}$ & $\frac{33}{R}$ & $\frac{34}{v}$ & $\frac{35}{w}$ & $\frac{36}{r}$ & $\begin{array}{l}37 \\
\text { Varios } \\
\text { RPA I }\end{array}$ & $\begin{array}{l}36 \\
\text { Varios } \\
\text { RPA 2 }\end{array}$ & $\begin{array}{l}39 \\
\text { Vorios } \\
\text { RPA } 3\end{array}$ & \begin{tabular}{|l|}
40 \\
Varios \\
RPA 6 \\
\end{tabular} & \begin{tabular}{|l}
41 \\
Varios \\
RPA 8
\end{tabular} & $\frac{42}{r}$ & $\begin{array}{r}43 \\
\text { I } \\
\text { N }\end{array}$ \\
\hline & 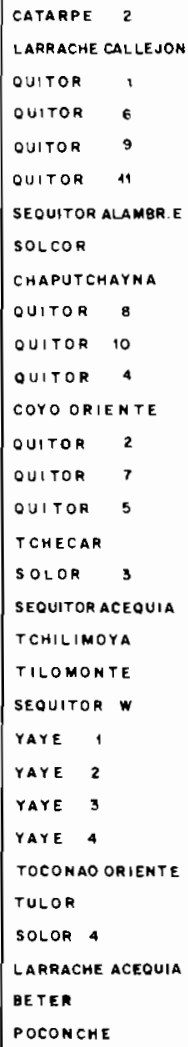 & 2 & 1 & 2 & ${ }^{2}$ & $\begin{array}{c}1 \\
27\end{array}$ & $\begin{array}{c}1 \\
09\end{array}$ & $\begin{array}{r}99 \\
2\end{array}$ & 1 & 2 & 1 & 2 \\
\hline
\end{tabular}




\section{CERAMICA DEL AREA DE SAN PEDRO DE ATACAMA}

Rojo grabado $(1,2)$, Medio rojo y negro (3), Rosado (4), Negro grabodo $(5,6,7,8,9$, 10), Extranjera (11)

\begin{tabular}{|c|c|c|c|c|c|c|c|c|c|c|c|c|}
\hline & & (1) & (2) & (3) & (4) & (5) & (6) & $(7)$ & (B) & (9) & $(10)$ & (11) \\
\hline $\begin{array}{c}\text { FILAS } \\
\text { TARAAQO } \\
\text { BMT }\end{array}$ & $\begin{array}{l}\overline{\text { SIT IOS }} \\
\text { I.D. }\end{array}$ & $\begin{array}{l}44 \\
\text { II }\end{array}$ & $\begin{array}{l}45 \\
\text { III } \\
\end{array}$ & $\frac{46}{1 / 2 R: N}$ & ${ }^{47}$ Rosado & $\begin{array}{l}48 \\
A_{1} \\
S_{2}\end{array}$ & $\begin{array}{l}49 \\
B \\
S_{3}\end{array}$ & $\begin{array}{c}50 \\
c \\
s_{1}\end{array}$ & ${ }^{51} 0$ & ${ }^{52} \mathrm{E}$ & $\frac{53}{F}$ & $\frac{54}{H}$ \\
\hline & 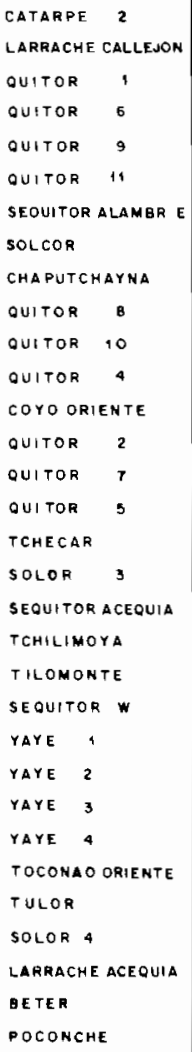 & 列 & 2 & 4 & $\begin{array}{l}5 \\
2 \\
1\end{array}$ & $\begin{array}{l}3 \\
5 \\
1 \\
2 \\
5 \\
1 \\
3 \\
2 \\
2\end{array}$ & $\begin{array}{l}5 \\
2 \\
6 \\
3\end{array}$ & 1 & 2 & 1 & 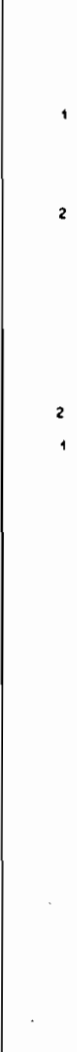 & 1 \\
\hline
\end{tabular}


CERAMICA del AREA de san PEDRo de ATACAMA

Extranjera

\begin{tabular}{|c|c|c|c|c|c|c|c|c|c|c|c|c|}
\hline $\begin{array}{c}\text { FILAS } \\
\text { TARRAGO } \\
\text { OWT }\end{array}$ & $\begin{array}{l}\overline{S 1 T 105} \\
\text { I. D. }\end{array}$ & $\frac{55}{\text { H. }}$ & $\frac{56}{H .3}$ & $\frac{57}{H .4}$ & $\frac{58}{H .5}$ & $\frac{59}{H .6}$ & $\frac{60}{E(N / R)}$ & $\frac{61}{H .8}$ & $\frac{62}{H .9}$ & $\frac{63}{H .10}$ & $\frac{64}{H .14}$ & $\frac{65}{H .12}$ \\
\hline &  & $d$ & ' & 1 & 1 & 1 & 2 & 2 & 9 & 1 & 4 & 1 \\
\hline
\end{tabular}


CERAMICA DEL AREA DE SAN PEDRO DE ATACAMA

Exiranjera

\begin{tabular}{|c|c|c|c|c|c|c|c|c|c|c|c|c|}
\hline & & (1) & (2) & (3) & (4) & (5) & (6) & $\mid+1$ & 101 & (9) & $(10)$ & (11) \\
\hline $\begin{array}{l}\text { FILAS } \\
\text { TAARABO } \\
\text { BMT }\end{array}$ & $\begin{array}{l}\overline{\text { SITIOS }} \\
\text { BMT }\end{array}$ & $\frac{66}{H .13}$ & $\frac{67}{H .14}$ & $\overrightarrow{H .15}$ & $\frac{69}{H .16}$ & $\frac{70}{H .17}$ & $\frac{71}{H .18}$ & $\frac{72}{H .19}$ & $\frac{73}{\mathrm{H} .20}$ & $\frac{74}{H .21}$ & $\frac{75}{\text { H.22 }}$ & $\frac{76}{H .23}$ \\
\hline & 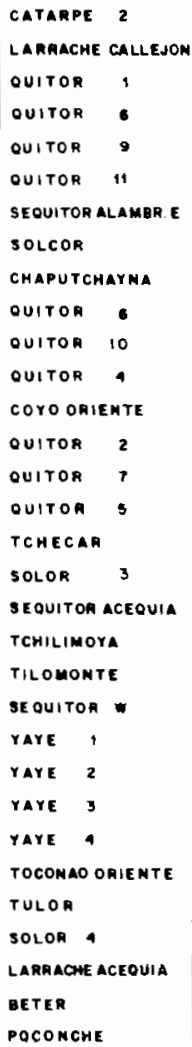 & 1 & 4 & 1 & 1 & $\uparrow$ & ' & 1 & 1 & 1 & 1 & \\
\hline
\end{tabular}


CERAMICA del AREA de san PEDRo de atACAMA

Extranjera

\begin{tabular}{|c|c|c|c|c|c|c|c|c|}
\hline $\begin{array}{l}\text { FILAS } \\
\text { TARRAGO } \\
\text { BMT }\end{array}$ & $\begin{array}{l}\text { SIT IOS } \\
\text { I.D. }\end{array}$ & $\frac{(1)}{\frac{77}{H .24}}$ & $\frac{(2)}{\frac{78}{H .25}}$ & $\frac{(3)}{\frac{79}{H .26}}$ & $\frac{(4)}{\frac{80}{-}}$ & $\begin{array}{l}\text { (3) } \\
\frac{81}{H .28}\end{array}$ & $\frac{(6)}{\frac{82}{E}}$ & $\frac{\mid 71}{\frac{83}{\varnothing}}$ \\
\hline & 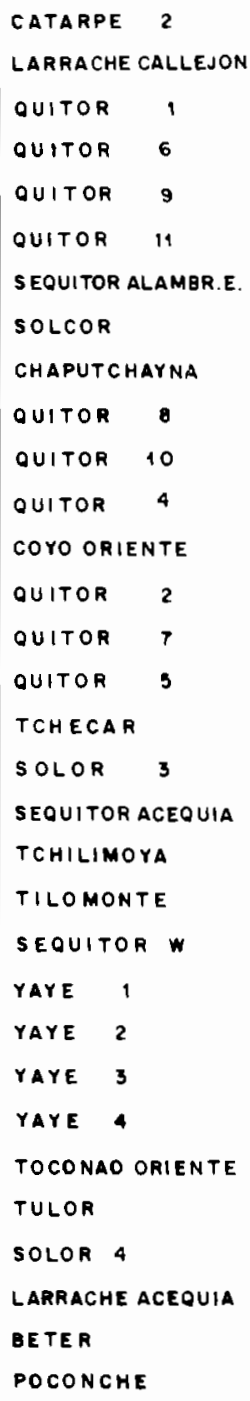 & 1 & 1 & 1 & 1 & 1 & 2 & 2 \\
\hline
\end{tabular}


Anexo 2

Correspondencia entre nomenclatura cerámica del área de San Pedro.

\begin{tabular}{|c|c|c|c|c|}
\hline \multicolumn{2}{|r|}{ M. Tarragó (1976) } & \multicolumn{2}{|c|}{ Benavente/Thomas } & \multirow{2}{*}{$\frac{\text { Redelinición }}{\text { UO }}$} \\
\hline & - & \multicolumn{2}{|c|}{ Urna $\mathrm{O}$} & \\
\hline & - & \multicolumn{2}{|c|}{$\begin{array}{l}\text { Unna X } \\
\text { Unnas Varias }\end{array}$} & UX \\
\hline & - & & $\mathrm{U}$ \\
\hline & - & \multicolumn{2}{|c|}{ Anfora Il } & Al \\
\hline & - & \multicolumn{2}{|c|}{ Anfora 12} & A2 \\
\hline & - & & $\mathrm{D}$ \\
\hline & - & \multicolumn{2}{|c|}{$\begin{array}{l}\text { Dupont } \\
\text { NcP A }\end{array}$} & $\mathrm{NcPl}$ \\
\hline & - & \multicolumn{2}{|c|}{$\mathrm{NcP} \quad \mathrm{C}$} & $\mathrm{NcP} 2$ \\
\hline & - & \multicolumn{2}{|c|}{ NcP T } & $\mathrm{NCP3}$ \\
\hline & - & \multicolumn{2}{|c|}{ Transición Rojo y Negro } & $\mathrm{RNI}$ \\
\hline & - & \multicolumn{2}{|c|}{ Concho de Vino $\mathbf{P}$} & $\mathrm{CV}$ \\
\hline NP & I & NP & K & NB 1 \\
\hline NP & II & NP & $\mathrm{Z}$ & NB2 \\
\hline NP & 111 & NP & $\mathrm{U} 2$ & NB3 \\
\hline NP & IV & NP & Ul & NB4 \\
\hline NP & V & & - & NB5 \\
\hline NP & VI & NP & $\tilde{\mathbf{N}}$ & NB6 6 \\
\hline NP & VII & NP & $\mathbf{M}$ & NB 7 \\
\hline NP & VIII & & - & NB8 \\
\hline NP & IX & NP & 21 & NB9 \\
\hline NP & $\mathrm{x}$ & & - & NB 10 \\
\hline NP & $\mathrm{xI}$ & NP & $\mathrm{L}$ & NB 11 \\
\hline NP & XII & & 一 & NB 12 \\
\hline$N P$ & XIII & & - & NB 13 \\
\hline NP & Decorado A & NP & $\mathrm{B} \mathrm{l}$ & NBD 1 \\
\hline NP & Decorado B & NP & B2 & NBI2 \\
\hline & - & $\mathrm{NP}$ & B3 & NBD3 \\
\hline & - & NP & B4 & NBI 4 \\
\hline & - & NP & $\mathrm{D}$ & NB 14 \\
\hline & - & NP & $G$ & NB 15 \\
\hline & - & NP & J & NB 16 \\
\hline & - & NP & $Q$ & NB 17 \\
\hline & - & $N P$ & $\overrightarrow{\mathrm{R}}$ & NB 18 \\
\hline & - & $\mathrm{NP}$ & V & NB 19 \\
\hline & - & $\mathrm{NP}$ & W & NB20 \\
\hline & - & Rojo & & R Y \\
\hline Vari & ias denominaciones & $\mathbf{R P}$ & Al & RPl \\
\hline Var & ias denominaciones & $\mathrm{RP}$ & A2 & RP2 \\
\hline Var & ias denominaciones & RP & A3 & RP3 \\
\hline Var & ias denominaciones & $\mathrm{RP}$ & A6 & RP4 \\
\hline
\end{tabular}




\begin{tabular}{|c|c|c|}
\hline M. Tarragó (1976) & Benavente/Thomas & Redefinición \\
\hline Varias denominaciones & RP A8 & RP5 \\
\hline Rojo Grabado I & RG $\mathrm{N}$ & RG 1 \\
\hline Rojo Grabado 1 I & - & RG2 \\
\hline Rojo Grabado III & - & RG3 \\
\hline- & Medio Rojo y Negro & $\mathrm{mRN}$ \\
\hline- & Rosada & Rs \\
\hline Negro Grabado A & Negro Grabado S2 & NGl \\
\hline Negro Grabado B & Negro Grabado S3 & NG2 \\
\hline Negro Grabado C & Negro Grabado S1 & NG3 \\
\hline Negro Grabado D & - & NG4 \\
\hline Negro Grabado E & - & NG5 \\
\hline- & Negro Grabado F & NG6 \\
\hline- & Extranjera $\mathrm{H}$ & El \\
\hline - & Extranjera $\mathrm{H} 2$ & E2 \\
\hline- & Extranjera H3 & E3 \\
\hline- & Extranjera $\mathrm{H} 4$ & $\mathrm{E} 4$ \\
\hline- & Extranjera H5 & E5 \\
\hline- & Extranjera Negro Rojo & E6 \\
\hline - & Extranjera H8 & E7 \\
\hline- & Extranjera H9 & E8 \\
\hline- & Extranjera Hio & E9 \\
\hline 一. & Extranjera Hll & E10 \\
\hline- & Extranjera $\mathrm{H} 12$ & E11 \\
\hline - & Extranjera H 13 & $\mathrm{E} 12$ \\
\hline - & Extranjera $\mathrm{Hl} 4$ & E13 \\
\hline - & Extranjera H 15 & $\mathrm{E} 14$ \\
\hline - & Extranjera H 16 & E 15 \\
\hline- & Extranjera H 17 & E 16 \\
\hline- & Extranjera H18 & E 17 \\
\hline - & Extranjera H H & El8 \\
\hline - & Extranjera H20 & E 19 \\
\hline - & Extranjera $\mathrm{H} \longleftarrow 1$ & $\mathrm{E} 20$ \\
\hline- & Extranjera $\mathrm{H} 22$ & E21 \\
\hline- & Extranjera H23 & $\mathrm{E} 22$ \\
\hline - & Extranjera H24 & E23 \\
\hline - & Extranjera $\mathrm{H} 25$ & E24 \\
\hline - & Extranjera $\quad \mathrm{H} 26$ & $\mathrm{E} 25$ \\
\hline - & Extranjera $\mathrm{H} 27$ & E26 \\
\hline - & Extranjera $\quad \mathrm{H} 28$ & $\mathrm{E} 27$ \\
\hline- & Extranjera E & E28 \\
\hline - & Extranjera H6 & E29 \\
\hline- & Rojo $\check{\varnothing}$ y RPA I I & RPn \\
\hline
\end{tabular}




\section{Bibliografía}

Benavente A., M. Antonia. Chiu-Chiu 200: Un campamento de pastores. Mimeo. Universidad de Chile, Depto. de Antropología, 1981 (tesis).

Benavente A., M. Antonia. Chiu-Chiu 200: Una comunidad pastora temprana en la Provincia del Loa (II Región). En actas del Ix Congreso Nacional de Arqueología, La Serena, octubre 1982 (en prensa).

Benavente A., M. Antonia; Massone, Claudio y Thomas, Carlos. El complejo del rapé. Un Diseño de Investigación. En: Revista Chilena de Humanidades, Santiago N"6, 1984 (pp. 39-51).

Bennett, W.; Bleiler, Everett y Sommer, Frank. Northwest Argentine Archaeology. The Viking Foundation lnc., New Hawen, USA, 1947.

Bittmann, B.; Le Paige, G. y Núñez, Lautaro. La cultura alacameña. Departamento de Extensión Cultural, Santiago, 1978.

Browman, David. Tiwanaku expansion and Aliplano economic patterns. En: Estudios Arqueológicos, Antofagasta, $\mathrm{N}^{\mathrm{O}}$ 5, 1980 (pp. 107-120).

Dixon, Wilfrid y Frank Massey. Introducción al análisis estadístico. Mc Graw Hill, México, 1973.

Dunnell, A.E. Sistematics in Prehistory - The Free- Press, Mac Millan. Publishing Co, New York, 1971.

Dury, G., Editor - Essay in Geomorphology- sin editorial, Londres, 1965.

HAgGet T, P. Análisis locacional en la geografía humana. Ed. Gustavo Gili, S.A. Barcelona, 1976.

Hawley, Amos. La estructura de los sistemas sociales. Editorial Tecnos, Madrid, 1966.

Hofstatter, Peter R. Psicología Social. U.T.E.H.A., México, 1960.

l garra Grasso, Dick Edgar. Argentina Indigena. Prehistoria Americana. Tipografía editora Argentina, Buenos Aires, 1967.

Le Paige, Gustavo. La antigüedad de una tumba comprobada por Carbono 14, y el ambiente que la rodea. En: Revista de la Universidad Católica, Santiago, Año xLVıII, 1963, pp. $167-176$.

Le Paige, Gustavo. Continuidad y discontinuidad de la cullura atacameña. En: Congreso Internacional de Arqueología en San Pedro de Atacama, Anales de la Universidad del Norte, Antofagasta, 1963, pp. 7-25.

Le Paige, Gustavo. El precerámico en la cordillera alacameña y los cementerios del periodo agroalfarero de San Pedro de Atacama. En: Anales de la Universidad del Norte, Antofagasta, $\mathrm{N}^{\circ} 3$, Año 1964, pp. 51-256.

Le Paige, Gustavo. Tres cementerios indígenas en San Pedro de Atacama y Toconao. En: Actas del Vi Congreso de Arqueología Chilena, Santiago, $N^{\circ}$ Especial, Año 1972-73, p. 163-187.

Maxwell, A.E. Análisis estadístico de datos cualitativos. U.T.E.H.A., México, 1966.

Munizaga, Carlos. Tipos cerámicos del sitio Coyo. En: Arqueologia Chilena, U. de Chile, $\mathrm{N}^{\circ} 3,1963$, p. $47-81$.

NúÑez, L.; Zlat AR, V. y Núñez, P. Relaciones Prehistóricas trasandinas entre el N.W. Argentino y Norte Chileno. (Periodo cerámico). En: Serie Documentos de trabajo. Antofagasta U. de Chile, $N^{\circ} 6,1975,3 a$. $p$.

Núñez, Laut ARo. Registro Regional de fechas radiocarbónicas del Norte de Chile. En: Estudios Atacameños, San Pedro de Atacama, $N^{\circ} 4$, 1976. p. 74-123.

Orellana, Mario. La Cultura San Pedro. En: Arqueologia Chilena, Santiago, U. de Chile, $N^{\circ} 3,1963$, p. 3-43.

Orellana, Mario. Influencias altiplánicas en San Pedro de Alacama. En: Actas Simposio Arqueología Atacameña, 1983, en prensa. 
Pollard, Gordon. Cultural change and adaptation in the Central Atacama desert of Northern Chile. En: Nawpa pacha, Berkeley, N* 9, 1971, p. 41-64.

Rex González, A. y Pérez, José A. Argentina Indígena. Vísperas de la Conquista. Buenos Aires, editorial Paidos, 1972, Vol. 1.

Román, A.; Deza, A; Berenguer, J. y Llagostera, A. TL dales. En: Ancient TL. 1984 (en prensa).

Tarragó, Miriam. Secuencias culturales de la elapa Agroalfarera de San Pedro de Alacama. En: Actas del xxxvi1 Congreso Internacional de Americanistas, Buenos Aires, Vol. 11, 1968, p. 119-144.

Tarragó, Miriam. Alfarería típica de San Pedro de Alacama. En: Estudios Atacameños, No4, U. del Norte, Antofagasta, 1976.

Thomas, Carlos y Benavente, M. Antonia. Proposición de un modelo de análisis de fragmentación cerámica poco diagnóstica. En: Boletín de Prehistoria de Chile, $\mathbf{N}^{\circ} 7-8 \mathrm{U}$. de Chile, Santiago, 1974, p. 39-58.

Thomas, Carlos y Benavente, M. Antonia. Reflexiones melodológicas acerca de lascreencias en la cultura San Pedro a través del análisis de correspondencia de las tabletas de rapé. En: xuIv Congreso Internacional de Americanistas, Manchester, $\mathrm{V}$ of Manchester School of Geography U. del Norte, Simposio Culturas Atacameñas, 1984, pp. 157-174.

W ASSEN, Henry. A medicine - man's Implements and Plants in a Tiahuanacoid Tomb in Highland Bolivia. Elanders Bok Tryckeri Aktiebolog, Göteborg, 1972, 183 p. 